Florida International University

FIU Digital Commons

$5-28-2019$

\title{
A Computational Approach for Modeling Plasma Sprayed Coatings from Splat to Bulk Deposits
}

Sadhana Bhusal

Florida International University, sbhus001@fiu.edu

Follow this and additional works at: https://digitalcommons.fiu.edu/etd

Part of the Mechanical Engineering Commons

\section{Recommended Citation}

Bhusal, Sadhana, "A Computational Approach for Modeling Plasma Sprayed Coatings from Splat to Bulk Deposits" (2019). FIU Electronic Theses and Dissertations. 4220.

https://digitalcommons.fiu.edu/etd/4220

This work is brought to you for free and open access by the University Graduate School at FIU Digital Commons. It has been accepted for inclusion in FIU Electronic Theses and Dissertations by an authorized administrator of FIU Digital Commons. For more information, please contact dcc@fiu.edu. 


\section{FLORIDA INTERNATIONAL UNIVERSITY}

Miami, Florida

\section{A COMPUTATIONAL APPROACH FOR MODELING PLASMA SPRAYED COATINGS FROM SPLAT TO BULK DEPOSITS}

A thesis submitted in partial fulfillment of

the requirements for the degree of

MASTER OF SCIENCE

in

MECHANICAL ENGINEERING

by

Sadhana Bhusal 
To: Dean John L. Volakis

College of Engineering and Computing

This thesis, written by Sadhana Bhusal, and entitled A Computational Approach for Modeling Plasma Sprayed Coatings from Splat to Bulk Deposits, having been approved in respect to style and intellectual content, is referred to you for judgment.

We have read this thesis and recommend that it be approved.

Sharan Ramaswamy

Yiding Cao

Benjamin Boesl, Co-Major Professor

Arvind Agarwal, Co-Major Professor

Date of Defense: May 28, 2019

The thesis of Sadhana Bhusal is approved.

Dean John L. Volakis

College of Engineering and Computing

Andrés G. Gil

Vice President for Research and Economic Development and Dean of the University Graduate School

Florida International University, 2019 
(C) Copyright 2019 by Sadhana Bhusal

All rights reserved. 


\section{DEDICATION}

I dedicate this thesis to my family and friends for always believing in me and inspiring me to follow my dreams and loving me unconditionally. 


\section{ACKNOWLEDGMENTS}

I would like to extend my sincere gratitude to my advisors Dr. Arvind Agarwal and Dr. Benjamin Boesl for their scholarly and affectionate encouragement, continuous guidance, and invaluable suggestions throughout the study period.

Special thanks to Dr. Agarwal for allowing me to be a part of the Plasma Forming Lab and for his guidance, trust, understanding, and mentorship. He always encouraged me to grow as an independent researcher. His persistence, promptness, and dedication towards the work have always been motivation for me to work harder. I will also like to thank Dr. Boesl for all the insights and discussion for the project. Learning from Dr. Agarwal and Dr. Boesl has helped me develop my skills and talents as a researcher and become the professional I am today. I will forever be grateful to you both.

I would also like to thank my committee members Dr. Yiding Cao and Dr.

Sharan Ramaswamy for their valuable inputs and guidance during this project. Thanks to Dr. Cheng Zhang for carrying out the plasma spray experiments.

I am extremely grateful for having so many lab members in the Plasma Forming Lab and would like to acknowledge their help and support. I am also thankful for the support I have received from the department. Special thanks to Tiziana.

I am very grateful with all the AMERI staff for your unconditional help especially Dr. Alex Franco and Jonathan Comparan.

I would like to acknowledge financial support from Florida International University in terms of Presidential Fellowship. And, I would forever be grateful to the kindness of Dr. Lidia Kos. 
Last but not least, I have no words to thank my parents, my siblings, my friends and for their selfless love, understanding, never-ending patience, moral support, encouragement, and wishes. Special thanks to my husband for his love and support.

Whatever I am today, I owe it all to you. 


\title{
ABSTRACT OF THE THESIS \\ A COMPUTATIONAL APPROACH FOR MODELING PLASMA SPRAYED \\ COATINGS FROM SPLAT TO BULK DEPOSITS
}

\author{
by \\ Sadhana Bhusal \\ Florida International University, 2019 \\ Miami, Florida

\section{Professor Arvind Agarwal, Co-Major Professor \\ Professor Benjamin Boesl, Co-Major Professor}

In this study, a multi-pronged computational approach is developed to predict the effect of spray parameters on aluminum oxide splat formation and mechanical properties of the coatings. The splat morphology is investigated using computational fluid dynamics approach. Simulated splat morphologies show a good agreement with the experimentally obtained splats. Three-dimensional coating structure is constructed using the stochastic approach using simulated splat morphologies. Finite Element Analysis is used to compute the elastic modulus of the coating. An inter-splat correction factor is introduced which considers inter-splat cracks, interface bonding and other effects like curling of splats and splat sliding. After the correction factor, the computed elastic modulus for simulated coating is comparable to the experimental values (4 5\%). This study shows that the proposed computational approach can predict the mechanical properties of the coating and is promising for developing plasma-sprayed coatings with predictable properties and can be extended to other materials systems. 


\section{TABLE OF CONTENTS}

CHAPTER

PAGE

CHAPTER 1. INTRODUCTION.................................................

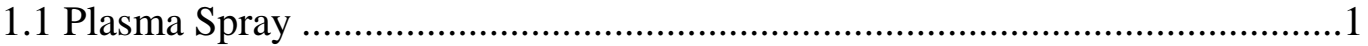

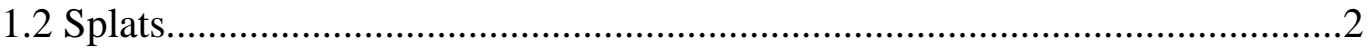

1.3 Computational Methods and Their Limitations..................................................

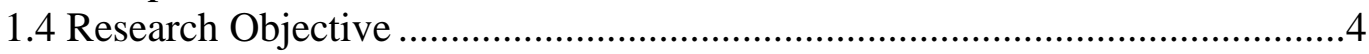

CHAPTER 2. LITERATURE REVIEW .............................................. 8

2.1 Processing Parameters in Plasma Spray .....................................................

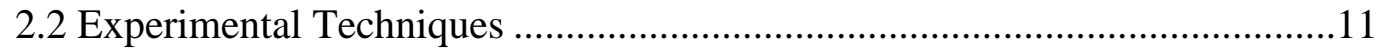

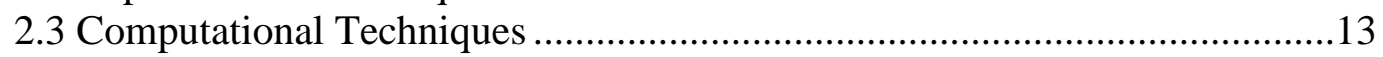

CHAPTER 3. MATERIALS AND METHODS ................................... 18

3.1 Experimental Methods ……………………………..........................18

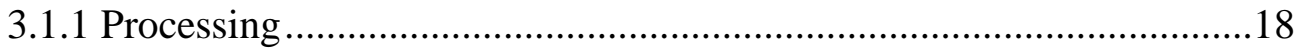

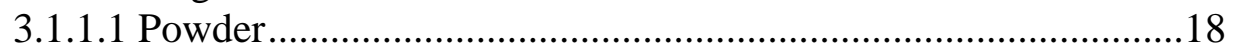

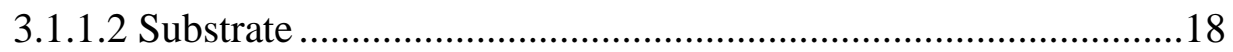

3.1.1.3 Processing Parameters ............................................................19

3.1.1.4 Formation of Splats and Coatings ............................................20

3.1.1.5 In-flight Particle Diagnostic Sensor ..........................................21

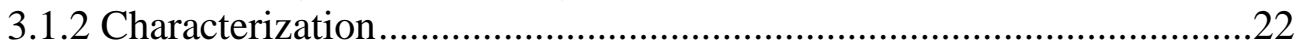

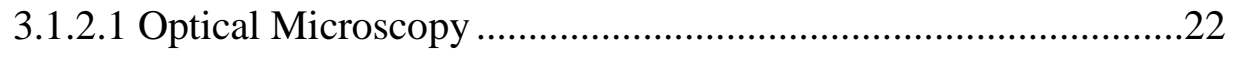

3.1.2.2 Porosity Measurement ...........................................................22

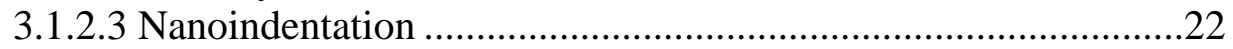

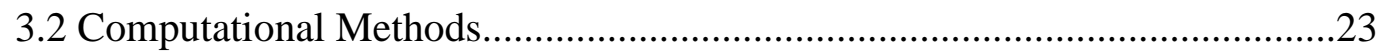

3.2.1 Simulation of Single Splats Using Computational Fluid Dynamics

Approach ...........................................................................................23

3.2.2 Formation of Three-dimensional Coating Structure Using Stochastic

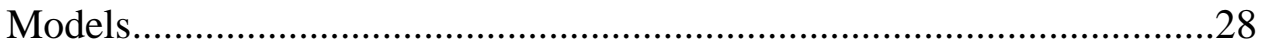

3.2.3 Object-Oriented Finite Element Analysis for Elastic Modulus

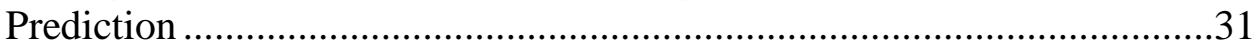

CHAPTER 4. RESULTS AND DISCUSSION ....................................

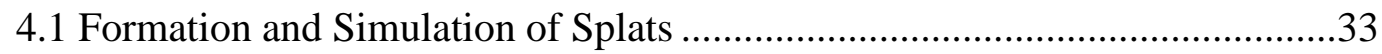

4.2 Simulated and Experimentally Obtained Coating Microstructure....................43

4.3 Computed and Experimental Elastic Modulus of the Coating .......................47

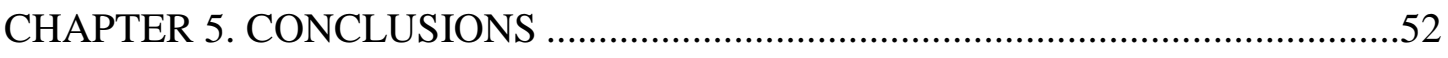

CHAPTER 6. RECOMMENDATIONS FOR FUTURE WORK ……………….........53

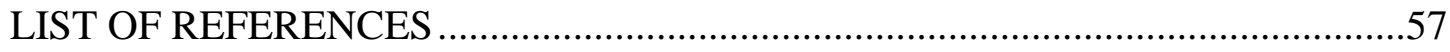


APPENDIX .65 


\section{LIST OF TABLES}

TABLE

PAGE

Table 3-1. Processing parameters used in the formation of splats and coatings 19

Table 3-2. Thermo-physical properties of Aluminum Oxide for splat simulation [77]

Table 3-3. Particle velocities and temperatures for different plasma power obtained from inflight diagnostic sensor during splat formation

Table 3-4. Smallest distance (1) between two neighboring splats based on the equations describing splat shapes (Based on the stochastic model developed by Ghafouri-Azar et al. [64]

Table 4-1. Elastic modulus obtained from nanoindentation and OOF2 for the crosssection

Table 4-2. Elastic modulus obtained from nanoindentation and OOF2 with an intersplat correction factor for the cross-section......

APPENDIX Table 1. Parameters used for formation of 2D image for Power $28 \mathrm{~kW}$ and substrate temperature $100{ }^{\circ} \mathrm{C}$

APPENDIX Table 2. Parameters used for formation of 2D image for Power $28 \mathrm{~kW}$ and substrate temperature $180{ }^{\circ} \mathrm{C}$

APPENDIX Table 3. Parameters used for formation of 2D image for Power $28 \mathrm{~kW}$ and substrate temperature $250{ }^{\circ} \mathrm{C}$

APPENDIX Table 4. Parameters used for formation of 2D image for Power $32 \mathrm{~kW}$ and substrate temperature $100{ }^{\circ} \mathrm{C}$

APPENDIX Table 5. Parameters used for formation of 2D image for Power $32 \mathrm{~kW}$ and substrate temperature $180{ }^{\circ} \mathrm{C}$

APPENDIX Table 6. Parameters used for formation of 2D image for Power $32 \mathrm{~kW}$ and substrate temperature $250{ }^{\circ} \mathrm{C}$

APPENDIX Table 7. Parameters used for formation of 2D image for Power $35 \mathrm{~kW}$ and substrate temperature $100{ }^{\circ} \mathrm{C}$

APPENDIX Table 8. Parameters used for formation of 2D image for Power $35 \mathrm{~kW}$ and substrate temperature $180^{\circ} \mathrm{C}$ 
APPENDIX Table 9. Parameters used for formation of 2D image for Power $35 \mathrm{~kW}$

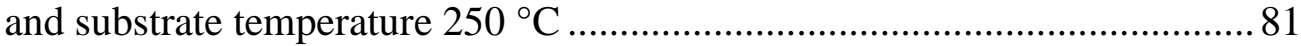




\section{LIST OF FIGURES}

FIGURE

PAGE

Figure 1-1. Schematic Diagram of Plasma Spray .......................................................

Figure 1-2. Morphologies of splats ..............................................................................2

Figure 1-3. Schematic Diagram of Computational Approach .......................................5

Figure 2-1. Nickel splat morphologies on AISI 304 substrate. (a) Splash splat, Ts = 300 K. (b) Disk splat Ts $=673$ K. (c) Fraction change of disk splat with substrate temperature [40].....

Figure 2-2. Morphologies and 3-D surface profiles of zirconia splats prepared on

(a) and (c) cold substrate $\left(100{ }^{\circ} \mathrm{C}\right)$ and (b) and (d) hot substrate $(250$

$\left.-300{ }^{\circ} \mathrm{C}\right)[19]$

Figure 3-1. Schematic Diagram for Plasma Spray Setup ........................................20

Figure 3-2. Operational Principle of AccuraSpray Diagnostic Sensor [67] ...................21

Figure 3-3. Maximum spread ratio for different values of CPR .................................28

Figure 4-1. Comparison of splat morphology obtained from experiments and simulations, a) Power $28 \mathrm{~kW}$, Substrate Preheat Temperature $100{ }^{\circ} \mathrm{C}$,

b) Power $28 \mathrm{~kW}$, Substrate Preheat Temperature $180^{\circ} \mathrm{C}$ and c) Power 28

$\mathrm{kW}$, Substrate Preheat Temperature $250{ }^{\circ} \mathrm{C}$.

Figure 4-2. Comparison of splat morphology obtained from experiments and simulations, a) Power $32 \mathrm{~kW}$, Substrate Preheat Temperature $100{ }^{\circ} \mathrm{C}$,

b) Power $32 \mathrm{~kW}$, Substrate Preheat Temperature $180^{\circ} \mathrm{C}$ and c) Power 32 $\mathrm{kW}$, Substrate Preheat Temperature $250{ }^{\circ} \mathrm{C}$

Figure 4-3. Comparison of splat morphology obtained from experiments and simulations, a) Power $32 \mathrm{~kW}$, Substrate Preheat Temperature $100{ }^{\circ} \mathrm{C}$, b) Power $32 \mathrm{~kW}$, Substrate Preheat Temperature $180^{\circ} \mathrm{C}$ and c) Power 32 $\mathrm{kW}$, Substrate Preheat Temperature $250{ }^{\circ} \mathrm{C}$.

Figure 4-4. Volume fraction of splats for a) $28 \mathrm{~kW}$, b) $32 \mathrm{~kW}$ and c) $35 \mathrm{~kW}$ plasma power

Figure 4-5. Splat size distribution for different substrate preheat temperatures for

a) $28 \mathrm{~kW}$, b) $32 \mathrm{~kW}$ and c) $35 \mathrm{~kW}$ plasma power.

Figure 4-6. Average diameter of different splat morphologies for a) $28 \mathrm{~kW}$,

b) $32 \mathrm{~kW}$ and c) $35 \mathrm{~kW}$ plasma power. 
Figure 4-7. Formation of three-dimensional coating structure from simulated splats......43

Figure 4-8. Cross-sectional image of coating, a) from experiments power $32 \mathrm{~kW}$, substrate preheat temperature $180{ }^{\circ} \mathrm{C}$ and b) from computational stacking power $32 \mathrm{~kW}$, substrate preheat temperature $180{ }^{\circ} \mathrm{C}$. ...............................44

Figure 4-9. Deposition of real time plasma process and computational model ..........45

Figure 4-10. Comparison of the porosity of the cross-sectional orientation of the coatings obtained from finite element analysis (FEA) for the computational coating structure and ImageJ for the experimental coatings

Figure 4-11. Finite element analysis, acquiring an image, adaptive meshing, and application of boundary conditions. 


\section{LIST OF ABBREVIATIONS}

\begin{tabular}{|c|c|}
\hline Symbol & Description \\
\hline HVOF & High Velocity Oxygen Fuel \\
\hline VOF & Volume of Fluid \\
\hline $\mathrm{V}$ & Velocity Vector \\
\hline $\mathrm{P}$ & Pressure \\
\hline$v$ & Kinematic viscosity \\
\hline$\rho$ & Density \\
\hline $\mathrm{F}$ & Body forces \\
\hline $\mathrm{h}$ & Enthalpy \\
\hline $\mathrm{k}$ & Thermal conductivity \\
\hline $\mathrm{T}$ & Temperature \\
\hline $\mathrm{f}$ & $\begin{array}{l}\text { The fraction of a cell volume occupied } \\
\text { by liquid }\end{array}$ \\
\hline$\nabla$ & Vector differential operator \\
\hline $\mathrm{R}$ & The radius of the impacting droplet \\
\hline Dn & The diameter of the impacting droplet \\
\hline 1 & $\begin{array}{l}\text { The distance between the droplet impact } \\
\text { point and the center point of previously } \\
\text { deposited splats }\end{array}$ \\
\hline $\mathrm{a}$ & $\begin{array}{l}\text { Major radius of splat (measured along Y- } \\
\text { axis) }\end{array}$ \\
\hline $\mathrm{b}$ & $\begin{array}{l}\text { Minor radius of splat (measured along X- } \\
\text { axis) }\end{array}$ \\
\hline
\end{tabular}




\section{CHAPTER 1. INTRODUCTION}

\subsection{Plasma Spray}

Plasma Spray is one of the thermal spray techniques in which a DC arc is generated between the anode and cathode resulting in the dissociation and ionization of gases to form plasma [1]. The temperature of plasma can reach up to $10,000 \mathrm{~K}$ making it suitable for the formation of metallic, ceramic as well as polymeric coatings [2]. The material in the form of powder is injected in the plasma stream where it is rapidly heated and accelerated to a high velocity towards the substrate material [3-5]. The coating is formed by the buildup of the successive layers of molten particles which flatten and solidify to form a lamellar microstructure. Due to the high cooling rates typically of the order of $10^{6}$ to $10^{8} \mathrm{~K} / \mathrm{sec}$, the microstructures of the coatings are fine-grained and homogeneous [6,7]. The schematic diagram of the plasma spray process is shown in Figure 1-1.

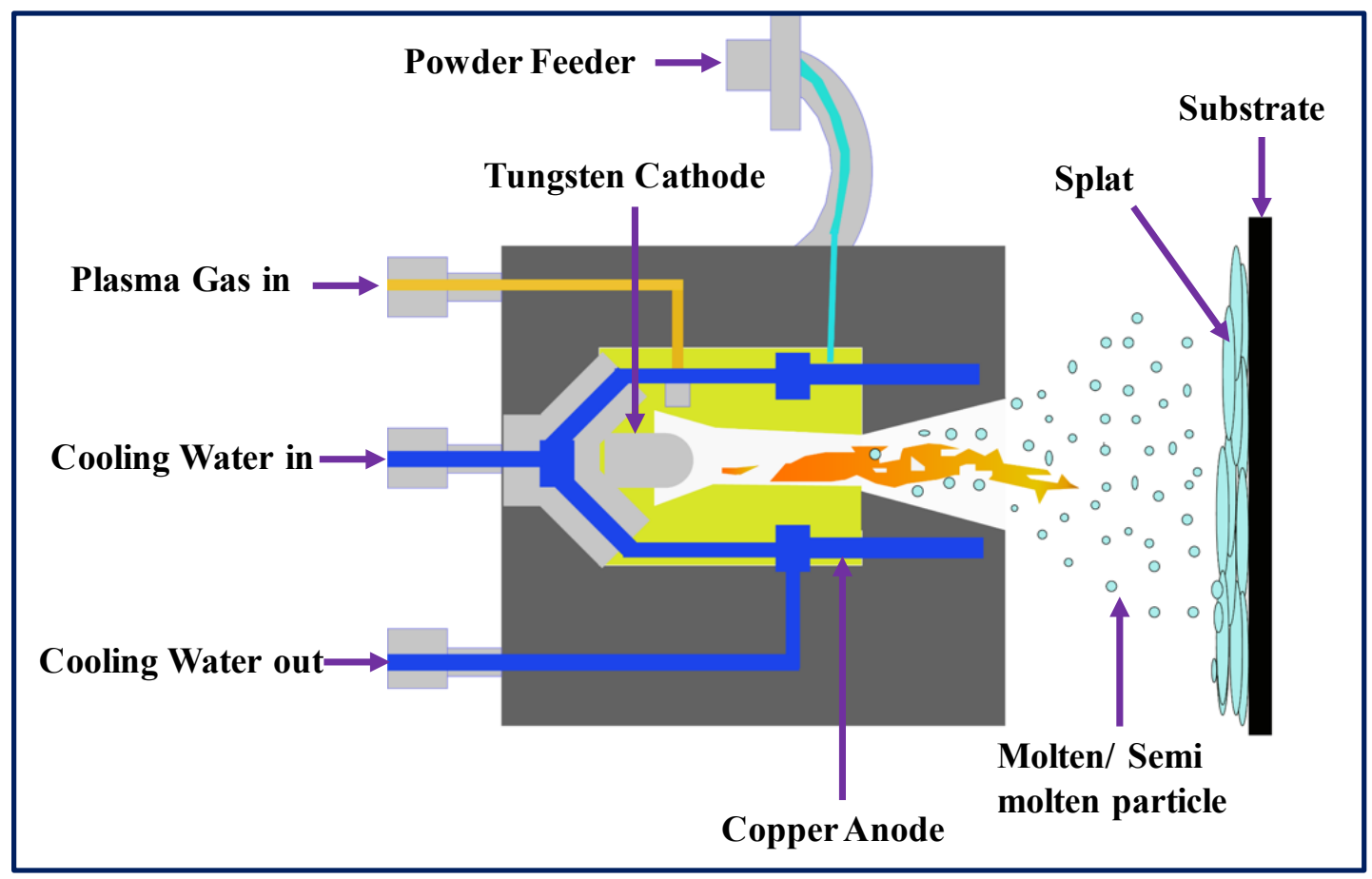

Figure 1-1. Schematic Diagram of Plasma Spray 
Plasma sprayed coatings are widely used due to their flexibility (any material can be deposited on any substrate), ability to produce homogeneous coating structure, the formation of thick coating structure and ability to produce coating structure in different environments (air, inert gas, vacuum) [8]. Plasma sprayed coatings find a wide range of applications in the automotive, aerospace, chemical, textile and biomedical industries [9]. The typical applications of plasma sprayed coatings are wear and erosion resistance for various machinery parts, improvement of friction properties, the formation of electrodes, biomedical coatings for the orthopedic and dental prosthesis, thermal and chemical barrier coatings for the piston, gas turbine blades, corrosion protection of equipment, etc. [10-12].

\subsection{Splats}

During the deposition and solidification of the molten particle, a lamellar structure called "splat" is formed [13]. The pancake-shaped splats are the building blocks of the plasma sprayed coating [14]. The thermal, mechanical and electrical properties of plasma sprayed coatings are dependent on the morphology, and arrangement of the splat [15-17]. There are three major shapes of splats commonly observed in the plasma sprayed coatingsdisk, fragmented and fingered (splashed) splats [18] as shown in Figure 1-2.

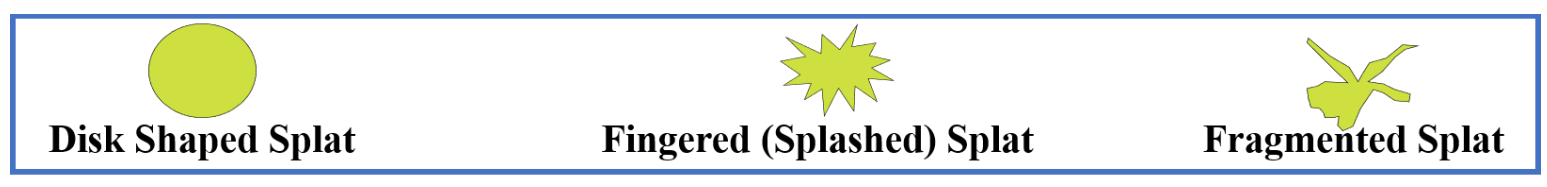

Figure 1-2. Morphologies of splats

Disk-shaped splats have better contact with substrate resulting in the increased adhesion and reduced porosity [19]. Presence of the fragmented and splashed splats in the coating structure increases porosity and pose a greater probability of delamination [20]. 
Several processing parameters influence splat morphologies - powder characteristics (chemistry, morphology, structure), plasma torch design (nozzle diameter, powder injection location, injection angle), arc current, arc voltage, spray distance, powder feed rate, carrier flow rate, and substrate preheat temperature [21-24].

To optimize the properties of the coatings, the plasma process parameters must be optimized. The entire process of the spray parameter development, microstructure evaluation, and the study of the properties of the coatings is determined experimentally and is iterative in nature. So, to better understand the effect of the processing parameters on the properties of the coating structure, computational methods are utilized.

\subsection{Computational Methods and Their Limitations}

With many variables in terms of processing parameters, equipment, and powder feedstock, it is very challenging to simulate coating structure as well as the microstructures. There have been numerous computational studies for the simulation of splats for the variation in plasma processing parameters. The formation of tungsten droplets on a wavy surface was studied by Liu et al. [25]. Bussman et al. [26] designed a 3D numerical model to simulate the splashing of the droplet in isothermal conditions. Pasandideh- Fard et al [27] studied the influence of substrate temperature on splat morphology of Nickel splats. Jiang et al. [20] investigated the influence of substrate temperature on the splat geometries of Molybdenum on different substrate materials.

Likewise, there are some computational techniques that are studied to develop the coating structure. A two-dimensional model based on the Monte Carlo technique was developed by Knoteck and Elsing [28]. Chen et al. [29] formulated a ballistic method to 
study coating growth and pore formation. Wei et al. [30] studied the formation of coating buildup using the LAVA3D-P program.

The available computational models are either focused on the simulation of the splats or the simulation of the coatings structure. There lacks a comprehensive computational model which can simulate both splats and the coating structure and predict the properties of the coatings. So, in this study, a comprehensive technique is introduced that can predict the microstructure as well as mechanical properties of the plasma sprayed coatings.

\subsection{Research Objective}

One of the areas of interest in the field of plasma spray is the development of a computational technique that can tailor the mechanical and thermal properties of the coatings. In this study a novel computational desktop manufacturing approach is developed that can predict the microstructure as well as mechanical properties of the coatings with the variation in the plasma processing parameters. In this scheme, splat microstructure is simulated for different spraying conditions, three-dimensional coating structure is formed using simulated splat morphologies and the mechanical properties of the coatings are

predicted. The results from the computational approach are validated with the results from experiments to determine the robustness of the model developed. The approach will allow for the development of the novel coatings in a shorter amount of time, resulting in the reduced cost and better estimation of coating properties. 


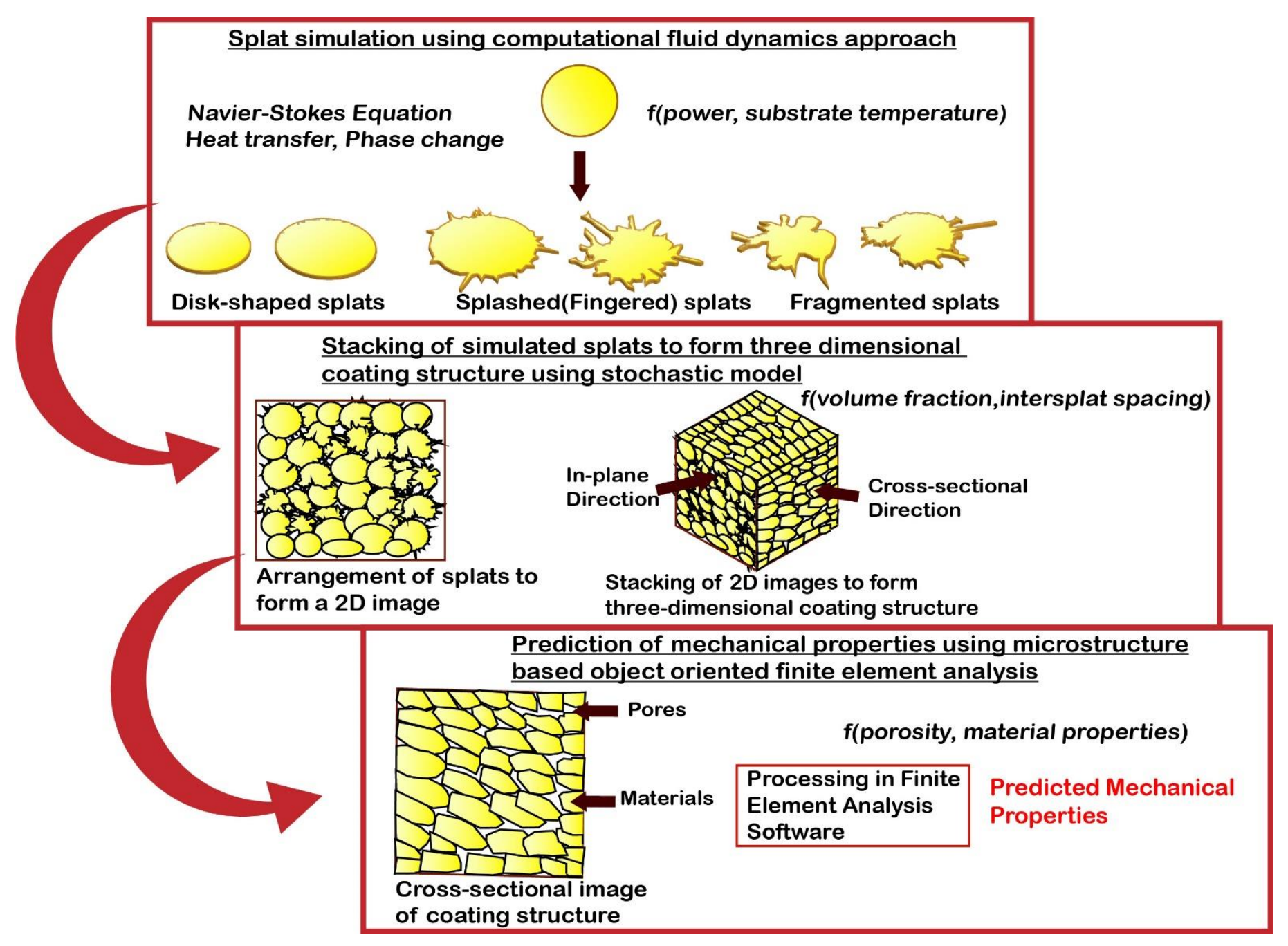

Figure 1-3. Schematic Diagram of Computational Approach 
Figure 1-3 summarizes the research objective which includes three specific aims:

1. Computational Fluid Dynamics for the simulation of splats

2. The arrangement of the simulated splats to form a two-dimensional coating structure and stacking of two-dimensional images together to create a threedimensional coating structure using a stochastic approach

3. Microstructure-based finite element analysis for the prediction of the mechanical properties

This computational approach can be used as the cornerstone in the development of a universal technique to predict the mechanical properties of the coatings. It needs to be emphasized that more than one hundred parameters are involved in plasma spray in terms of processing parameters, equipment, and starting powder feedstock. So, the development of the computational model can also reduce the cost of the development of the coatings as this approach allows for the tailoring of the coating properties with a reduced number of experiments. This approach can be further extended to other materials as well as other thermal spray processes such as HVOF (High-Velocity Oxygen Fuel).

In developing this thesis, six chapters are presented. Chapter one presents the introduction and background of the topics related with the plasma spray, their applications, and the benefits of developing a computational approach to predict the microstructures as well as the properties of the plasma sprayed coatings. The following chapter is Chapter 2, in which the state of art is presented. Some previous investigations on the determination of microstructure and mechanical properties of the coating structure using the empirical techniques and computational techniques are discussed. Chapter 3 details the experimental 
procedure, and the computational scheme. Chapter 4 provides the validation of the results obtained from the computational techniques with the experimental studies. Finally, Chapter 5 presents the major conclusions and Chapter 6 sets some suggestions for future studies to expand knowledge in the field of computational studies of plasma sprayed coatings. 


\section{CHAPTER 2. LITERATURE REVIEW}

The relationship between the microstructure and the properties of the plasma sprayed coatings is complex due to a large number of processing parameters- plasma current, plasma gas composition and flow rate, standoff distance, plasma gun transverse speed and powder parameters [31-34]. In this section, a brief overview of the effect of the spraying parameters in the formation of the splats and the coating structure is presented, along with the state of the art of the experimental techniques for the selection of the optimal processing parameters and computational techniques that are developed to predict the microstructure and properties of the plasma sprayed coatings.

\subsection{Processing Parameters in Plasma Spray}

The effect of some of the key- processing parameters in the formation of the microstructure and the properties of the coatings structure are discussed below:

\section{Feed rate}

The feed rate should be maintained in the plasma spray process. A higher feed rate increases the number of the particles in the plasma plume resulting in the increase of the unmolten particles and porous coating structure. The unmolten particles may also not adhere properly to the substrate and bounce back, resulting in the decreased deposition for higher feed rate [35]. The feed rate also affects the thickness of the coating developed.

\section{Stand-off Distance}

Stand-off distance or the spray distance is the distance between the tip of the gun and the substrate surface. At the larger stand-off distance, the particles become partially solidified before impacting the substrate resulting in the formation of the splashed or the 
fragmented splats. And, at the lower spray distance, the particles may not have enough time to melt and may erode the surface of the substrate [36].

\section{Substrate Temperature}

Fukumoto and Huang discovered from their studies that morphologies of splats were highly dependent on the substrate temperature. The Transition temperature (Tc) is defined as the substrate temperature in which half of the splats are disk type, and the transition temperature is dependent on the coating material than the substrate material [37,38]. Sampath et al. estimated the transition temperature to be close to $10 \%$ of the melting point of the material [18]. Though the exact explanation of this mechanism is unknown, it is believed that at the transition temperature, the adsorbates, and the condensates are removed from the surface [38].
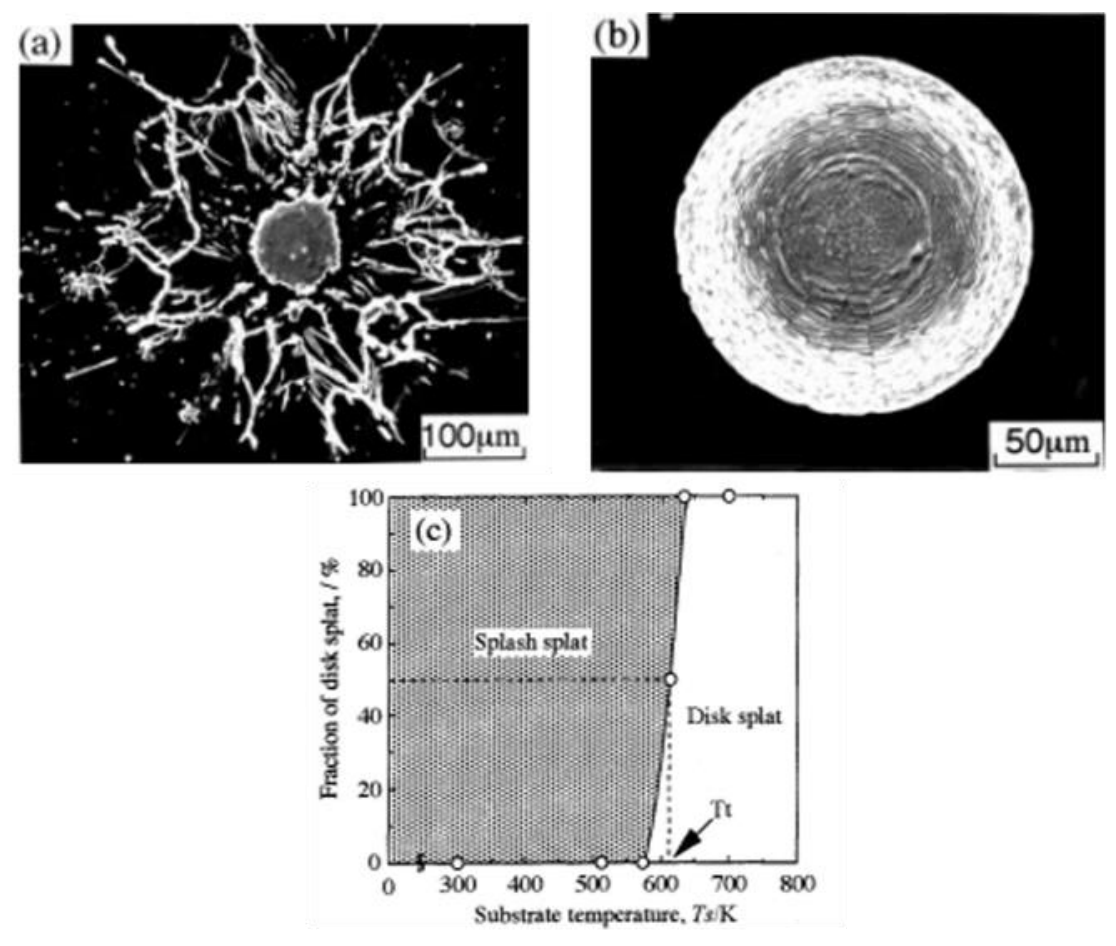

Figure 2-1. Nickel splat morphologies on AISI 304 substrate. (a) Splash splat, Ts = 300 K. (b) Disk splat Ts $=673 \mathrm{~K}$. (c) Fraction change of disk splat with substrate temperature [37] 


\section{Plasma Gas Flow Rate}

Plasma gas flow rate affects the microstructure and the properties of the coatings as it influences the dwell time as well as the trajectories of radially injected particles. With low gas flow rate, fine particles bounce off the plasma jet and are not melted and a porous coating structure is obtained. And, for a high carrier gas flow rate, the plasma temperature and the velocity of the particles in increased significantly causing the particles to escape the hottest region of plasma resulting in the low flow rate [39].

\section{Substrate roughness}

Substrate roughness is another critical parameter that affects the splat morphology. With the increase in the substrate roughness, the friction for the liquid droplet increases which results in the decrease of the flattening degree, forming more fingered splats [40].

\section{Thermal Contact Resistance:}

Pasandideh-Fard et al. [27] found that the rate of solidification is much more sensitive to the values of the thermal contact resistance than the substrate temperature. The value of the thermal contact resistance is affected by the gases and the solid impurities trapped at the particle - substrate interfaces [41]. If the thermal contact resistance is too low, cooling is rapid, so the splat begins to solidify. The solid layer obstructs and destabilizes the flow of the liquid resulting in the formation of fingered splats. If the contact resistance is too high, the particle remains liquid and spreads into a thin film, that ruptures internally forming splashed splat morphologies [42].

To understand the complex thermo-physical phenomenon occurring during the plasma spray process, several studies have been carried out. These studies can be grouped 
broadly into two different techniques: Experimental techniques and computational techniques.

\subsection{Experimental Techniques}

A common way to study the effect of plasma spray processing parameters on the coating properties is to use a statistical design of experiments (DOE) approach to empirically relate the parameters to the properties $[40,43]$. The empirical technique involves changing one process parameter at a time to observe its effect on the microstructure and the properties of the coating [44]. In this process, several experiments are carried out to identify the optimum parameters required for tailoring the properties of the coatings. The first step in the design of experiments is to determine the choice of the significant process parameters. The parameters are fixed at low (-1) and high (+1) inside the experimental domain. The four major techniques utilizing the design of experiments in plasma spray techniques are:

1. Hadamard or Plackett-Burman matrices $[40,45]$

2. Two-level full factorial design $\left(2^{\mathrm{k}}\right)[45,46]$

3. Two levels fractional factorial design $\left(2^{\mathrm{k}-\mathrm{m}}\right)[43]$

4. Response of surface methodology (RSM) designs [47]

Many experimental studies are carried out to understand the effect of different spraying parameters on the microstructure and the properties of the plasma sprayed coatings. McPherson [48] studied the relationship between the microstructure and the mechanical properties of the coatings. The mechanical properties of the coatings were found to improve with the increase in contact between lamellae and between lamellae and substrate. Kulkarni et al. [15] studied the correlations between the processing and the 
porosity and properties of yttria-stabilized zirconia coatings. With the increase in the size of the particles, fragmented and fingered splats were observed resulting in the increase of the porosity of the coatings leading to lower thermal conductivity and elastic modulus. Also, the increased substrate temperature resulted in the formation of disk-shaped splats resulting in the enhanced coating properties. Sampath et al. [18] studied the effect of the substrate temperature on the microstructure and properties of yttria-stabilized zirconia coatings. The study confirms that at the threshold temperature of around $10 \% \sim 250-300^{\circ} \mathrm{C}$ of the melting temperature of zirconia, the splat morphologies change from fragmented (splashed) to disk-shaped. At the higher substrate temperature, the inter-splat and intrasplat contact are improved resulting in the reduced porosity and increased strength.
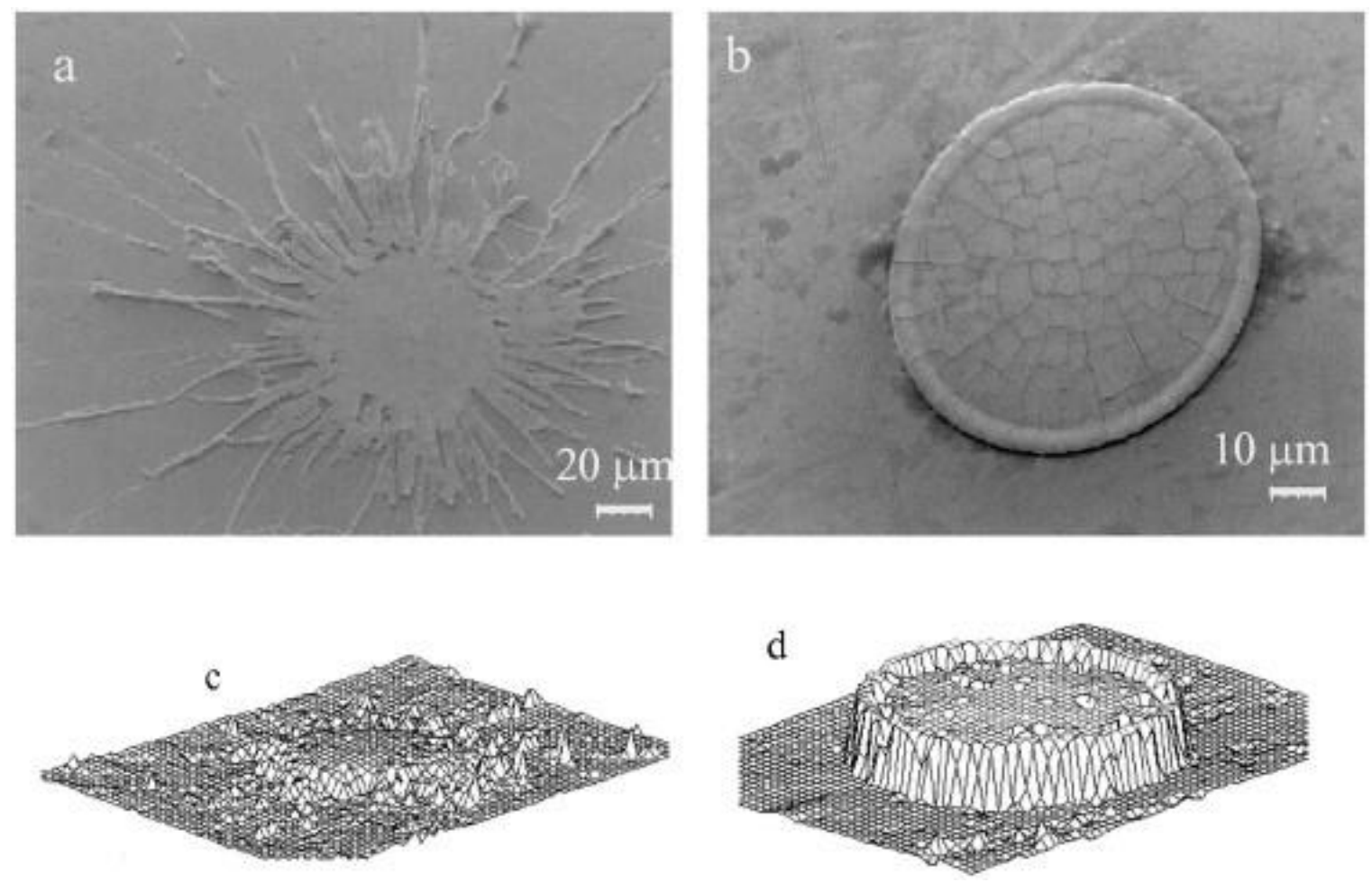

Figure 2-2. Morphologies and 3-D surface profiles of zirconia splats prepared on (a) and (c) cold substrate $\left(100^{\circ} \mathrm{C}\right)$ and (b) and (d) hot substrate $\left(250-300^{\circ} \mathrm{C}\right)[18]$ 
Bianchi et al. [46] splat morphologies of zirconia at two different substrate temperatures. Disk-shaped splats with low thermal contact resistance were observed for the hot substrate and the fragmented splats were observed for the cold substrates. The adhesion-cohesion of the splats was found to be almost three times for the hot substrate over the cold substrate. Wang et al. [47] studied the effect of the splat interfaces in the effective properties of the plasma sprayed zirconia coatings. They observed that the splat interfaces result in $25-60 \%$ of the total reduction in the effective properties of the coatings. The splat interfaces were observed to have greater influences in the thermal conductivity than on the elastic modulus. Jiang et al. [20] studied the splat morphologies of Molybdenum for different substrates at different temperatures. They found that splat morphologies changed from fragmented to the disk-shaped with the increase in the

substrate temperature. The lamellar structure with fewer pores was observed for the increased substrate temperature. The thermal conductivity and hardness were found to increase at a higher substrate temperature.

Using the experimental techniques, determination of the relationship between the processing variables and the resulting particle characteristics and properties of coatings is very tedious, time-consuming and expensive. Also, the reproducibility of the coatings formed from the experimental routes is also one major challenge in the field of plasma spray [49].

\subsection{Computational Techniques}

Several computational techniques are used in the modeling of the particle flow in plasma spray processes such as Eulerian-Lagrangian model, and Eulerian-Eulerian approach [50]. In Eulerian approach, a control volume is defined and the flow of the 
material through the control volume is analyzed. In Lagrangian approach, the properties are determined by tracking the motion of the particles. In the plasma flow process, for the Eulerian-Lagrangian approach, the Lagrangian model is used for the simulation of the particle phase, and the gas is modeled as a continuum phase [51]. In the EulerianLagrangian model, the force controlling the motion of the particles is the drag. The Lagrangian models are classified as stochastic and deterministic models. The stochastic model considers the gas turbulence effects while the deterministic models neglect the gas turbulence effects [52]. In the Eulerian-Eulerian approach, the particles, as well as the gas, are modeled as a continuum [53]. Interface tracking methods such as Volume fraction method (VOF) are also used for the prediction of splat morphologies and coating build up in the plasma spray processes. Various computational tools that use either one or the combination of those above-mentioned techniques have been used by researchers to simulate splat formation and the coating structure to understand the effect of the processing parameters on the overall properties of the coatings.

A large amount of research has been conducted on the impact and solidification of the molten droplet on the substrate. Madejski developed a two-dimensional radial flow model to study the degree of flattening of molten droplet upon impact in 1976 [54]. A twodimensional model that investigated the droplet impact velocity and temperature, the effect of the substrate and its temperature and the effect of the thermal contact resistance was developed by Bennett and Poulikakos [55]. Zhao et al. [31,56] used both experiments and a two-dimensional numerical model based on the Lagrangian approach to study the fluid dynamics and heat transfer during the impact of the liquid droplets. Pasandideh-Fard et al. [57] simulated the impact and solidification of tin droplets on a steel plate and validated 
the results with experiments. Bussmann et al. [26] developed a three-dimensional computational model for the simulation of impacting droplet at the isothermal condition. Ghafouri -Azar et al. [58,59] studied the interactions between the splats using a threedimensional model. The volume of Fluid (VOF) algorithm was used to track the free surface deformation.

The formation of the coating is very complex in nature. Konteck and Elsing [28] developed a two-dimensional computational model to calculate the temperature distribution in the coating and substrate. The thermal conduction equation is solved for the coating subsegments according to the growth law. The study predicted the size and distribution of interlamellar cracks and pores in the coating. Cirolini et al. [60] formulated a two-dimensional stochastic model and postulated the interactions of the splats deposited on top of others. The model shows how the complex features of the plasma sprayed coatings depend on the process of its deposition. Harding et al. [61] studied the formation of a two-dimensional computational model to build up the coating structure and correlate the properties of the coatings with the process parameters. Kanouff et al. [62] studied the computational modeling of coating inclined at an angle to the substrate and calculated the surface roughness of the coating. String method was used for the modeling of coatings in which the equally spaced node points define the shape of the coating structure and the change in the shape is tracked as the deposition is made. This stochastic model was capable of the deposition of a large number of thermal spray droplets and computing the surface roughness of the coatings.

Hansbo and Nylén [63] developed a spray deposition model to simulate the coating layer build up. An iterative method was used to simulate the robot motion. Chen et al. [29] 
developed a two-dimensional ballistic deposition model to study coating growth and pore formation. The deposition of the particles using plasma spraying process was assumed to follow a Gaussian distribution and the computer program was developed to simulate the growth of the coating and generation of the pores based on the droplet deformation. Wei G. et al. [64] studied the formation of the coating buildup using the LAVA3D-P program. The 3D model developed was based on the probability density function. Ghaufouri et al. [65] developed a three-dimensional stochastic model capable of predicting the porosity, thickness, and roughness of the coatings as a function of process parameters. Several equations were formulated in this study to calculate the splat sizes after the droplet impact and the interactions of the splats with one another. The porosity is assumed to be due to the curling of the splats and the three-dimensional cartesian grid with the volume tracking VOF algorithm was used.

As discussed, different computational techniques and tools have been utilized for the simulation of the microstructure and the coatings for plasma spray. The complete modeling of the plasma spray involves three distinct processes: spray particles, impact and splat formation and the deposition of the coating. Despite the scientific and technical progress, there is a lack of understanding of the process-microstructure- property relationship. Several computational fluid dynamics analysis of the gas and the particle dynamics has been performed but the research works for the complete modeling of the plasma spray from the spray particles to the formation of the bulk coating structure is still in the rudimentary stage. Furthermore, the present computational studies are limited to the simulation of either only the microstructures or the coating structure. So, this work aims to take the modeling of the plasms spray process further by studying the formation of the 
microstructure, as well as the coating structure and predict the mechanical properties of the coatings. In this study, a computational model approach is developed to predict the effect of various spray parameters on the microstructure as well as the properties of the bulk coating. 


\section{CHAPTER 3. MATERIALS AND METHODS}

This chapter discusses in detail the experimental and computational methods used to synthesize and characterize the plasma sprayed aluminum oxide splats and coatings. The processing parameters, characterization techniques, and tools for the microstructural and mechanical evaluation of the coatings are discussed. The various computational tools used for the simulation of the microstructure and coating structure are presented.

\subsection{Experimental Methods}

\subsubsection{Processing}

\subsubsection{Powder}

Aluminum oxide is quite abundant and relatively inexpensive material making it ideal for the plasma spray applications due to its abrasion- resistance, chemical inertness, resistance to thermal shock and mechanical strength at high temperatures $[66,67]$. Aluminum oxide $\left(\mathrm{Al}_{2} \mathrm{O}_{3}\right)$ powder from Praxair (AlO-101) with the size distribution of 15$45 \mu \mathrm{m}$ was used in this study.

\subsubsection{Substrate}

Low carbon steel coupons of dimensions $50 \mathrm{~mm} \times 19 \mathrm{~mm} \times 3.2 \mathrm{~mm}$ was used as the substrate material. The roughness of the substrates was measured by an Optical Profilometer (Nanovea PS50, Irvine, California, USA). The substrates were polished to obtain roughness values $\left(\mathrm{R}_{\mathrm{a}}\right)$ less than $0.1 \mu \mathrm{m}$ for obtaining the splats. Heat gun (STEINEL, HG 2510 ESD, MN, USA) was used for preheating the substrate. The substrate temperature was continuously monitored with the thermocouple (KMQSS-020U, Omega Engineering Inc.) that was placed by drilling through the substrate thickness. 
For the deposition of the coatings, the substrate was grit blasted $\left(\mathrm{R}_{\mathrm{a}} \sim 2-3 \mu \mathrm{m}\right)$. The substrate temperature was monitored using the infrared pyrometer (IR) (Raytek Raynger MX®) and the deposition of the coatings was done when the substrate temperature reached the desired values.

\subsubsection{Processing Parameters}

The effect of the two processing parameters: power and substrate preheat temperature on the microstructure and the properties of the coatings were investigated in this study. Three different powers: $28 \mathrm{~kW}, 32 \mathrm{~kW}$, and $35 \mathrm{~kW}$ and three different substrates preheat temperatures: $100^{\circ} \mathrm{C}, 180^{\circ} \mathrm{C}$, and $250^{\circ} \mathrm{C}$ were used. The range of the power and the substrate preheat temperature were taken from the literature $[66,67]$.

For the variation of the power, the current was changed keeping the voltage constant at 40 Volts. Plasma spraying of three powders (A-SD, A4C-SD, and A8C-SD) was carried out using Praxair SG 100 plasma gun (Praxair, Danbury, CT, USA) on low carbon steel substrate. Powders were carried by argon gas through Praxair model \#1264 powder feeder and internally injected in the plasma gun. And the plasma gun movement was maintained at $25 \mathrm{~mm} / \mathrm{sec}$.

Table 3-1. Processing parameters used in the formation of splats and coatings

\begin{tabular}{cccc}
\hline Primary & Secondary & Stand-off from the substrate & Powder feed \\
Gas, Argon & Gas, Helium & $(\mathbf{m m})$ & rate \\
$(\mathbf{s l m})$ & $(\mathbf{s l m})$ & & $(\mathrm{g} / \mathbf{m i n})$ \\
\hline 56.6 & 59.5 & 100 & 3.7 \\
\hline
\end{tabular}




\subsubsection{Formation of Splats and Coatings}

For obtaining single splats, a shield plate with the holes of $2 \mathrm{~mm}$ diameter was placed in front of the plasma gun aligned in the direction of the spray to collect the single layer of splats without overpopulating the substrate. The substrate with the roughness less than $1 \mu \mathrm{m}$ was placed behind the shield plate at the distance of $25 \mathrm{~mm}$. The distance between the shield plate and the plasma gun was $75 \mathrm{~mm}$ maintaining the total spray distance of $100 \mathrm{~mm}$. For obtaining coating structures, the same spray parameters used for the synthesis of the splats were used. About 8-10 passes on the grit blasted steel substrate was done to obtain about $150-200 \mu \mathrm{m}$ thick coatings. The schematic diagram for the experimental setup is shown in Figure 3-1.

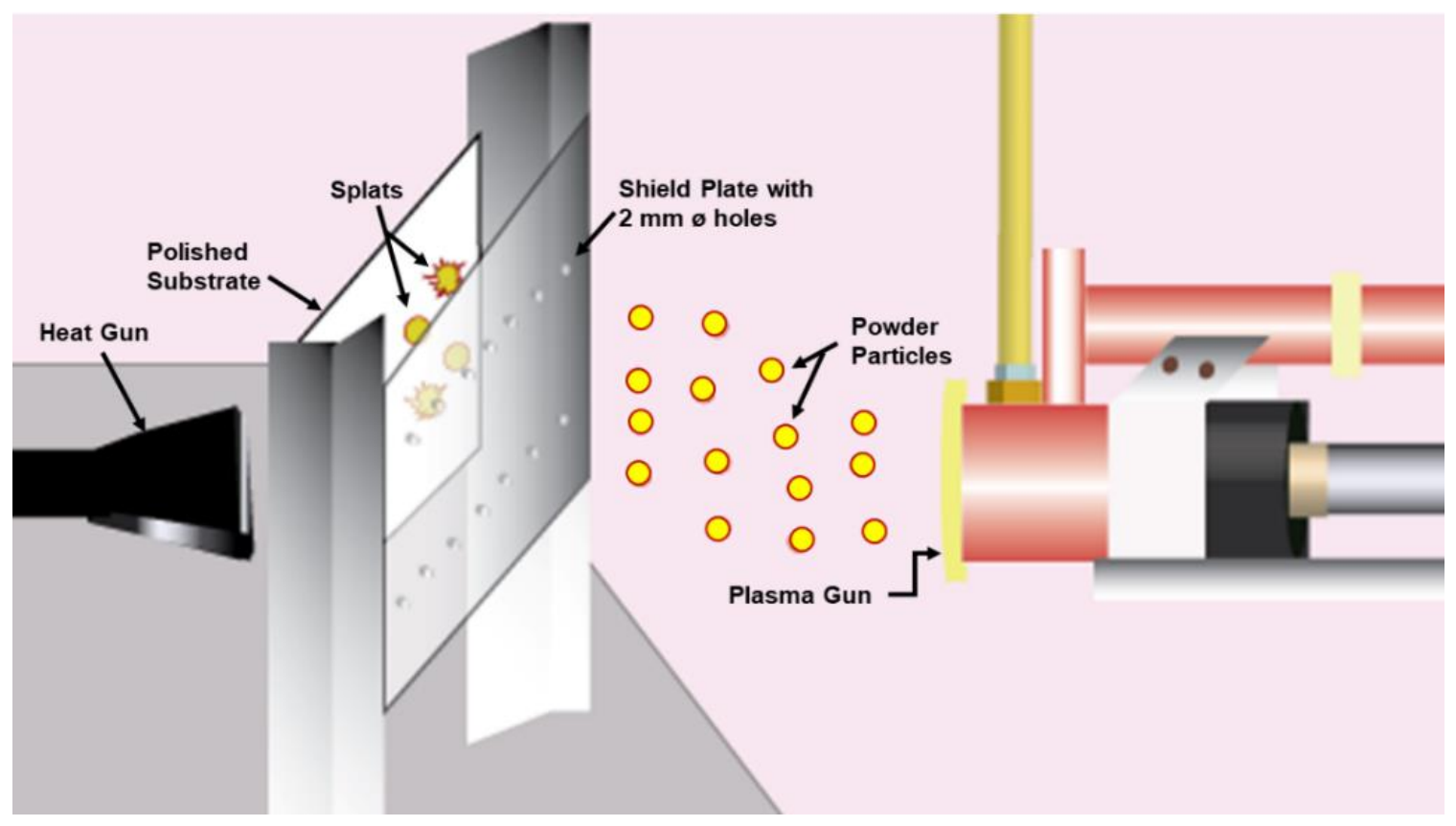

Figure 3-1. Schematic Diagram for Plasma Spray Setup 


\subsubsection{In-flight Particle Diagnostic Sensor}

For measuring the inflight particle temperature and velocities an in-flight diagnostic sensor AccuraSpray ${ }^{\mathrm{TM}}$ in-flight diagnostic sensor (Tecnar Automation Ltée, QC, Canada) was used. Accuraspray diagnostic system provides ensemble average data which represents the particle properties that are measured in the volume of approximately 75 $\mathrm{mm}^{3}$. The diagnostic sensor measures the time of the travel of particles over two closely placed optical fibers to determine the particle velocities. The electronic pulses generated by the photomultiplier to identify the particles and calculate the time of travel for a certain distance. These signals are then cross-correlated with the precision of $99.5 \%$ to measure the particle velocities. The temperature of the in-flight particles is measured by two-color pyrometry. The range of the particle velocities and temperatures that can be measured with the diagnostic sensor are $5-1200 \mathrm{~m} / \mathrm{s}$ and $1300-4000^{\circ} \mathrm{C}$ with the cross-correlation factor > 0.9. CCD camera in the diagnostic system enables the analysis of the plume appearance $[68,69]$.
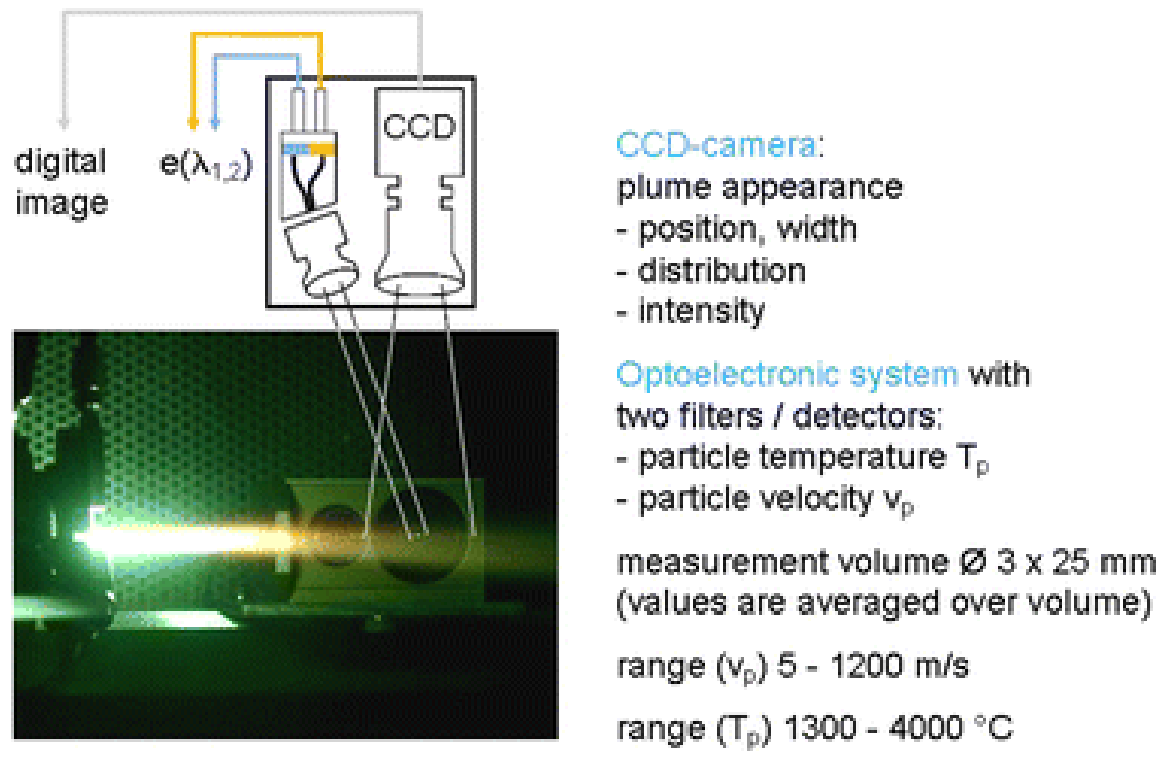

Figure 3-2. Operational Principle of AccuraSpray Diagnostic Sensor [68] 


\subsubsection{Characterization}

\subsubsection{Optical Microscopy}

The morphology of splats was studied using an Optical Microscope (VERSAMET 3 Metallography Microscope). A total of 80 splats from 6-7 images were analyzed for each spray condition. The splat size distribution and the volume fraction of splat shapes (disk, fingered, and fragmented) were determined from the optical micrographs. For the fragmented and fingered splats, the diameter of the splats was measured from the center to the end of the finger. The volume fraction of the splats was defined as the ratio of the number of splats with specific morphology to the total number of the splats analyzed.

The coatings were cut, mounted and polished and the cross-sectional images of the coatings were captured with the optical microscope. About 3-5 images of the coatings for each spraying condition was obtained to study the porosity distribution.

\subsubsection{Porosity Measurement}

The porosity of the coatings was measured by a public domain image processing software ImageJ [70,71]. All the images of coatings were threshold appropriately and converted into binary images to calculate the porosity. The similar image analysis technique is reported in the computation of the porosity of the coatings [72]. Around 4-5 optical images of the coatings were used for the calculation of the porosity to compute the relative porosity of the coatings for each spraying condition.

\subsubsection{Nanoindentation}

Nano-indentation tests were conducted to obtain the elastic modulus from the polished cross-sectional area of the $\mathrm{Al}_{2} \mathrm{O}_{3}$ coatings using TI 900 Triboindenter (Hysitron Inc., Minneapolis, USA). A 100-nm diameter diamond Berkovich tip was first calibrated 
with a standard fused silica sample, by fitting the contact area with a polynomial function of contact depth. Tests were carried out in a quasi-static load control mode. The peak load of $8500 \mu \mathrm{N}$ was applied. The elastic modulus was obtained from the unloading curve from nanoindentation using Oliver-Pharr method [73]. At least 25 indents were performed on each sample.

\subsection{Computational Methods}

\subsubsection{Simulation of Single Splats Using Computational Fluid Dynamics Approach}

Computational fluid dynamics software, SIMULENT- DROP (SimDrop)

developed by Simulent Inc., Toronto [74] was used for the simulation of splats. SimDrop employs a three-dimensional Eulerian fixed grid algorithm that utilizes volume tracking approach to track the deformation of fluid. The Navier- Stokes equation along with the heat transfer and phase change is solved using a finite difference scheme. VOF tracking algorithm is used to track the droplet-free surface.

The free surface of the deforming droplet is tracked by VOF scheme.

$\mathrm{f}$ is the fraction of the cell volume occupied by the liquid

$\mathrm{f}=1$, Cell is occupied by liquid

$\mathrm{f}=0$, empty cell

$0<\mathrm{f}<1$, free surface

The equations of conservation of mass, momentum, and energy for the Newtonian, compressible and laminar flow are:
1. Conservation of mass:
$\nabla \cdot V=0$
2. Conservation of momentum: $\quad \frac{d V}{d t}+\nabla \cdot(V V)=-\frac{1}{\rho} \nabla P+\nabla^{2} \vartheta V+\frac{1}{\rho} F$ 
where $\mathrm{V}$ is the velocity vector, $\mathrm{P}$ is the pressure, $\vartheta$ is the kinematic viscosity, $\rho$ is the density, $\mathrm{F}$ is the body forces (surface forces)

Neglecting the viscous dissipation and assuming that the densities of liquid and solid are constant at melting point and equal

$$
\text { 3. Energy Equation: } \quad \frac{\partial h}{\partial t}+(\mathrm{V} . \nabla) h=\frac{1}{\rho} \nabla \cdot(k \nabla T)
$$

where $h$ is enthalpy, $\mathrm{k}$ is the thermal conductivity, and $\mathrm{T}$ is the temperature

$\mathrm{f}$ is the fraction of the cell volume occupied by liquid, and the scalar function $\mathrm{f}$ is passively advected with the flow, f should satisfy the advection equation

$$
\text { 4. Advection Equation: } \quad \frac{\partial f}{\partial t}+(V . \nabla) f=0
$$

Young's algorithm is used to track the free surface. The algorithm consists of two steps: approximate reconstruction of the surface and the geometrical evaluation of volume fluxes across the cell faces. Surface tension effects are included in the body force acting on the fluid surface by using the Continuum Surface Force (CSF) method developed by Brackbill et al. [75].

For all the simulations, due to the presence of the symmetric boundaries, only a quarter of the domain was considered. This helped to save computational time due to the reduction of the problem size. Along the symmetric boundaries, free slip, no penetration conditions, and adiabatic thermal boundary conditions were applied. Similar use of computational fluid dynamics approach for the simulation of hydrophobicity of the water droplets in lotus leaf [76], impact of molten Nickel and Zirconia on different patterned surfaces of silicon [77], simulation of splat morphologies of the Aluminum oxide reinforced CNTs [78], and 
simulation of splat morphologies of the spray dried Aluminum Oxide- graphene nanoplates [79] has been reported by the researchers.

The simulation of splats was performed for the spraying conditions mentioned in section 3.1.1.3. Seven different powder size distribution of 15, 20, 25, 30, 35, 40 and 45 $\mu \mathrm{m}$ were used for the simulation. From the previous studies on the crystallographic phases of the aluminum oxide powder and plasma sprayed coating structure, it was found that only a trace amount of gamma phase is present [80]. So, in this study, it is assumed that the crystallographic phase of the aluminum oxide remains the same (alpha-phase) throughout the entire plasma spray process.

The thermo-physical properties of aluminum oxide obtained from the literature were taken as the input parameter and listed in Table 3-2 [78]. 
Table 3-2. Thermo-physical properties of Aluminum Oxide ( $\alpha$-phase) for splat simulation [78]

\begin{tabular}{ll}
\hline Property & Value \\
\hline Density $\left(\mathrm{kg} / \mathrm{m}^{3}\right)$ & 3990 \\
Liquid phase kinematic viscosity $\left(\mathrm{m}^{2} / \mathrm{s}\right)$ & $1.026 \times 10^{-5}$ at $2437 \mathrm{~K}$ \\
Liquid phase thermal conductivity $(\mathrm{W} / \mathrm{mK})$ & 7.86 at $2327 \mathrm{~K}$ \\
Liquid phase specific heat $(\mathrm{J} / \mathrm{kgK})$ & 1358 at $2327 \mathrm{~K}$ \\
Liquid phase surface tension $\left(\mathrm{kg} / \mathrm{s}^{2}\right)$ & 0.69 at $2327 \mathrm{~K}$ \\
Solid phase thermal conductivity $(\mathrm{W} / \mathrm{mK})$ & 36.16 at $298 \mathrm{~K}$ \\
& 5.9 at $1312 \mathrm{~K}$ \\
Solid phase specific heat $(\mathrm{J} / \mathrm{kgK})$ & 772 at $298 \mathrm{~K}$ \\
& 1273 at $1312 \mathrm{~K}$ \\
Heat of fusion $(\mathrm{J} / \mathrm{kg})$ & 1358 at $2327 \mathrm{~K}$ \\
& 2327 \\
& $1.16 \times 10^{6}$ \\
\hline
\end{tabular}

Thermal contact resistance at the droplet-substrate interface was assumed as $10^{-7}$ $\mathrm{m}^{2} \mathrm{~K} / \mathrm{W}$ for 180 and $250{ }^{\circ} \mathrm{C}$ and $10^{-6} \mathrm{~m}^{2} \mathrm{~K} / \mathrm{W}$ for $100{ }^{\circ} \mathrm{C}[78,79,81,82]$. The average particle temperature and velocity measured by the in-flight diagnostic sensor were taken as input parameters for the simulation of splats. The particle velocities and temperature for different power are presented in Table 3-3. 
Table 3-3. Particle velocities and temperatures for different plasma powerobtained from the in-flight diagnostic sensor during splat formation

\begin{tabular}{ccc}
\hline Power $(\mathbf{k W})$ & Particle velocity $(\mathbf{m} / \mathbf{s})$ & Particle Temperature $\left({ }^{\circ} \mathbf{C}\right)$ \\
\hline 28 & 270 & 2477 \\
32 & 277 & 2492 \\
35 & 287 & 2497 \\
\hline
\end{tabular}

The particle velocities, as well as the temperature, were found to be increased with the plasma power. To account for the cross-correlation factor of the measurement accuracy from the in-flight diagnostic sensor, the particle velocities and temperatures were varied by $\pm 10 \%$ during the simulation of splats.

The resolution of the simulation in SimDrop is defined in terms of cell per radius (CPR). CPR is defined as:

$$
\mathrm{CPR}=\frac{\text { Diameter of the impinging droplet }}{\text { Calculation domain }} * \text { Number of grids }(6)
$$

The higher the value of the CPR, the higher is the resolution of the grid. But, increasing the CPR value increases the number of grids resulting in the requirement of a large amount of computing time. The CPR value of at least 10 is recommended to obtain the solutions [73]. For choosing the optimum value of CPR for simulation, mesh independent study was carried out. Spread ratio, i.e., the ratio of the final splat size to the initial powder size $(30 \mu \mathrm{m})$ was plotted for different CPR values as shown in Figure 3-3. It was observed that for the CPR value of 15 , the change in the spread ratio is less than $5 \%$. 
So, the CPR value of 15 was used in the SimDrop software for the high-resolution simulation of one-quarter of splat to reduce the computational time.

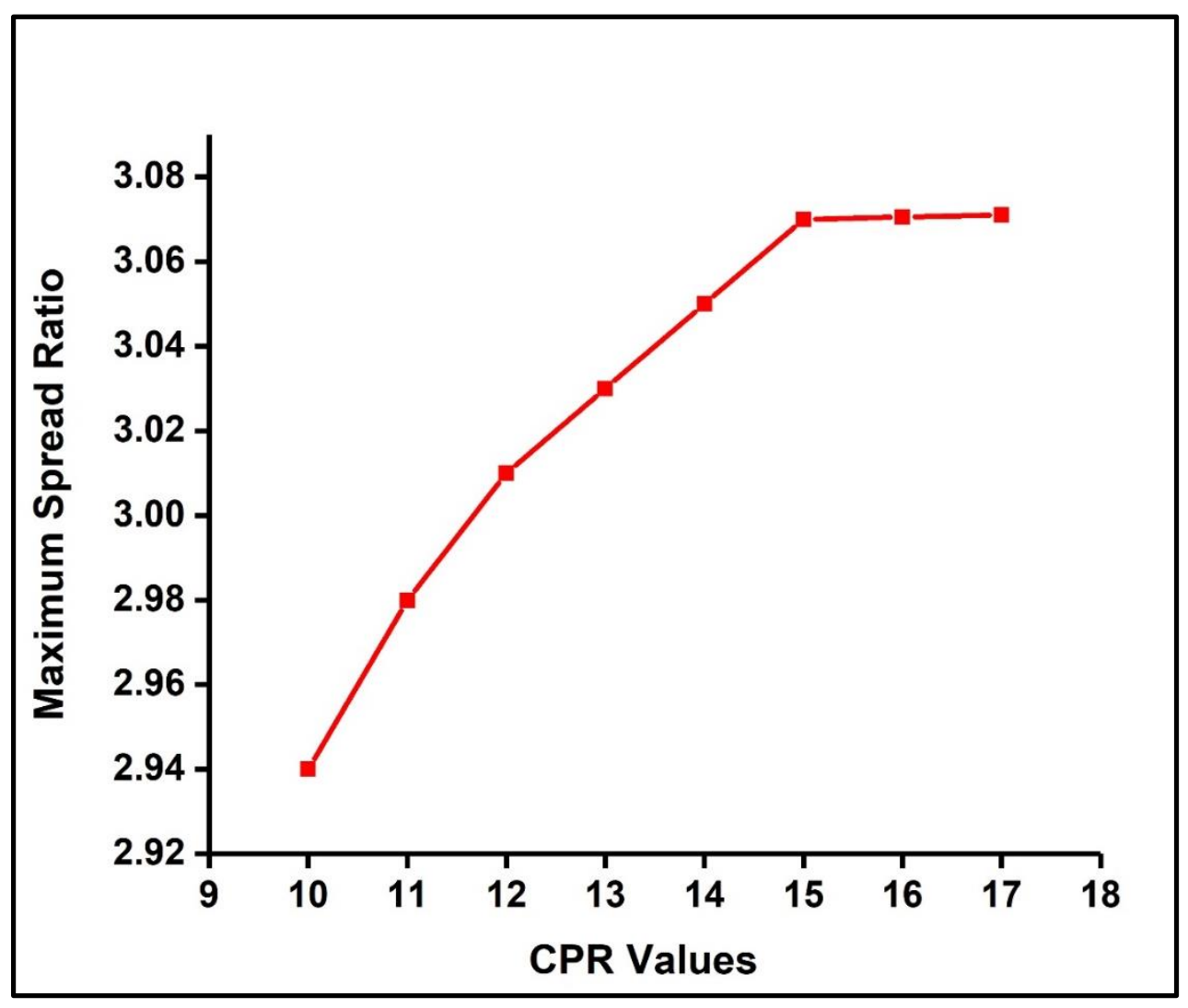

Figure 3-3. Maximum spread ratio for different values of CPR

\subsubsection{Formation of Three-dimensional Coating Structure Using Stochastic Models}

After obtaining the splat morphology computationally, the next step was to create a three-dimensional coating structure by stacking simulated splats. The splats were first arranged in a two-dimensional grid structure to obtain a two-dimensional image. It was assumed that the spreading of a splat depends on the previously deposited splat adjacent to it. The images from SimDrop were arranged according to the splat geometry and distance between the splats based on the stochastic model developed by Ghafouri-Azar et al.[65]. Ghaufouri-Azar had developed four different possible conditions to study the shape of the 
second splat formed due to the interactions between two splats; previously deposited splat and impacting splat. The distance between the neighboring splats that determine the shape of the splats as per the stochastic model developed by Ghaufori-Azar et al. [65] is presented in Table 3-4. ' $R$ ' is the radius, and 'Dn' is the diameter of the impacting splat under consideration. Dm is the diameter of the splat nearest previously deposited splat. ' 1 ' is the smallest distance between the droplet impact point and the center point of the previously deposited splats. The shapes were determined based on the equations from the stochastic model. The ratios of the parameters $a$ and $b$ were obtained from the measurements and are presented in Appendix Table 1 - Appendix Table 9.

For the creation of the two-dimensional image, the volume fraction of splat morphologies (disk-shaped, fingered, and fragmented) and splat diameter distribution obtained experimentally were taken as the input parameters. Splats were arranged in a grid based on the distances as described in Table 3. A grid of $100 \mu \mathrm{m}$ x $100 \mu \mathrm{m}$ was created, and the simulated splats from SimDrop were arranged using a random walk probabilistic approach. Grid sizes were limited to $100 \mu \mathrm{m}$ to minimize computational time and resources. The simulated splats were arranged randomly over the grid. The distances between the shapes were provided as the input parameter based on the shapes of the impacting splat morphology and previously deposited splat according to the four possible scenarios for the droplet interactions as referred in the stochastic model and Table 3-4 [65]. 
Table 3-4. Smallest distance (1) between two neighboring splats based on the equations describing splat shapes (Based on the stochastic model developed by Ghafouri-Azar et al. [65]

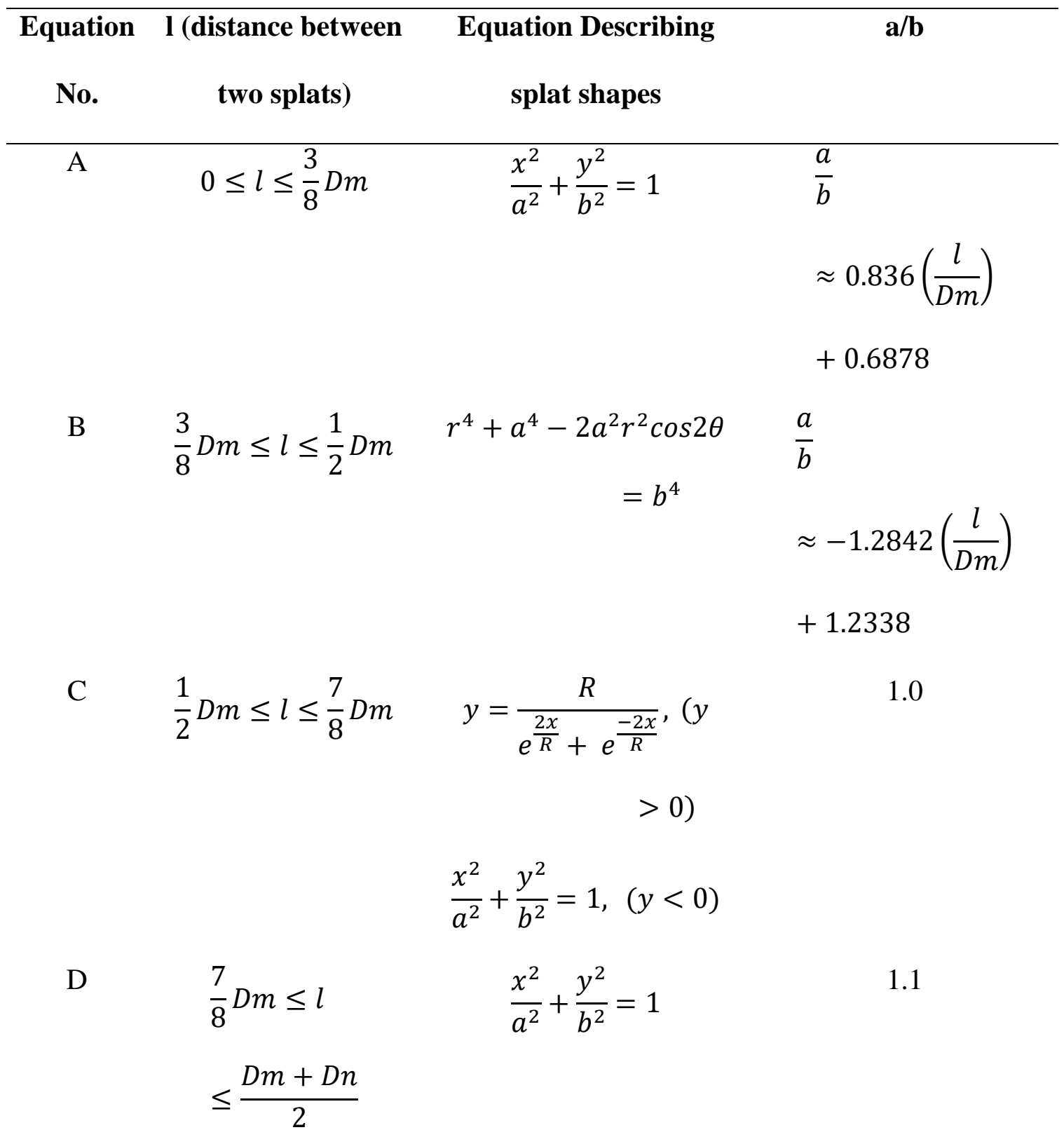

To obtain the variation in the size of the splats, powder size of $15,20,25,30,35$, 40 , and $45 \mu \mathrm{m}$ were simulated. And, the values of the velocity and temperature were varied as $\pm 10 \%$ of the value measured from the in-flight diagnostic sensor in the experiments. As 
presented in the stochastic model developed by Ghaufouri-Azar et al. [65] and Table 3, equations $\mathrm{A}$ and $\mathrm{D}$ were used for the arrangement of the disk and fingered splats, and equations $\mathrm{B}$ and $\mathrm{C}$ were used for the arrangement of the fragmented splat morphologies in a two-dimensional image. The input parameters taken for the formation of the 2D images are presented in the Appendix Tables 1-9. The 2D images were taken as an input in the MATLAB code where the images were stacked to form a three-dimensional coating structure. The various effects like "curling of the splats," relieving of the residual stresses, micro-cracks, splat interfaces were not considered. The pores were assumed to be formed only due to the incomplete filling of the interstices.

\subsubsection{Object-Oriented Finite Element Analysis for Elastic Modulus Prediction}

The open source program Object oriented finite element analysis software, OOF2 developed by the National Institute of Standards and Technology (NIST), has the capability of predicting the macroscopic mechanical properties of the materials using microstructural features as the input [83]. The simulated coating's cross-sectional microstructure was used as an input image for OOF2. The pixels from the image were first converted into two different groups based on the colors and two different groups are obtained- for materials and pores. A coarse mesh with a grid size of 50 x 50 pixels was made. The elements near the interfaces were refined and adjusted so that the interfaces were well described with element boundaries. For the mesh refinement, first, the edges are subdivided and marked and subsequently marked elements are replaced with smaller elements. This was done using the adaptive mesh refinement techniques, to refine the mesh. The mesh is generated by minimizing the energy function which is composed of the homogeneity part of the mesh and shape part of the element as described by equation 5 . 
$E=\alpha$ Ehom $+(1-\alpha)$ Eshape

where $\alpha$ is a tunable parameter and varies between 0 and 1 .

The homogeneity is the measure of how close an element is to enclosing a region that contains a single material. The shape energy Eshape (shape part of the element) is a measure of a feature of the shape of the element [84]. The quality of the mesh is determined by the homogeneity. The homogeneity of the images was obtained to be more than $98 \%$ for the mesh refinement, to ensure the grid independent and accurate solutions. During the mesh refinement, bigger elements are converted into smaller elements by moving the element nodes at the pixel boundaries using the snap tool. Smooth and anneal tools are utilized to move the nodes according to the selection criterion. The actual boundary of the mesh was obtained by the intense refinement of pixels at the boundary. OOF2 creates a finite element-mesh which reflects the shape of the different phases in the microstructure with the associated material parameters.

The values of elastic modulus for Aluminum oxide as 385 GPa and the Poisson's ratio as 0.23 were provided as the input parameter in the finite element analysis software [85]. The pores were considered as the viscoelastic material. The input values for pores were provided as $10^{-8} \mathrm{GPa}$ for Elastic modulus and 0.48 for the Poisson's ratio [48].

After the definition of the material properties and the construction of the mesh, the boundary condition of a uniaxial tensile strain of $1 \%$ was applied in the positive Y-axis direction. $1 \%$ strain value was chosen to be within the elastic regime of the material. After the strain was applied, the integral stress value at the boundary was measured for the uniaxial strain of $1 \%$. And the elastic modulus of the coatings for different spraying conditions was computed. 


\section{CHAPTER 4. RESULTS AND DISCUSSION}

This chapter examines the results obtained from both the experimental and computational methods. The results from the computational analysis are validated by the results of the experimental techniques to determine the robustness of the proposed computational approach.

\subsection{Formation and Simulation of Splats}

In this study, the effect of power and substrate preheat temperature on the formation of plasma sprayed Aluminum splats were studied using both experiments and simulation. Simulated splat morphologies are obtained from the SimDrop software. The splat morphologies obtained from simulation and experiments are compared in Figure 4-1 to 43. 


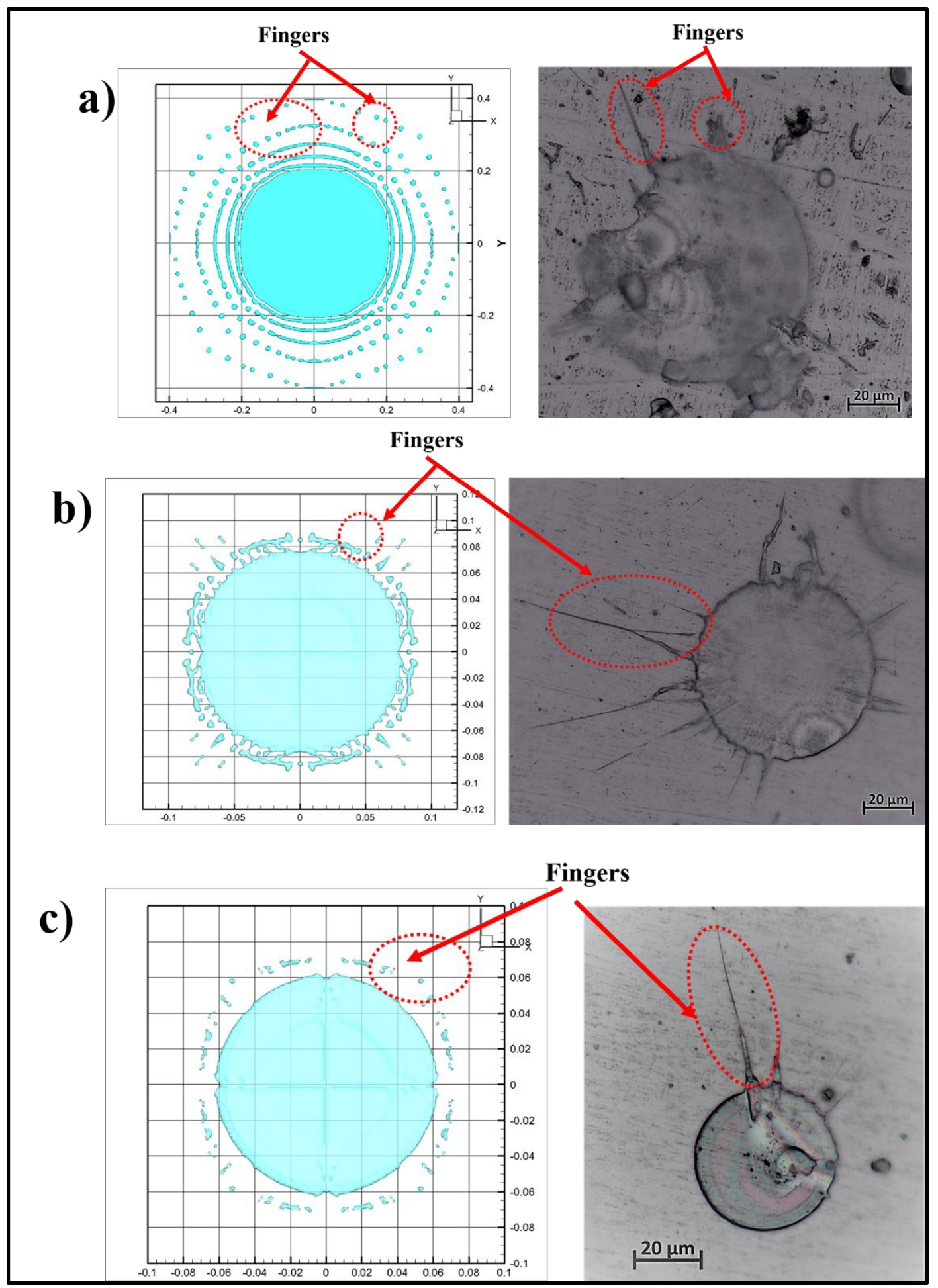

Figure 4-1. Comparison of splat morphology obtained from experiments and simulations, a) Power $28 \mathrm{~kW}$, Substrate Preheat Temperature $100{ }^{\circ} \mathrm{C}$, b) Power $28 \mathrm{~kW}$, Substrate Preheat Temperature $180{ }^{\circ} \mathrm{C}$ and c) Power $28 \mathrm{~kW}$, Substrate Preheat Temperature $250{ }^{\circ} \mathrm{C}$ 


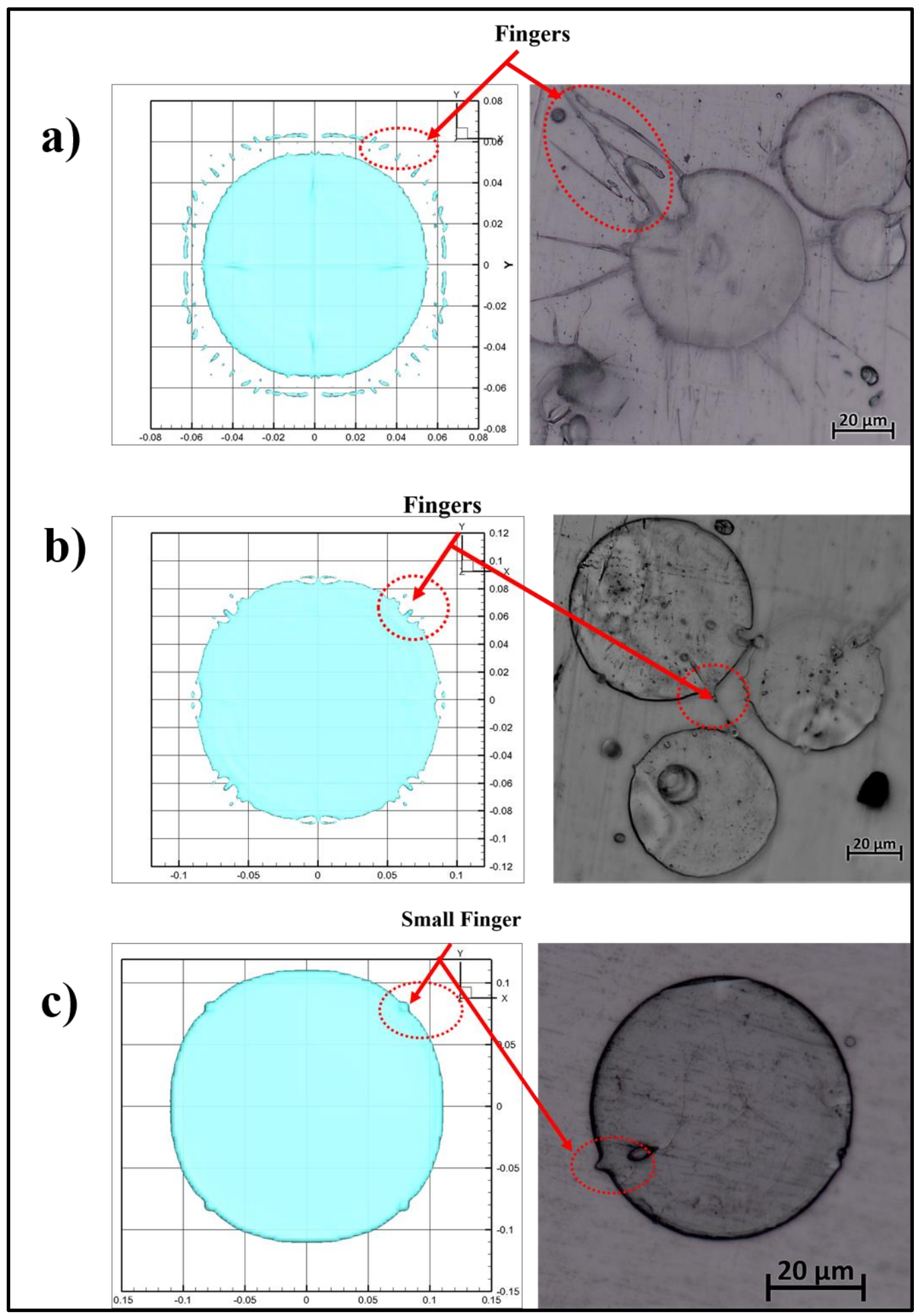

Figure 4-2. Comparison of splat morphology obtained from experiments and simulations, a) Power $32 \mathrm{~kW}$, Substrate Preheat Temperature $100{ }^{\circ} \mathrm{C}$, b) Power $32 \mathrm{~kW}$, Substrate Preheat Temperature $180{ }^{\circ} \mathrm{C}$ and c) Power $32 \mathrm{~kW}$, Substrate Preheat Temperature $250{ }^{\circ} \mathrm{C}$ 


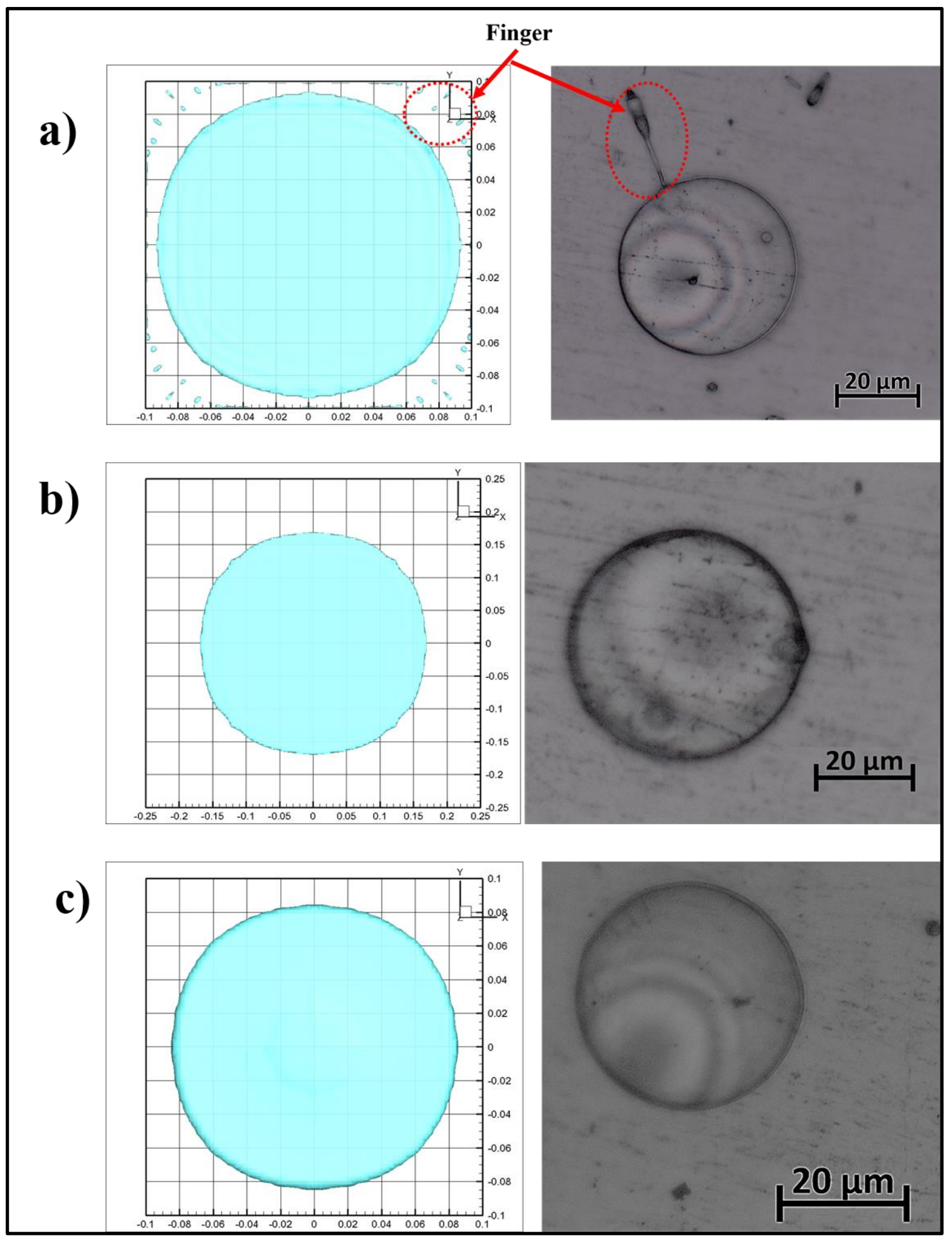

Figure 4-3. Comparison of splat morphology obtained from experiments and simulations, a) Power $32 \mathrm{~kW}$, Substrate Preheat Temperature $100{ }^{\circ} \mathrm{C}, \mathrm{b}$ ) Power $32 \mathrm{~kW}$, Substrate Preheat Temperature $180{ }^{\circ} \mathrm{C}$ and c) Power $32 \mathrm{~kW}$, Substrate Preheat Temperature $250{ }^{\circ} \mathrm{C}$ 
A larger number of fragmented and fingered splats were observed for lower power and substrate preheat temperature. This can be related to the localized solidification of the molten droplets which obstructs the spreading resulting in the formation of fingers and fragments. The results from the SimDrop software accurately captured all the intricate features like fingers and fragments of the splats. The splat morphologies from the simulations showed a great resemblance to the morphologies obtained from experiments.

The volume fraction of splat shapes (disk, fingered, fragmented) for varying plasma power and the substrate temperature was determined experimentally as shown in Figure 4-4. A total of 80 splats from 6-7 images were analyzed for each spray condition. The volume fraction of the splat shapes (disk, fingered and fragmented) for the variation in the processing parameters were determined experimentally. The volume fraction of the splat morphology was measured as the ratio of the number of the splats with specific morphology to the total number of splats analyzed. 


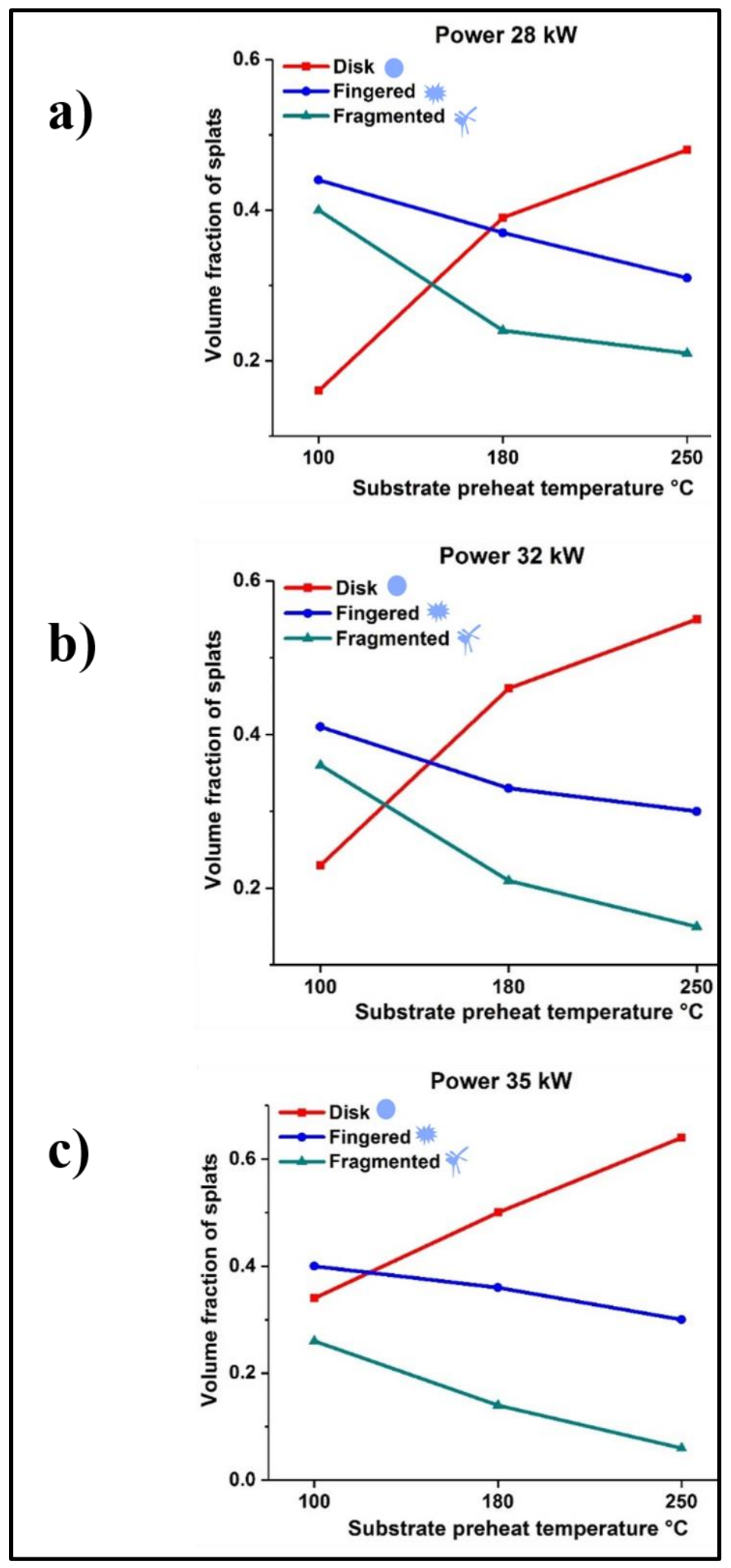

Figure 4-4. Volume fraction of splats for a) $28 \mathrm{~kW}$, b) $32 \mathrm{~kW}$ and c) $35 \mathrm{~kW}$ plasma power 
Figure 4-4 shows that the volume fraction of the disk-shaped splats increased with the increase in power and substrate temperature. Disk-shaped splats increased four-fold from a mere $15 \%$ at $28 \mathrm{~kW}, 100^{\circ} \mathrm{C}$ to $63 \%$ at $35 \mathrm{~kW}, 250^{\circ} \mathrm{C}$.

A wide range of powder size $15-45 \mu \mathrm{m}$ was used for the splat formation. So, to understand the size distribution of the splat size for the various spraying conditions, size distribution plot was made. 


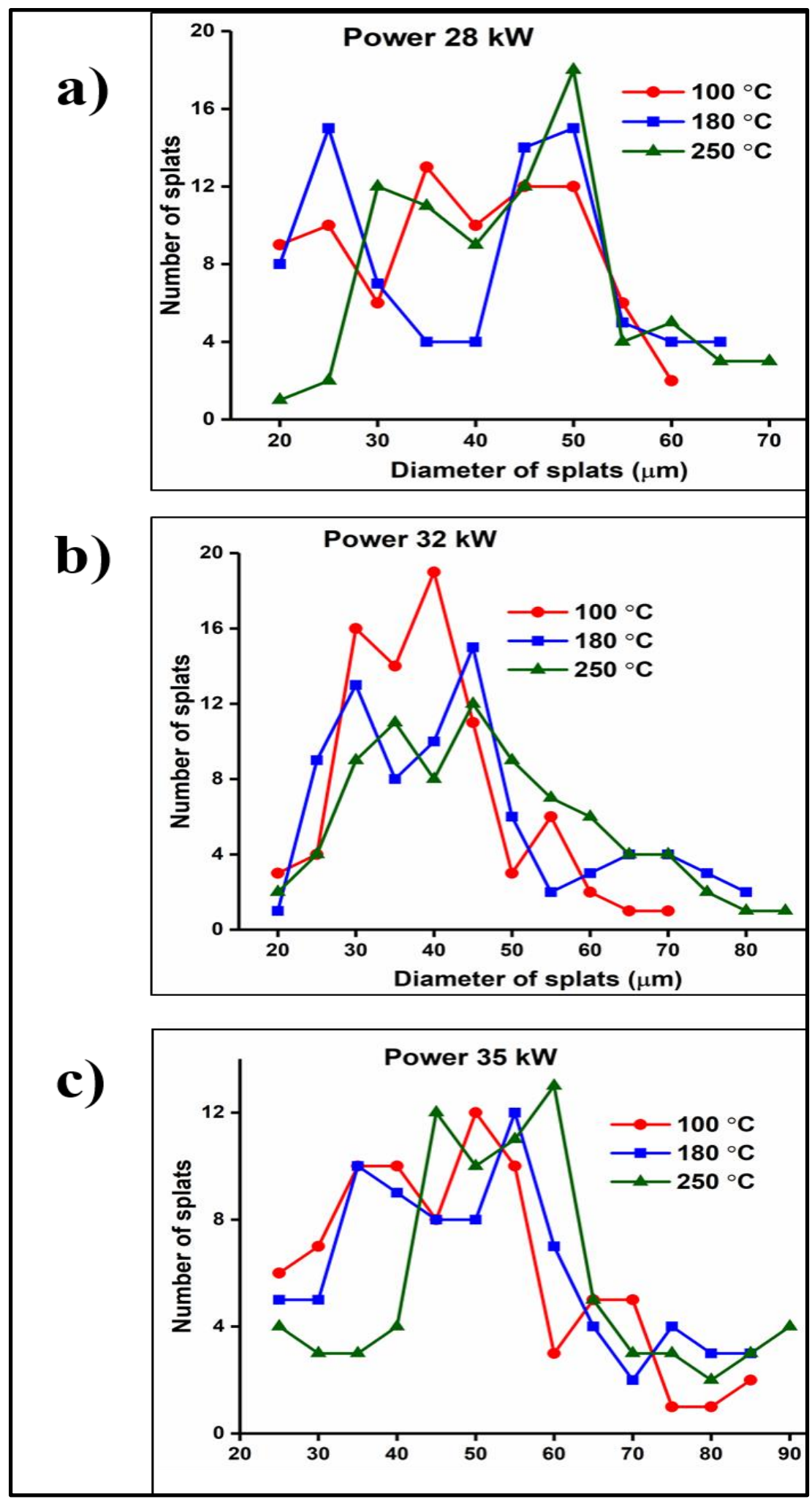

Figure 4-5. Splat size distribution for different substrate preheat temperatures for a) 28 $\mathrm{kW}$, b) $32 \mathrm{~kW}$ and c) $35 \mathrm{~kW}$ plasma power 

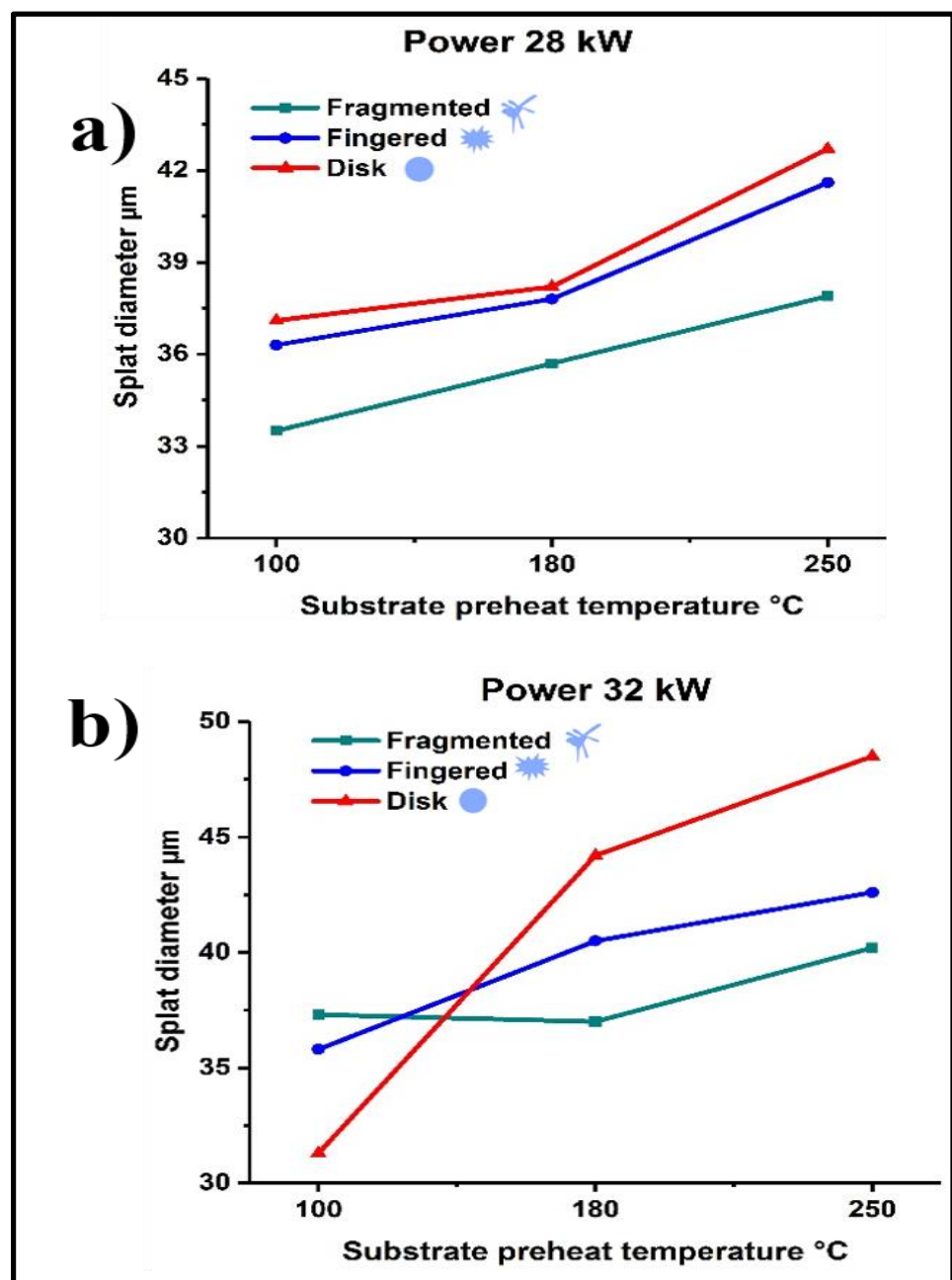

Power 35 kW

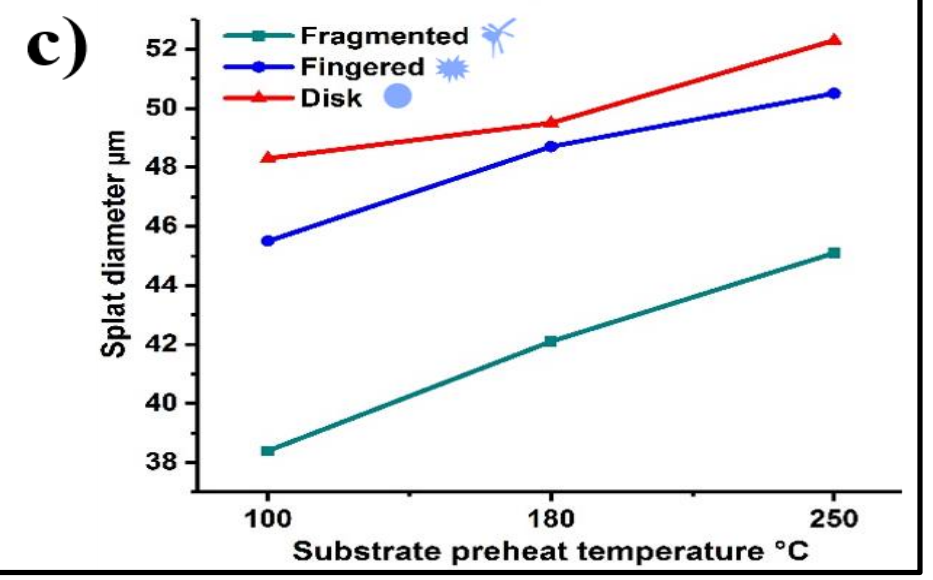

Figure 4-6. Average diameter of different splat morphologies for a) $28 \mathrm{~kW}$, b) $32 \mathrm{~kW}$ and c) $35 \mathrm{~kW}$ plasma power 
From the figures 4-5 and 4-6, it is observed that the diameter of the splats, as well as the number of the splats with larger diameter increases with the increase in power as well as substrate, preheat temperature.

The power directly affects the degree of the melting of the powder particles. Higher power results in the better spreading of the molten droplets, thus increasing the population of the splats with higher splat diameter. So, with the increase in the power and substrate temperature, the splats with the larger diameter for all splat morphologies- the disk, splashed and fragmented were observed.

Splat size, as well as the volume fraction of the disk-shaped splats, increased with an increasing plasma power and substrate temperature. This can be explained by the improved wetting (or lower viscosity) that occurs between the molten droplet and the substrate allowing for a better spread at higher substrate temperature [86]. With the increase in plasma power, both the in-flight particle temperature and velocity increases allowing the particle to spread uniformly increasing disk-shaped splats. Increase in the substrate temperature delays the localized solidification allowing the molten droplet to spread uniformly resulting in the disk-shaped splats.

Although the exact mechanism and the effects of the substrate preheat temperature on the splat morphologies are unknown, it is believed that the enhanced wetting is also resulted due to the removal of the adsorbed gas and condensates [38].

At the higher substrate temperature, better contact and uniform heat and heat conduction can lower the chance of local solidification or delay the initiation of the solidification. According to Vardelle et al.[87], preheating the substrate above the transition temperature ensures that the temperature of the molten liquid droplet remains 
above the hyper-cooling temperature and the splat remains in the liquid phase resulting in the uniform solidification.

\subsection{Simulated and Experimentally Obtained Coating Microstructure}

The formation of a two-dimensional image and the stacking of the images to form a three-dimensional coating structure is shown in Figure 4-7.

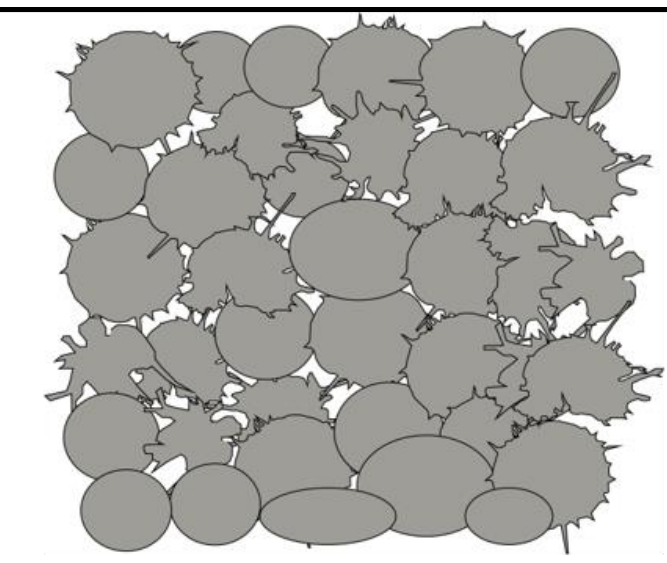

Two-dimensional image formed using the stochastic approach

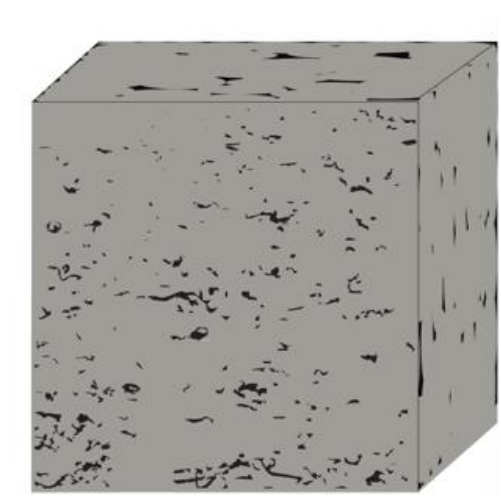

Three-dimensional image formed by the stacking of images

Figure 4-7. Formation of three-dimensional coating structure from simulated splats

From the literature, it is found that the first layer of the splats deposited on the substrate play a vital role in the coating build-up process. Jiang et al. [88] suggested that the spreading of the splats deposited on top of the previously deposited splats follow the similar pattern as that of the spreading of the droplet on the substrate or previously deposited splat layer during the coating build-up process. In, this study, the first layer of the splats deposited on the substrate is stacked to form a three-dimensional coating structure with a thickness of $100 \mu \mathrm{m}$. The thickness was chosen such that the obtained computational coating is thick enough to be considered a bulk coating for computing porosity and mechanical properties. 
The comparison of the cross-sectional images of the coating structure from experiments and computational routes is shown in the figures 4-8.

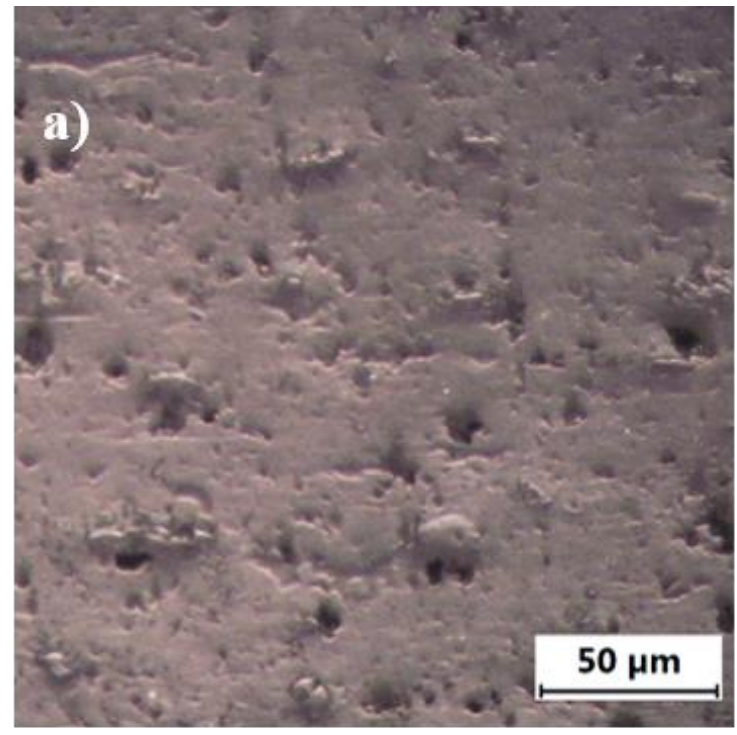

Cross-sectional image of coating obtained from experiments

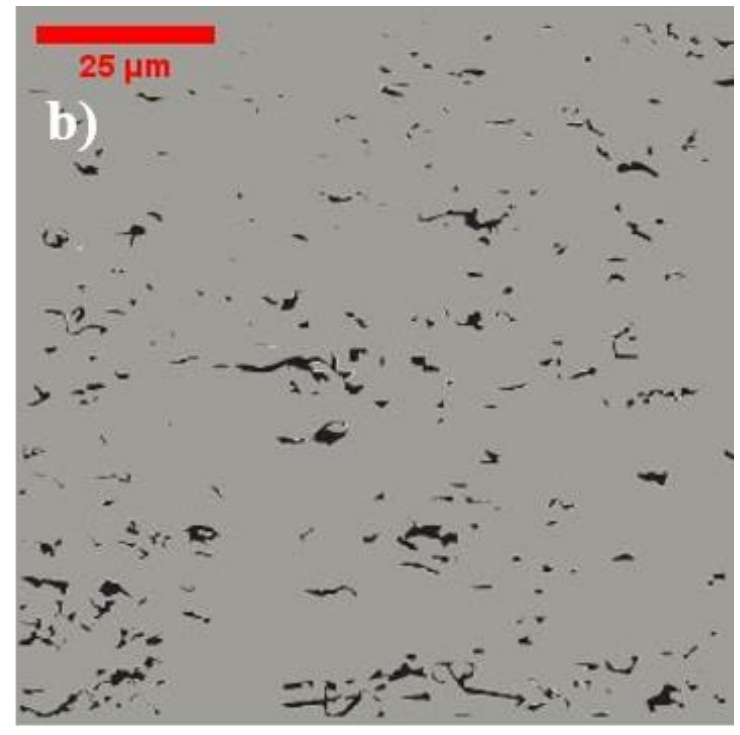

Cross-sectional image of simulated coating structure

Figure 4-8. Cross-sectional image of coating, a) from experiments power $32 \mathrm{~kW}$, substrate preheat temperature $180{ }^{\circ} \mathrm{C}$ and b) from computational stacking power $32 \mathrm{~kW}$, substrate preheat temperature $180^{\circ} \mathrm{C}$.

The porosity of the coatings obtained from experiment Figure 4-5 (a) was measured using image analysis software ImageJ and the porosity of the simulated coatings Figure 46 (b) was measured using finite element analysis (FEA). The porosity from the finite element analysis are assumed to be formed only due to the incomplete filling of the splats and are more elongated or plate-shaped in nature, while the porosity of the experimentally obtained coatings is more globular or round due to the curling of the splats. Figure 4-9 helps to understand better how the porosity differs for the real-time plasma spray deposition process and the computational approach. 


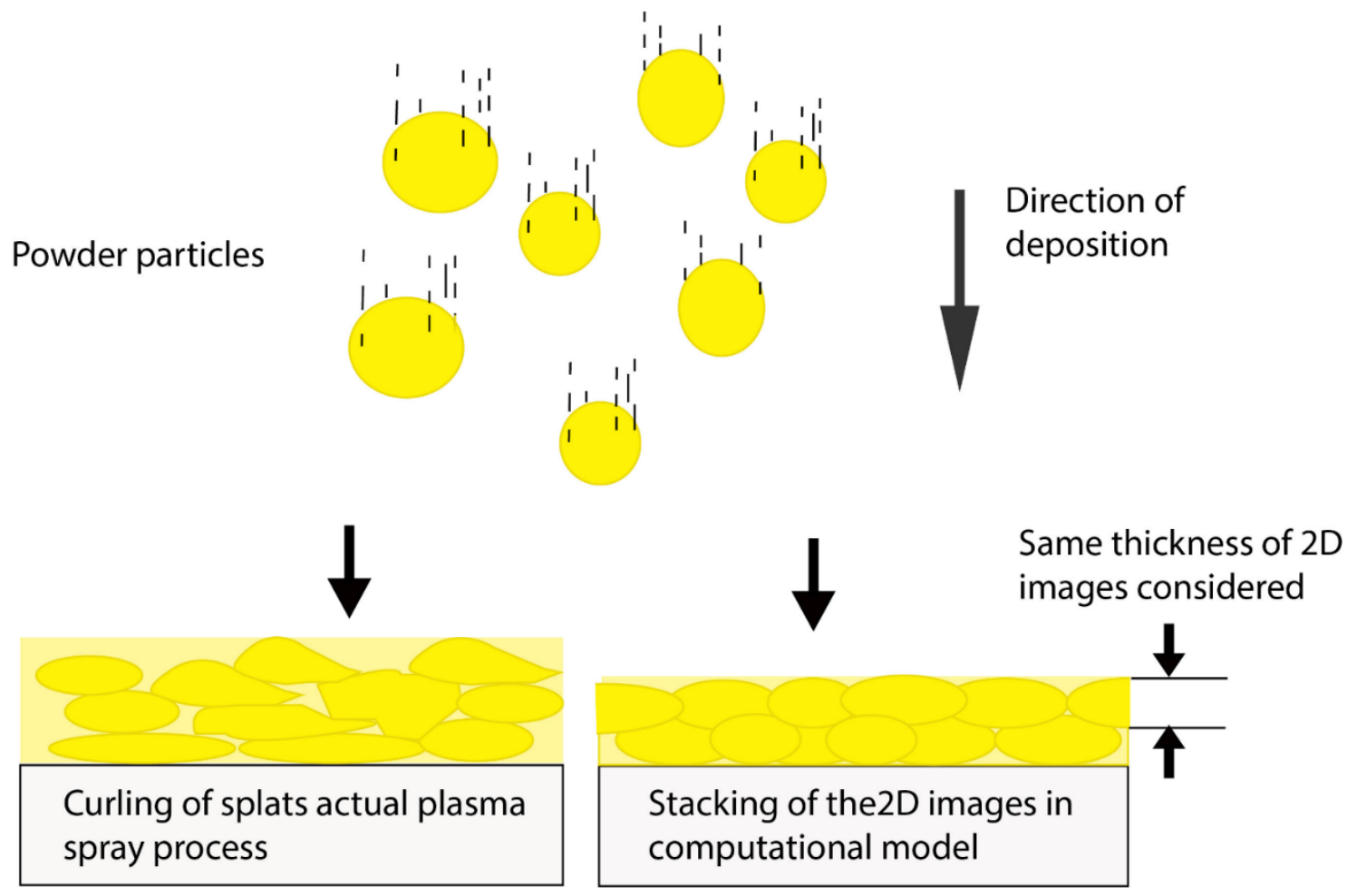

Figure 4-9. Deposition of real-time plasma process and computational model

In the real-time plasma process, the splats curl during the solidification process. Not, only this the entrapment of the air or the gas bubbles, release of the thermal stress during the cooling, imperfect contact, and stress relaxation causing the intra-splat cracks results in the formation of the globular or spherical pores. For, the computational model, a unit thickness is assumed for the 2D images during the stacking process in MATLAB code resulting in the plate-shaped or elongated thickness.

The porosity values obtained from the experimental and simulated routes are compared in Figure 4-10. 


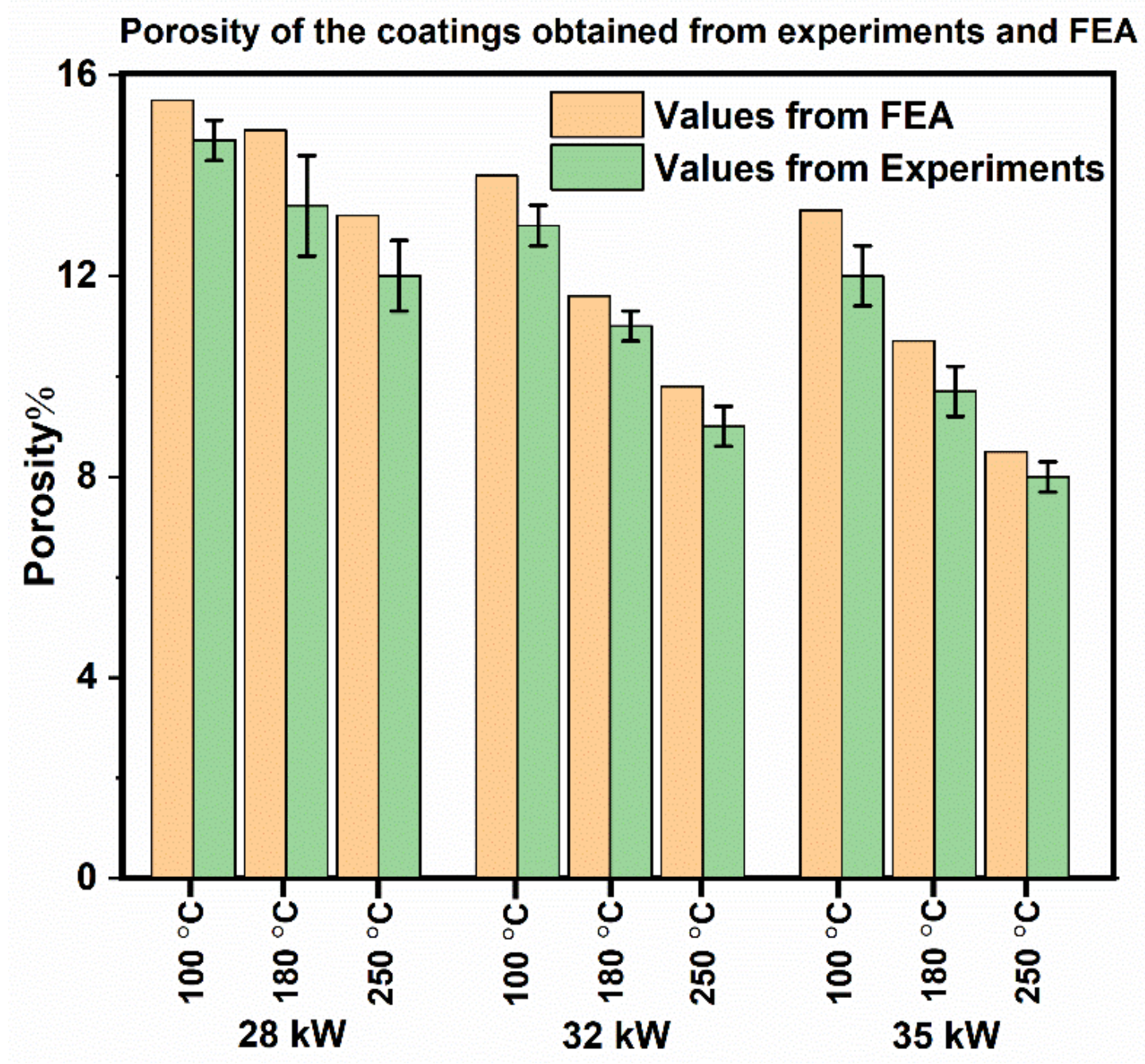

Figure 4-10. Comparison of the porosity of the cross-sectional orientation of the coatings obtained from finite element analysis (FEA) for the computational coating structure and ImageJ for the experimental coatings.

The average values of the porosity in the coatings obtained from experiments were measured from 4-5 different images for each spraying condition. It is observed that experimental porosity values are within 1-2\% error margin of the porosity in the simulated coatings. The marginal difference in the porosity values can be attributed to the 
assumptions that were made during the stacking of the image. Intersplat porosity and curling of the splats were not accounted for in the simulated coating.

Figure 4-10 shows that the porosity of the coating reduced from $15.5 \%$ for $28 \mathrm{~kW}$, $100^{\circ} \mathrm{C} \sim 8.5 \%$ for $35 \mathrm{~kW}, 250^{\circ} \mathrm{C}$. The increase in power and substrate preheat temperature resulted in the reduced porosity for the coatings obtained both by the computational and experimental routes. This can be related to the increase in the fraction of disk-shaped splats which improves the packing. This also substantiates the findings of the increased volume fraction of disk-shaped splat morphologies for the increase in power and substrate preheat temperature. With the increased in the number of the disk-shaped splats the inter-splats adhesion and cohesion is enhanced resulting in the formation of dense coating structure.

\subsection{Computed and Experimental Elastic Modulus of the Coating}

Object-Oriented Finite Element Analysis software (OOF2) was utilized to compute the elastic modulus of the coating and compared with experimental values obtained using nanoindentation.. The various steps involved in obtaining elastic modulus from object oriented finite element analysis are shown in Figure 4-11. 


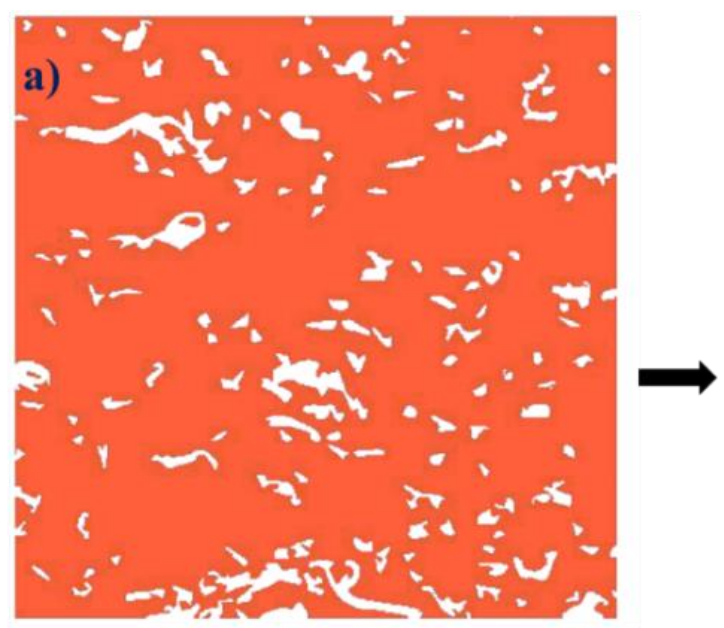

Cross-sectional view of coating

(Power 32 kW, $180^{\circ} \mathrm{C}$ )

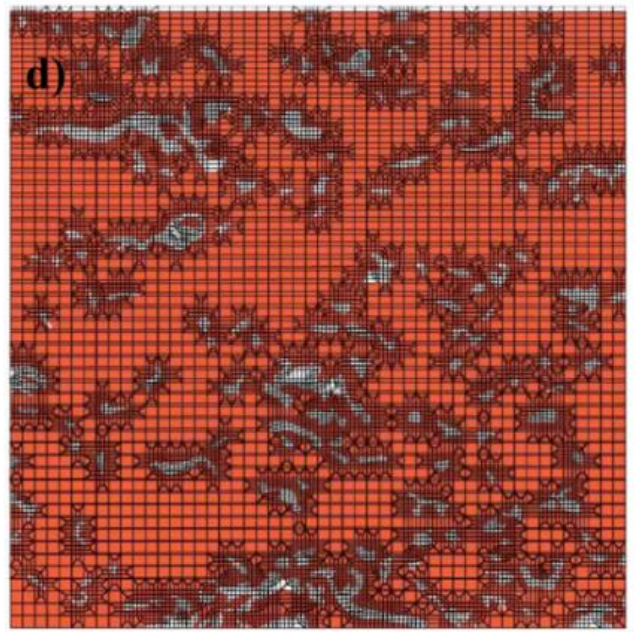

Strain 1\% applied in Y-direction

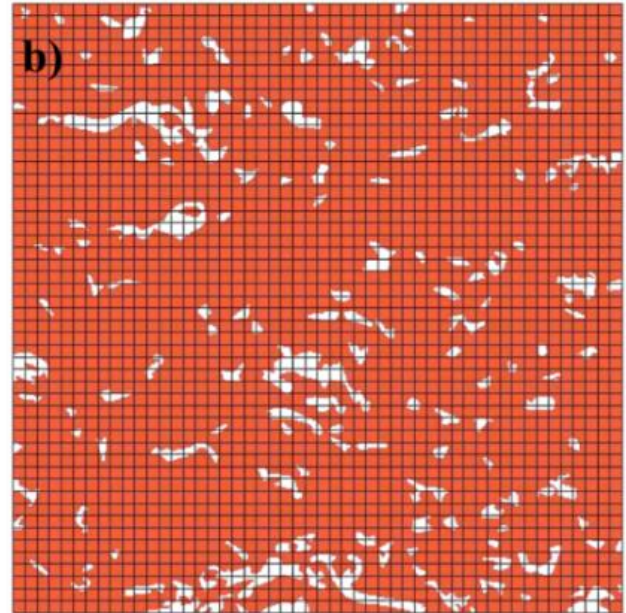

Mesh of (50 x 50 grid)

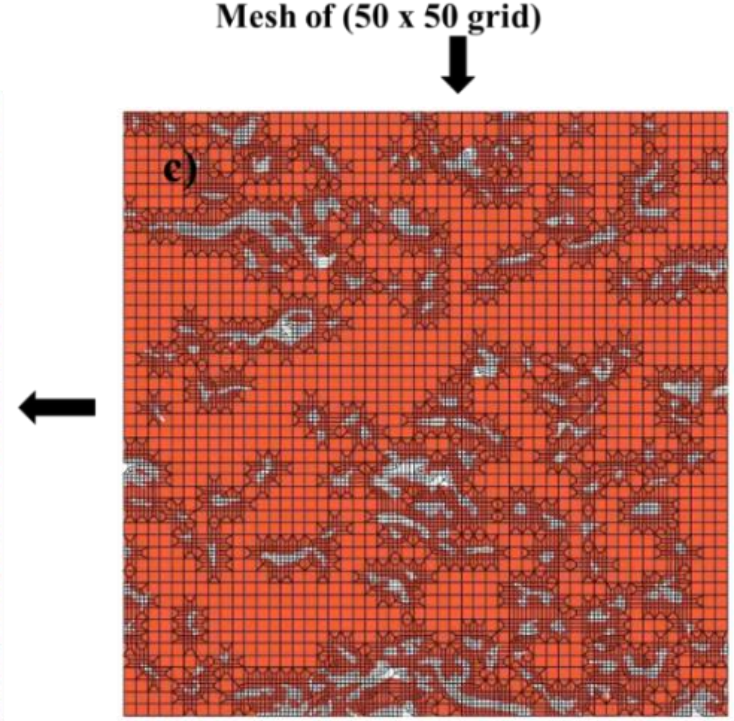

Refined mesh with snapped nodes

Figure 4-11. Finite element analysis, acquiring an image, adaptive meshing, and application of boundary conditions. 
The results from the nanoindentation and finite element analysis are compared in Table 41 below.

Table 4-1. Elastic modulus obtained from nanoindentation and OOF2 for the crosssection

\begin{tabular}{|c|c|c|c|c|c|c|}
\hline \multirow{3}{*}{$\begin{array}{c}\text { Substrate } \\
\text { preheat } \\
\text { temperature }\end{array}$} & \multicolumn{6}{|c|}{ Power } \\
\hline & \multicolumn{2}{|c|}{$28 \mathrm{~kW}$} & \multicolumn{2}{|c|}{$32 \mathrm{~kW}$} & \multicolumn{2}{|c|}{$35 \mathrm{~kW}$} \\
\hline & Nano & Finite & Nano & Finite & Nano & Finite \\
\hline & indentation & Element & indentation & Element & indentation & Element \\
\hline & (GPa) & Analysis & (GPa) & Analysis & (GPa) & Analysis \\
\hline & & (GPa) & & (GPa) & & (GPa) \\
\hline $100^{\circ} \mathrm{C}$ & $255 \pm 14.3$ & 297.7 & $263 \pm 17.6$ & 307.8 & $270 \pm 15.1$ & 308.2 \\
\hline $180^{\circ} \mathrm{C}$ & $268 \pm 34.9$ & 303.6 & $271 \pm 22.5$ & 312.9 & $274 \pm 13.9$ & 316.6 \\
\hline $250^{\circ} \mathrm{C}$ & $272 \pm 16.8$ & 307.1 & $280 \pm 19.7$ & 320.2 & $285 \pm 18.4$ & 328.4 \\
\hline
\end{tabular}

The values of the elastic modulus in cross-section of the coating predicted by the microstructure based OOF approach are $\sim 12 \%$ greater than experimental values.

This discrepancy between the predicted and experimental values can largely be attributed to the inability of the computational tools to perfectly capture inter-splat effects such as (i) inter-lamellar porosity, (ii) inter-splat microcracks, and (iii) curling of the splats.

Since these features are fine and thin, inter-splat cracks could not be modeled effectively in the finite element analysis resulting in an overestimation of the elastic modulus. Moreover, the occurrence of splat-sliding in the thermally sprayed coatings during nanoindentation results in the lower elastic modulus $[89,90]$. Splats slide past each 
other resulting in the decrease of the resistance to deformation. To account for these differences caused by splat related effects, we introduce "inter-splat correction factor," $f_{i s}$. This factor establishes a quantitative comparison of elastic modulus obtained from computational modeling vis-à-vis experimental values as shown in equation 7.

$$
E_{\text {expt }}=f_{\text {is }} * E_{\text {comp }}
$$

Where $E_{\text {expt }}$ is the elastic modulus determined by nanoindentation, $E_{\text {comp }}$ is the elastic modulus of the cross-section determined by the object-oriented finite element analysis, and $f_{i s}$ is the inter-splat correction factor.

To compute the inter-splat correction factor, the line of best fit was determined using the ordinary least squares method regressing the values of elastic modulus from the finite element analysis as the variable (x) and the values from the nanoindentation as the variable (y). The method of linear calibration regression employed by Rosner et al [91] was used to compute the inter-splat correction factor (fis) as 0.89 .

The values of the elastic modulus obtained from the finite element analysis were corrected using the correction factor and compared with the values of the elastic modulus obtained from the nanoindentation as shown in the Table 4-2. 
Table 4-2. Elastic modulus obtained from nanoindentation and OOF2 with an inter-splat correction factor for the cross-section

\begin{tabular}{|c|c|c|c|c|c|c|}
\hline \multirow[b]{3}{*}{$\begin{array}{c}\text { Substrate } \\
\text { preheat } \\
\text { temperature }\end{array}$} & \multicolumn{6}{|c|}{ Power } \\
\hline & \multicolumn{2}{|c|}{$28 \mathrm{~kW}$} & \multicolumn{2}{|c|}{$32 \mathrm{~kW}$} & \multicolumn{2}{|c|}{$35 \mathrm{~kW}$} \\
\hline & $\begin{array}{c}\text { Nano } \\
\text { indentation } \\
(\mathbf{G P a}) \\
\end{array}$ & $\begin{array}{c}\text { OOF } \\
\text { Analysis } \\
(\mathbf{G P a}) \\
\end{array}$ & $\begin{array}{c}\text { Nano } \\
\text { indentation } \\
(\mathbf{G P a}) \\
\end{array}$ & $\begin{array}{c}\text { OOF } \\
\text { Analysis } \\
(\mathbf{G P a})\end{array}$ & $\begin{array}{c}\text { Nano } \\
\text { indentation } \\
(\mathrm{GPa})\end{array}$ & $\begin{array}{c}\text { OOF } \\
\text { Analysis } \\
(\mathbf{G P a})\end{array}$ \\
\hline $100^{\circ} \mathrm{C}$ & $255 \pm 14.3$ & 266 & $263 \pm 17.6$ & 271 & $270 \pm 15.1$ & 274 \\
\hline $180^{\circ} \mathrm{C}$ & $268 \pm 34.9$ & 271 & $271 \pm 22.5$ & 278 & $274 \pm 13.9$ & 282 \\
\hline $250^{\circ} \mathrm{C}$ & $272 \pm 16.8$ & 274 & $280 \pm 19.7$ & 285 & $285 \pm 18.4$ & 292 \\
\hline
\end{tabular}

The results from the computational approach and experiments are comparable within $3-5 \%$ deviation which depicts the ability of the computational approach to accurately predict the mechanical properties. Not, only this, the approach can also be used for the prediction of the thermal properties of the coatings [83]. 


\section{CHAPTER 5. CONCLUSIONS}

In this thesis, a novel multi-step computational approach is developed for predicting the effect of spray parameters on both the microstructure as well as the mechanical properties of the plasma sprayed coating structure. The volume fraction of the disk-shaped splats, as well as the porosity and the elastic modulus of the coatings, is improved with the increase in the plasma power and substrate preheat temperature.

The computational models are largely successful in predicting the mechanical properties of the ceramic coatings with some deviation $(\sim 12 \%)$ from experimental results. The deviation between experimental and computational results is attributed to the limitation of the computational models which does not account for intersplat features as microcracks, curling of splats, and splat-sliding. An inter-splat correction factor $\left(f_{i s}\right)$ was introduced to overcome the limitations of the computational model. After the correction factor, the elastic modulus values from computations are observed to be in reasonable agreement with the experimental values.

This study demonstrates that the proposed computational scheme can predict the mechanical properties of the coatings with a reduced number of experiments for various spraying parameters. This desktop design approach can be further extended to other materials for the development of coating structure with predictable properties and would be of immense importance to the thermal spray community. 


\section{CHAPTER 6. RECOMMENDATIONS FOR FUTURE WORK}

In this work, a computational model has been successfully developed to predict the microstructure as well as the mechanical properties of the plasma sprayed coatings. Based on the conclusions of this research work, several recommendations for future work are made:

\begin{tabular}{|c|c|}
\hline Limitations & Recommendations \\
\hline $\begin{array}{l}\text { 1. Simulation of the splat morphology } \\
\text { The properties of the particle such } \\
\text { thermal conductivity is taken as } \\
\text { the input parameters which are not } \\
\text { well known for various materials } \\
\text { at high temperature range } \\
\text { Constant thermal contact } \\
\text { resistance is assumed during the } \\
\text { simulation of splats } \\
\text { Formation of oxide during the } \\
\text { the particle velocities and } \\
\text { splat formation has not been } \\
\text { considered in this model } \\
\text { simulation of splats in this study }\end{array}$ & $\begin{array}{l}\text { - Inclusion of predictive analytical } \\
\text { model to compute thermal contact } \\
\text { resistance for variation in time } \\
\text { and position would make the } \\
\text { model more realistic } \\
\text { Addition of the study about the } \\
\text { formation of the oxide, thickness } \\
\text { of the oxide layers, and its } \\
\text { subsequent effects in the } \\
\text { morphology of the splats should } \\
\text { be investigated } \\
\text { Study of the composition of the } \\
\text { plasma gas including the } \\
\text { temperature and velocity }\end{array}$ \\
\hline
\end{tabular}




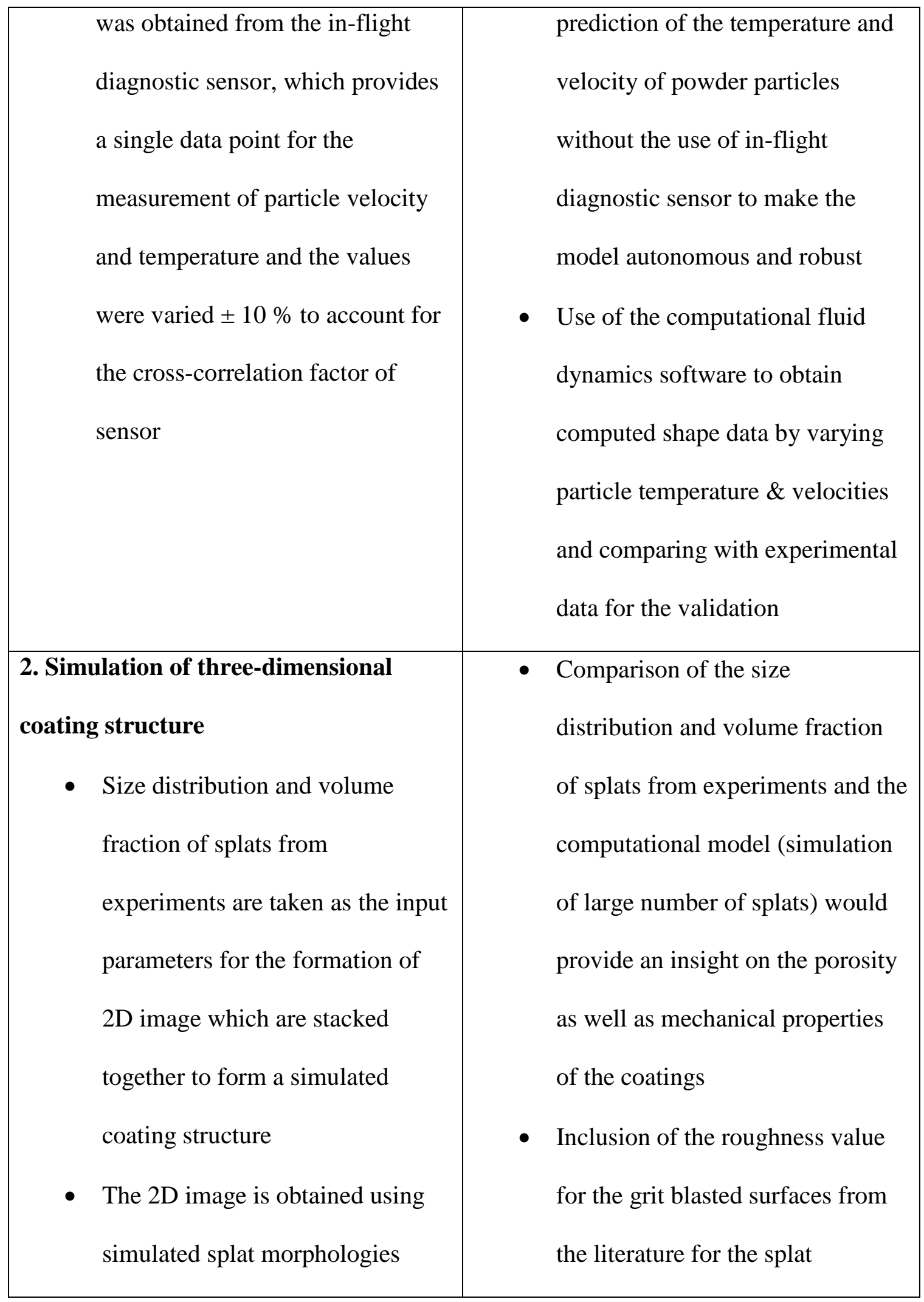




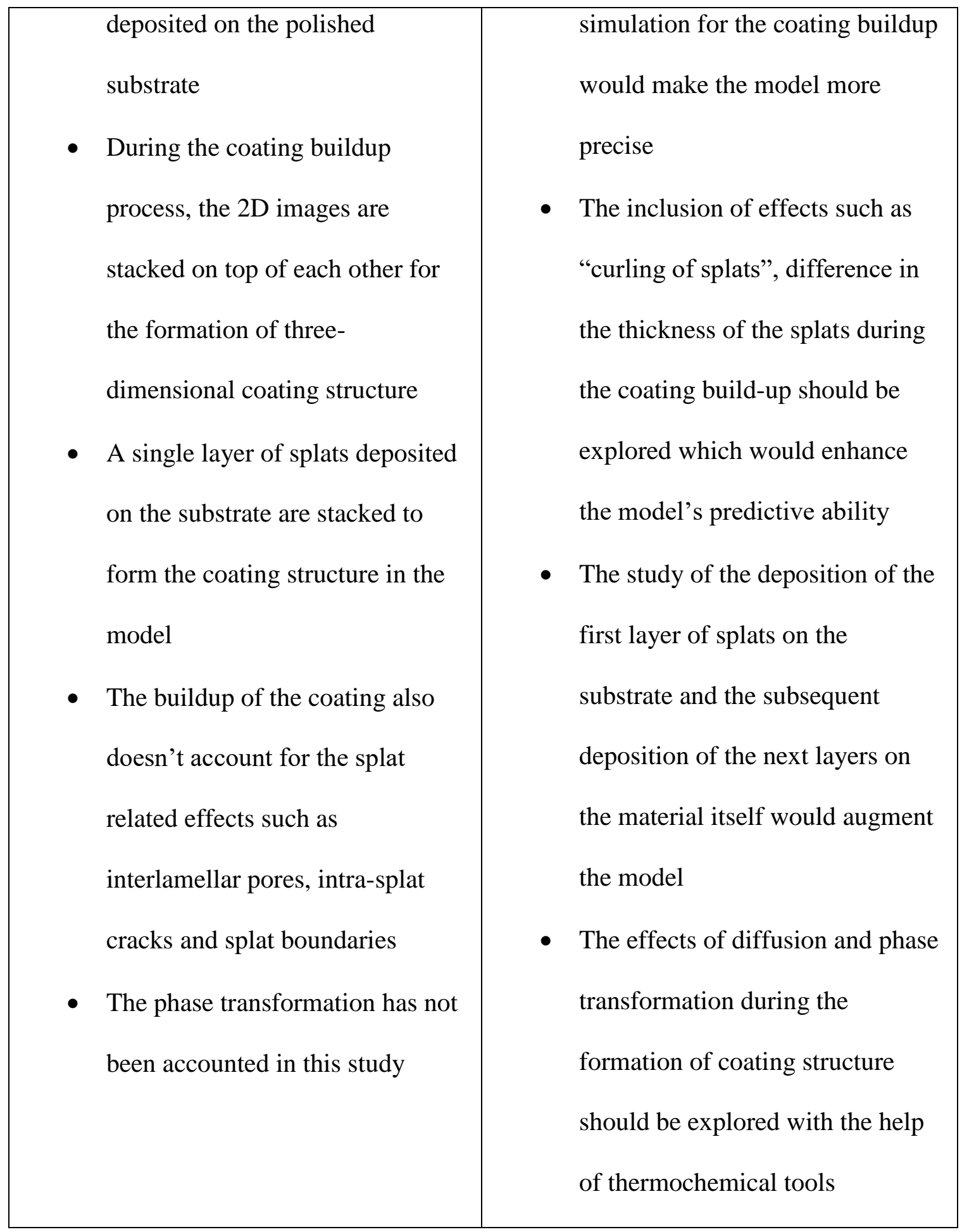




\begin{tabular}{|c|c|}
\hline $\begin{array}{l}\text { 3. Prediction of mechanical properties } \\
\text { using oriented finite element analysis } \\
\text { approach }\end{array}$ & $\begin{array}{l}\text { - Use of the alternative approaches } \\
\text { to study the three-dimensional } \\
\text { coating structure for the }\end{array}$ \\
\hline - The finite element-based & prediction of the mechanical \\
\hline approach is unable to account for & properties with the consideration \\
\hline the boundary or the interface & of the micro and Nano-pores \\
\hline related effects & would make the model more \\
\hline - The input taken for the prediction & reliable \\
\hline of the mechanical properties are & - Study of a different material \\
\hline the $2 \mathrm{D}$ images which may not & would provide an insight into the \\
\hline accurately represent the & robustness of the technique \\
\hline orientation of the pores in the & developed \\
\hline coating structure & \\
\hline
\end{tabular}




\section{LIST OF REFERENCES}

[1] J. Davis, Handbook of thermal spray technology, 2004.

[2] M. Zhang, X. Wang, J. Luo, Q. Zhao, X. Liao, Influence of plasma spraying on the performance of oxide cathodes, IEEE Trans. Electron Devices. 58 (2011) 2143 2148. doi:10.1109/TED.2011.2141996.

[3] R. McPherson, A review of microstructure and properties of plasma sprayed ceramic coatings, Surf. Coatings Technol. 39-40 (1989) 173-181. doi:10.1016/0257-8972(89)90052-2.

[4] J. Phillips, C.C. Luhrs, M. Richard, Review: Engineering particles using the aerosol-through-plasma method, IEEE Trans. Plasma Sci. 37 (2009) 726-739. doi:10.1109/TPS.2009.2016969.

[5] S.C. Mishra, A. Satapathy, M. Chaithanya, P. V. Ananthapadmanabhan, K.P. Sreekumar, Wear characteristics of plasma sprayed nickel-aluminum composite coatings, J. Reinf. Plast. Compos. 28 (2009) 2931-2940. doi: $10.1177 / 0731684408094067$.

[6] P. Fauchais, Understanding plasma spraying, J. Phys. D. Appl. Phys. 37 (2004) R86-R108. doi:10.1088/0022-3727/37/9/R02.

[7] P. Fauchais, A. Vardelle, B. Dussoubs, Quo Vadis thermal spraying?, J. Therm. Spray Technol. 10 (2001) 44-66. doi:10.1361/105996301770349510.

[8] N.R. Council, Coatings for High-Temperature Structural Materials: Trends and Opportunities, 1996.

[9] R. Suryanarayanan, Plasma spraying: theory and applications, 1993.

[10] R.B. Heimann, Plasma Spray Coating, Wiley-VCH, 2008.

[11] S. Matthews, B. James, Review of Thermal Spray Coating Applications in the Steel Industry: Part 1-Hardware in Steel Making to the Continuous Annealing Process, J. Therm. Spray Technol. 19 (2010) 1267-1276. doi:10.1007/s11666-0109518-8.

[12] B. V. Tilak, A.C. Ramamurthy, B.E. Conway, High performance electrode materials for the hydrogen evolution reaction from alkaline media, Proc. Indian Acad. Sci. - Chem. Sci. 97 (n.d.) 359-393. doi:10.1007/bf02849200.

[13] T. Nakamura, G. Qian, C.C. Berndt, Effects of Pores on Mechanical Properties of Plasma-Sprayed Ceramic Coatings, J. Am. Ceram. Soc. 83 (2004) 578-584. doi:10.1111/j.1151-2916.2000.tb01236.x.

[14] G. Montavon, S. Sampath, C.C. Berndt, H. Herman, C. Coddet, Effects of vacuum plasma spray processing parameters on splat morphology, J. Therm. Spray Technol. 4 (1995) 67-74. doi:10.1007/BF02648530. 
[15] A. Kulkarni, A. Vaidya, A. Goland, S. Sampath, H. Herman, Processing effects on porosity-property correlations in plasma sprayed yttria-stabilized zirconia coatings, Mater. Sci. Eng. A. 359 (2003) 100-111. doi:10.1016/S0921-5093(03)00342-3.

[16] M. Robert A., Current status of thermal barrier coatings - An overview, Surf. Coatings Technol. 30 (1987) 1-11. doi:10.1016/0257-8972(87)90003-X.

[17] P. Cheang, K.A. Khor, Addressing processing problems associated with plasma spraying of hydroxyapatite coatings* 1, Biomaterials. 17 (1996) 537-544. https://www.sciencedirect.com/science/article/pii/0142961296827293 (accessed July 12, 2018).

[18] S. Sampath, X.. Jiang, J. Matejicek, A.. Leger, A. Vardelle, Substrate temperature effects on splat formation, microstructure development and properties of plasma sprayed coatings Part I: Case study for partially stabilized zirconia, Mater. Sci. Eng. A. 272 (1999) 181-188. doi:10.1016/S0921-5093(99)00459-1.

[19] S. Chandra, COATING DEPOSITION BY THERMAL SPRAY PROCESSES, Annu. Rev. Heat Transf. 20 (2018) 121-148. doi:10.1615/annualrevheattransfer.2018019747.

[20] X. Jiang, J. Matejicek, S. Sampath, Substrate temperature effects on the splat formation, microstructure development and properties of plasma sprayed coatings: Part II: case study for molybdenum, Mater. Sci. Eng. A. 272 (1999) 189-198. doi:10.1016/S0921-5093(99)00461-X.

[21] V. Pershin, M. Lufitha, S. Chandra, J. Mostaghimi, Effect of substrate temperature on adhesion strength of plasma-sprayed nickel coatings, J. Therm. Spray Technol. 12 (2003) 370-376. doi:10.1361/105996303770348249.

[22] A. Kulkarni, Z. Wang, T. Nakamura, S. Sampath, A. Goland, H. Herman, J. Allen, J. Ilavsky, G. Long, J. Frahm, R.W. Steinbrech, Comprehensive microstructural characterization and predictive property modeling of plasma-sprayed zirconia coatings, Acta Mater. 51 (2003) 2457-2475. doi:10.1016/S1359-6454(03)00030-2.

[23] S. Ozkan, Effect of some parameters on microstructure and hardness of alumina coatings prepared by the air plasma spraying process, Surf. Coatings Technol. 190 (2005) 388-393. http://www.sciencedirect.com/science/article/pii/S0257897204000738.

[24] C. Coddet, J.F. Li, H.L. Liao, C.X. Ding, Optimizing the plasma spray process parameters of yttria stabilized zirconia coatings using a uniform design of experiments, J. Mater. Process. Technol. 160 (2005) 34-42. doi:10.1016/j.jmatprotec.2004.02.039.

[25] H. Liu, E.J. Lavernia, R.H. Rangel, Modeling of molten droplet impingement on a non-flat surface, Acta Metall. Mater. 43 (1995) 2053-2072. doi:10.1016/09567151(94)00386-V. 
[26] M. Bussmann, J. Mostaghimi, S. Chandra, On a three-dimensional volume tracking model of droplet impact, Phys. Fluids. 11 (1999) 1406-1417.

doi:10.1063/1.870005.

[27] M. Pasandideh-Fard, V. Pershin, S. Chandra, J. Mostaghimi, Splat Shapes in a Thermal Spray Coating Process: Simulations and Experiments, J. Therm. Spray Technol. 11 (2002) 206-217. doi:10.1361/105996302770348862.

[28] O. Knotek, R. Elsing, Monte Carlo Simulation of the Lamellar Structure of Thermally Sprayed Coatings, Elsevier. 32 (1987) 261-271. https://www.sciencedirect.com/science/article/pii/0257897287901125 (accessed July 12, 2018).

[29] Y. Chen, G. Wang, H. Zhang, Numerical simulation of coating growth and pore formation in rapid plasma spray tooling, Thin Solid Films. 390 (2001) 13-19. doi:10.1016/S0040-6090(01)00933-6.

[30] G. Wei, H. Xiong, L. Zheng, H. Zhang, Modelling From Particle In-Flight to Coating Build-Up for Thermal Spray Processes, in: ASME International, 2009: pp. 989-998. doi:10.1115/ht-fed2004-56368.

[31] Y.Y. Zhao, P.S. Grant, B. Cantor, Modelling and experimental analysis of vacuum plasma spraying. Part I: prediction of initial plasma properties at plasma gun exit, Model. Simul. Mater. Sci. Eng. 8 (2000) 497-513. doi:10.1088/09650393/8/4/308.

[32] T.J. Steeper, D.J. Varacalle, G.C. Wilson, W.L. Riggs, A.J. Rotolico, J. Nerz, A design of experiment study of plasma-sprayed alumina-titania coatings, J. Therm. Spray Technol. 2 (1993) 251-256. doi:10.1007/BF02650473.

[33] K. Balani, A. Agarwal, Process map for plasma sprayed aluminum oxide-carbon nanotube nanocomposite coatings, Surf. Coatings Technol. 202 (2008) 4270-4277. doi:10.1016/j.surfcoat.2008.03.024.

[34] L. Sun, C. Berndt, C.G.-M.S. and E. A, undefined 2003, Phase, structural and microstructural investigations of plasma sprayed hydroxyapatite coatings, Elsevier. (n.d.). https://www.sciencedirect.com/science/article/pii/S0921509303004398 (accessed May 7, 2019).

[35] J. Cizek, K.A. Khor, Z. Prochazka, Influence of spraying conditions on thermal and velocity properties of plasma sprayed hydroxyapatite, Mater. Sci. Eng. C. 27 (2007) 340-344. doi:10.1016/j.msec.2006.05.002.

[36] C.W. Kang, H.W. Ng, Splat morphology and spreading behavior due to oblique impact of droplets onto substrates in plasma spray coating process, Surf. Coatings Technol. 200 (2006) 5462-5477. doi:10.1016/j.surfcoat.2005.07.067.

[37] M. Fukumoto, Y. Huang, Flattening Mechanism in Thermal Sprayed Nickel Particle Impinging on Flat Substrate Surface, J. Therm. Spray Technol. 8 (1999) 427-432. doi:10.1361/105996399770350386. 
[38] X. Jiang, Y. Wan, H. Herman, S. Sampath, Role of condensates and adsorbates on substrate surface on fragmentation of impinging molten droplets during thermal spray, Thin Solid Films. 385 (2001) 132-141. doi:10.1016/S0040-6090(01)007696.

[39] D.K. Christoulis, D.I. Pantelis, Effect of Substrate Roughness and Temperature on Splat Formation in Plasma Sprayed Aluminium Bronze, (n.d.) 1-12.

[40] C. Pierlot, M. Bigan, P. Chagnon, Design of experiments in thermal spraying: A review, Surf. Coatings Technol. 202 (2008) 4483-4490. doi:10.1016/J.SURFCOAT.2008.04.031.

[41] R.L. Plackett, J.P. Burman, The Design of Optimum Multifactorial Experiments, Biometrika. 33 (2006) 305. doi:10.2307/2332195.

[42] Z. Mohammadi, A.A. Ziaei-Moayyed, A.S.-M. Mesgar, Grit blasting of Ti-6Al4V alloy: Optimization and its effect on adhesion strength of plasma-sprayed hydroxyapatite coatings, J. Mater. Process. Technol. 194 (2007) 15-23. doi:10.1016/J.JMATPROTEC.2007.03.119.

[43] G. Box, N. Draper, Empirical model-building and response surfaces., 1987. https://psycnet.apa.org/record/1987-97236-000 (accessed May 7, 2019).

[44] B.T. Lin, M. Der Jean, J.H. Chou, Using response surface methodology for optimizing deposited partially stabilized zirconia in plasma spraying, Appl. Surf. Sci. 253 (2007) 3254-3262. doi:10.1016/j.apsusc.2006.07.021.

[45] R. McPherson, The relationship between the mechanism of formation, microstructure and properties of plasma-sprayed coatings, Thin Solid Films. 83 (1981) 297-310. doi:10.1016/0040-6090(81)90633-7.

[46] L. Bianchi, A.C. Leger, M. Vardelle, A. Vardelle, P. Fauchais, Splat formation and cooling of plasma-sprayed zirconia, Thin Solid Films. 305 (1997) 35-47. doi:10.1016/S0040-6090(97)80005-3.

[47] Z. Wang, A. Kulkarni, S. Deshpande, T. Nakamura, H. Herman, Effects of pores and interfaces on effective properties of plasma sprayed zirconia coatings, Acta Mater. (2003). doi:10.1016/S1359-6454(03)00390-2.

[48] S.R. Bakshi, A. Bhargava, S. Mohammadizadeh, A. Agarwal, I. Tsukanov, Computational estimation of elastic properties of spark plasma sintered $\mathrm{TaC}$ by meshfree and finite element methods, Comput. Mater. Sci. 50 (2011) 2615-2620. doi:10.1016/j.commatsci.2011.04.003.

[49] S.R. Bakshi, V. Singh, K. Balani, D.G. McCartney, S. Seal, A. Agarwal, Carbon nanotube reinforced aluminum composite coating via cold spraying, Surf. Coatings Technol. 202 (2008) 5162-5169. doi:10.1016/j.surfcoat.2008.05.042.

[50] J. Schwarzkopf, M. Sommerfeld, C. Crowe, Y. Tsuji, Multiphase flows with droplets and particles, 2011. 
[51] W.L. Oberkampf, M. Talpallikar, Analysis of a high-velocity oxygen-fuel (HVOF) thermal spray torch part 1: Numerical formulation, J. Therm. Spray Technol. 5 (1996) 53-61. doi:10.1007/BF02647518.

[52] F. Jabbari, M. Jadidi, R. Wuthrich, A. Dolatabadi, A Numerical Study of Suspension Injection in Plasma-Spraying Process, J. Therm. Spray Technol. 23 (2014) 3-13. doi:10.1007/s11666-013-0030-9.

[53] S.A. Esfarjani, A. Dolatabadi, A 3D simulation of two-phase flow in an effervescent atomizer for suspension plasma spray, Surf. Coatings Technol. 203 (2009) 2074-2080. doi:10.1016/j.surfcoat.2008.10.024.

[54] J. Madejski, Solidification of Molten Metal Droplets Impinging on a Cold Surface, Int. J. Heat Mass Transf. 19 (1975) 1009-1013. doi:10.1080/08916159408946474.

[55] T. Bennett, D. Poulikakos, Heat transfer aspects of splat-quench solidification: modelling and experiment, J. Mater. Sci. 29 (1994) 2025-2039. doi:10.1007/BF01154677.

[56] Z. Zhao, D. Poulikakos, J. Fukai, Heat transfer and fluid mechanics during the collision of a liquid droplet on a substrate-I. Modelling, Int J Heat Mass Tran. 239 (1996) 2771-2789.

[57] M. Pasandideh-Fard, R. Bhola, S. Chandra, J. Mostaghimi, Deposition of tin droplets on a steel plate: simulations and experiments, Int. J. Heat Mass Transf. 41 (1998) 2929-2945. doi:10.1016/S0017-9310(98)00023-4.

[58] R. Ghafouri-Azar, J. Mostaghimi, S. Chandra, M. Charmchi, A Stochastic Model to Simulate the Formation of a Thermal Spray Coating, J. Therm. Spray Technol. 12 (2003) 53-69. doi:10.1361/105996303770348500.

[59] R. Ghafouri-Azar, J. Mostaghimi, S. Chandra, A Three-Dimensional Numerical Study of Tin Droplets Landing Sequentially on a Solid Surface, in: ASME International, 2009: pp. 503-510. doi:10.1115/fedsm2002-31234.

[60] S. Cirolini, J.H. Harding, G. Jacucci, Computer simulation of plasma-sprayed coatings I. Coating deposition model, Surf. Coatings Technol. 48 (1991) 137-145. doi:10.1016/0257-8972(91)90137-L.

[61] J.H. Harding, P.A. Mulheran, S. Cirolini, M. Marchese, G. Jacucci, Modeling the deposition process of thermal barrier coatings, J. Therm. Spray Technol. 4 (1995) 34-40. doi:10.1007/BF02648526.

[62] M.P. Kanouff, R.A. Neiser Jr, T.J. Roemer, Surface Roughness of Thermal Spray Coatings Made with Off-Normal Spray Angles, J. Therm. Spray Technol. 7 (1998) 219-228. doi:10.1361/105996398770350963.

[63] A. Hansbo, P. Nylén, Models for the simulation of spray deposition and robot motion optimization in thermal spraying of rotating objects, Surf. Coatings Technol. 122 (1999) 191-201. doi:10.1016/S0257-8972(99)00255-8. 
[64] G. Wei, H. Xiong, L. Zheng, H. Zhang, Modelling From Particle In-Flight to Coating Build-Up for Thermal Spray Processes, in: Vol. 3, 2004: pp. 989-998. doi:10.1115/HT-FED2004-56368.

[65] R. Ghafouri-Azar, J. Mostaghimi, S. Chandra, M. Charmchi, A stochastic model to simulate the formation of a thermal spray coating, J. Therm. Spray Technol. 12 (2003) 53-69. doi:10.1361/105996303770348500.

[66] A.A. Abdel-Samad, A.M.M. El-Bahloul, E. Lugscheider, S.A. Rassoul, Comparative study on thermally sprayed alumina based ceramic coatings, J. Mater. Sci. 35 (2000) 3127-3130. doi:10.1023/A:1004824104162.

[67] T.C. Chou, T.G. Nieh, S.D. McAdams, G.M. Pharr, Microstructures and mechanical properties of thin films of aluminum oxide, Scr. Metall. Mater. 25 (1991) 2203-2208. doi:10.1016/0956-716X(91)90001-H.

[68] G. Mauer, R. Vaßen, D. Stöver, Comparison and Applications of DPV-2000 and Accuraspray-g3 Diagnostic Systems, J. Therm. Spray Technol. 16 (2007) 414 424. doi:10.1007/s11666-007-9047-2.

[69] T. Patterson, A. Leon, B. Jayaraj, J. Liu, Y.H. Sohn, Thermal cyclic lifetime and oxidation behavior of air plasma sprayed CoNiCrAlY bond coats for thermal barrier coatings, Surf. Coatings Technol. 203 (2008) 437-441. doi:10.1016/j.surfcoat.2008.08.054.

[70] http://rsbweb.nih.gov/ij/index.html, (n.d.).

[71] C.T. Rueden, J. Schindelin, M.C. Hiner, B.E. DeZonia, A.E. Walter, E.T. Arena, K.W. Eliceiri, ImageJ2: ImageJ for the next generation of scientific image data, BMC Bioinformatics. 18 (2017) 529. doi:10.1186/s12859-017-1934-z.

[72] P. Sokolowski, L. Latka, S. Kozerski, A. Ambroziak, B. Pateyron, P. Sokolowski, L. Latka, S. Kozerski, A. Ambroziak, L. Pawlowski, A comparison of microstructure and of thermal transport properties of yttria and ceria stabilized zirconia coatings deposited by suspension plasma spraying, (2015).

[73] W.C. Oliver and G.M. Pharr (1992)., An improved technique for determining hardness and elastic modulus using load and displacement sensing indentation experiments., J. Mater. Res. 7 (1992) 1564-1583.

[74] Simulent | Engineering Consulting Company, (n.d.). http://simulent.com/ (accessed July 12, 2018).

[75] B. J, K. D, Z. C, A Continuum Method for Modeling Surface Tension, J. Comput. Phys. 100 (1992) 335-354.

[76] K. Balani, R.G. Batista, D. Lahiri, A. Agarwal, The hydrophobicity of a lotus leaf: a nanomechanical and computational approach, Nanotechnology. 20 (2009) 305707. doi:10.1088/0957-4484/20/30/305707. 
[77] H.B. Parizi, L. Rosenzweig, J. Mostaghimi, S. Chandra, T. Coyle, H. Salimi, L. Pershin, A. McDonald, C. Moreau, Numerical Simulation of Droplet Impact on Patterned Surfaces, J. Therm. Spray Technol. 16 (2007) 713-721. doi:10.1007/s11666-007-9122-8.

[78] A.K. Keshri, A. Agarwal, Splat morphology of plasma sprayed aluminum oxide reinforced with carbon nanotubes: A comparison between experiments and simulation, Surf. Coatings Technol. 206 (2011) 338-347. doi:10.1016/j.surfcoat.2011.07.025.

[79] X. Lu, S. Bhusal, G. He, D. Zhao, C. Zhang, A. Agarwal, Y. Chen, Efficacy of graphene nanoplatelets on splat morphology and microstructure of plasma sprayed alumina coatings, Surf. Coatings Technol. 366 (2019) 54-61. doi:10.1016/j.surfcoat.2019.03.018.

[80] A. Agarwal, T. McKechnie, S. Seal, Net Shape Nanostructured Aluminum Oxide Structures Fabricated by Plasma Spray Forming, J. Therm. Spray Technol. 12 (2003) 350-359. doi:10.1361/105996303770348221.

[81] J. Mostaghimi, M. Pasandideh-Fard, S. Chandra, Dynamics of Splat Formation in Plasma Spray Coating Process, Plasma Chem. Plasma Process. 22 (2002) 59-84. doi:10.1023/A:1012940515065.

[82] L. Bianchi, A. Denoirjean, F. Blein, P. Fauchais, Microstructural investigation of plasma-sprayed ceramic splats, Thin Solid Films. 299 (1997) 125-135. doi:10.1016/S0040-6090(96)09307-8.

[83] https://www.ctms.nist.gov/oof/oof2, (n.d.).

[84] A.C.E. Reid, S.A. Langer, R.C. Lua, V.R. Coffman, S.I. Haan, R.E. García, Image-based finite element mesh construction for material microstructures, Comput. Mater. Sci. 43 (2008) 989-999. doi:10.1016/j.commatsci.2008.02.016.

[85] P. Auerkari, Mechanical and physical properties of engineering alumina ceramics, 1996. https://www.vtt.fi/inf/pdf/tiedotteet/1996/T1792.pdf (accessed May 7, 2019).

[86] M. Vardelle, A. Vardelle, A.C. Leger, P. Fauchais, D. Gobin, Influence of particle parameters at impact on splat formation and solidification in plasma spraying processes, J. Therm. Spray Technol. 4 (1995) 50-58. doi:10.1007/BF02648528.

[87] A. Vardelle, N.J. Themelis, B. Dussoubs, M. Vardelle, P. Fauchais, TRANSPORT AND CHEMICAL RATE PHENOMENA IN PLASMA SPRAYS, High Temp. Mater. Process. (An Int. Q. High-Technology Plasma Process. 1 (2014) 295-313. doi:10.1615/hightempmatproc.v1.i3.20.

[88] X. Jiang, J. Matejicek, S. Sampath, Substrate temperature effects on the splat formation, microstructure development and properties of plasma sprayed coatings: Part II: case study for molybdenum, Mater. Sci. Eng. A. 272 (1999) 189-198. doi:10.1016/S0921-5093(99)00461-X. 
[89] Y. Chen, S.R. Bakshi, A. Agarwal, Intersplat Friction Force and Splat Sliding in a Plasma-Sprayed Aluminum Alloy Coating during Nanoindentation and Microindentation, ACS Appl. Mater. Interfaces. 1 (2009) 235-238. doi:10.1021/am800114h.

[90] P. Nautiyal, C. Zhang, V.K. Champagne, B. Boesl, A. Agarwal, In-situ mechanical investigation of the deformation of splat interfaces in cold-sprayed aluminum alloy, Mater. Sci. Eng. A. 737 (2018) 297-309. doi:10.1016/j.msea.2018.09.065.

[91] B. ROSNER, D. SPIEGELMAN, W.C. WILLETT, CORRECTION OF LOGISTIC REGRESSION RELATIVE RISK ESTIMATES AND CONFIDENCE INTERVALS FOR MEASUREMENT ERROR: THE CASE OF MULTIPLE COVARIATES MEASURED WITH ERROR, Am. J. Epidemiol. 132 (1990) 734-745. doi:10.1093/oxfordjournals.aje.a115715. 
APPENDIX

APPENDIX Table 1. Parameters used for formation of 2D image for Power $28 \mathrm{~kW}$ and substrate temperature $100{ }^{\circ} \mathrm{C}$

\begin{tabular}{|c|c|c|c|c|c|c|c|c|c|}
\hline \multirow{2}{*}{$\begin{array}{l}\text { Size } \\
\text { distribution } \\
(\mu \mathrm{m})\end{array}$} & \multicolumn{3}{|c|}{ Disk-shaped splats } & \multicolumn{3}{|c|}{ Fingered (Splashed) splats } & \multicolumn{3}{|c|}{ Fragmented splats } \\
\hline & $\begin{array}{l}\text { Numbers of } \\
\text { splats }\end{array}$ & $\begin{array}{l}\text { Diameter } \\
(\mu \mathrm{m})\end{array}$ & $\mathbf{a} / \mathbf{b}$ & $\begin{array}{l}\text { Numbers of } \\
\text { splats }\end{array}$ & $\begin{array}{l}\text { Diameter } \\
(\mu \mathrm{m})\end{array}$ & $\mathbf{a} / \mathbf{b}$ & $\begin{array}{l}\text { Numbers } \\
\text { of splats }\end{array}$ & $\begin{array}{l}\text { Diameter } \\
(\mu \mathrm{m})\end{array}$ & $\mathbf{a} / \mathbf{b}$ \\
\hline 15-20 & 2 & $\begin{array}{l}\text { 1) } 18.7 \\
\text { 2) } 17.6\end{array}$ & $\begin{array}{l}\text { 1) } 0.97 \\
\text { 2) } 1.03\end{array}$ & 3 & $\begin{array}{l}\text { 1) } 19.7 \\
\text { 2) } 18.6 \\
\text { 3) } 16.4\end{array}$ & $\begin{array}{l}\text { 1) } 1.02 \\
\text { 2) } 1.21 \\
\text { 3) } 1.14\end{array}$ & 4 & $\begin{array}{l}\text { 1) } 15.3 \\
\text { 2) } 18.6 \\
\text { 3) } 19.3 \\
\text { 4) } 17.7 \\
\end{array}$ & $\begin{array}{l}\text { 1) } 1.02 \\
\text { 2) } 2.30 \\
\text { 3) } 1.70 \\
\text { 4) } 1.23 \\
\end{array}$ \\
\hline $20-25$ & 3 & $\begin{array}{l}\text { 1) } 22.7 \\
\text { 2) } 23.4 \\
\text { 3) } 21.7\end{array}$ & $\begin{array}{l}\text { 1) } 1.11 \\
\text { 2) } 0.82 \\
\text { 3) } 0.89\end{array}$ & 4 & $\begin{array}{l}\text { 1) } 23.4 \\
\text { 2) } 24.8 \\
\text { 3) } 21.6 \\
\text { 4) } 20.8\end{array}$ & $\begin{array}{l}\text { 1) } 0.93 \\
\text { 2) } 0.89 \\
\text { 3) } 0.95 \\
\text { 4) } 1.13\end{array}$ & 3 & $\begin{array}{l}\text { 1) } 24.7 \\
\text { 2) } 23.1 \\
\text { 3) } 20.4\end{array}$ & $\begin{array}{l}\text { 1) } 1.20 \\
\text { 2) } 1.07 \\
\text { 3) } 1.16\end{array}$ \\
\hline $25-30$ & 1 & 1) 28.9 & 1) 1.02 & 2 & $\begin{array}{l}\text { 1) } 25.6 \\
\text { 2) } 27.8\end{array}$ & $\begin{array}{l}\text { 1) } 0.87 \\
\text { 2) } 0.72\end{array}$ & 3 & $\begin{array}{l}\text { 1) } 29.2 \\
\text { 2) } 26.7 \\
\text { 3) } 25.2\end{array}$ & $\begin{array}{l}\text { 1) } 1.30 \\
\text { 2) } 1.13 \\
\text { 3) } 1.15\end{array}$ \\
\hline $30-35$ & 2 & $\begin{array}{l}\text { 1) } 33.6 \\
\text { 2) } 34.7\end{array}$ & $\begin{array}{l}\text { 1) } 1.14 \\
\text { 2) } 0.97\end{array}$ & 5 & $\begin{array}{l}\text { 1) } 31.6 \\
\text { 2) } 30.2 \\
\text { 3) } 34.6 \\
\text { 4) } 33.6 \\
\text { 5) } 31.8\end{array}$ & $\begin{array}{l}\text { 1) } 1.04 \\
\text { 2) } 1.13 \\
\text { 3) } 1.12 \\
\text { 4) } 1.09 \\
\text { 5) } 0.88\end{array}$ & 6 & $\begin{array}{l}\text { 1) } 30.8 \\
\text { 2) } 31.2 \\
\text { 3) } 32.7 \\
\text { 4) } 33.9 \\
\text { 5) } 34.7 \\
\text { 6) } 34.3\end{array}$ & $\begin{array}{l}\text { 1) } 0.90 \\
\text { 2) } 1.36 \\
\text { 3) } 1.28 \\
\text { 4) } 1.35 \\
\text { 5) } 0.87 \\
\text { 6) } 0.86\end{array}$ \\
\hline $35-40$ & 0 & - & - & 7 & $\begin{array}{l}\text { 1) } 36.2 \\
\text { 2) } 35.2 \\
\text { 3) } 38.3 \\
\text { 4) } 37.7\end{array}$ & $\begin{array}{l}\text { 1) } 1.03 \\
\text { 2) } 1.19 \\
\text { 3) } 1.24 \\
\text { 4) } 1.12\end{array}$ & 3 & $\begin{array}{l}\text { 1) } 38.9 \\
\text { 2) } 39.4 \\
\text { 3) } 37.1\end{array}$ & $\begin{array}{l}\text { 1) } 0.88 \\
\text { 2) } 0.92 \\
\text { 3) } 0.79\end{array}$ \\
\hline
\end{tabular}




\begin{tabular}{|c|c|c|c|c|c|c|c|c|c|}
\hline & & & & & $\begin{array}{l}\text { 5) } 38.9 \\
\text { 6) } 39.2 \\
\text { 7) } 36.8 \\
\end{array}$ & $\begin{array}{l}\text { 5) } 0.98 \\
\text { 6) } 0.87 \\
\text { 7) } 0.91 \\
\end{array}$ & & & \\
\hline $40-45$ & 3 & $\begin{array}{l}\text { 1) } 42.3 \\
\text { 2) } 44.7\end{array}$ & $\begin{array}{l}\text { 1) } 1.21 \\
\text { 2) } 1.02\end{array}$ & 4 & $\begin{array}{l}\text { 1) } 44.7 \\
\text { 2) } 43.5 \\
\text { 3) } 41.7\end{array}$ & $\begin{array}{l}\text { 1) } 1.02 \\
\text { 2) } 0.84 \\
\text { 3) } 0.99\end{array}$ & 5 & $\begin{array}{l}\text { 1) } 43.4 \\
\text { 2) } 44.9 \\
\text { 3) } 41.3 \\
\text { 4) } 42.6 \\
\text { 5) } 42.9 \\
\end{array}$ & $\begin{array}{l}\text { 1) } 0.92 \\
\text { 2) } 0.86 \\
\text { 3) } 1.13 \\
\text { 4) } 0.84 \\
\text { 5) } 1.24\end{array}$ \\
\hline $45-50$ & 2 & $\begin{array}{l}\text { 1) } 46.5 \\
\text { 2) } 48.1\end{array}$ & $\begin{array}{l}\text { 1) } 0.87 \\
\text { 2) } 1.12\end{array}$ & 5 & $\begin{array}{l}\text { 1) } 48.9 \\
\text { 2) } 49.4 \\
\text { 3) } 45.2 \\
\text { 4) } 46.3 \\
\text { 5) } 47.4 \\
\end{array}$ & $\begin{array}{l}\text { 1) } 1.02 \\
\text { 2) } 1.13 \\
\text { 3) } 1.20 \\
\text { 4) } 1.17 \\
\text { 5) } 1.31 \\
\end{array}$ & 5 & $\begin{array}{l}\text { 1) } 48.4 \\
\text { 2) } 46.3 \\
\text { 3) } 45.9 \\
\text { 4) } 49.3 \\
\text { 5) } 45.4 \\
\end{array}$ & $\begin{array}{l}\text { 1) } 1.20 \\
\text { 2) } 1.13 \\
\text { 3) } 0.86 \\
\text { 4) } 0.97 \\
\text { 5) } 1.17 \\
\end{array}$ \\
\hline $50-55$ & 1 & 1) 54.6 & 1) 1.14 & 1 & 1) 50.2 & 1) 0.98 & 4 & $\begin{array}{l}\text { 1) } 51.8 \\
\text { 2) } 53.5 \\
\text { 3) } 54.9 \\
\text { 4) } 50.7 \\
\end{array}$ & $\begin{array}{l}\text { 1) } 1.16 \\
\text { 2) } 0.76 \\
\text { 3) } 0.85 \\
\text { 4) } 0.97 \\
\end{array}$ \\
\hline $55-60$ & 0 & - & - & 1 & 1) 55.7 & 1) 0.96 & 1 & 1) 58.2 & 1) 1.13 \\
\hline
\end{tabular}


APPENDIX Table 2. Parameters used for formation of 2D image for Power $28 \mathrm{~kW}$ and substrate temperature $180{ }^{\circ} \mathrm{C}$

\begin{tabular}{|c|c|c|c|c|c|c|c|c|c|}
\hline \multirow{2}{*}{$\begin{array}{l}\text { Size } \\
\text { distribution } \\
(\mu \mathrm{m})\end{array}$} & \multicolumn{3}{|c|}{ Disk-shaped splats } & \multicolumn{3}{|c|}{ Fingered (Splashed) splats } & \multicolumn{3}{|c|}{ Fragmented splats } \\
\hline & $\begin{array}{l}\text { Numbers of } \\
\text { splats }\end{array}$ & $\begin{array}{l}\text { Diameter } \\
(\mu \mathrm{m})\end{array}$ & $\mathbf{a} / \mathbf{b}$ & $\begin{array}{l}\text { Numbers } \\
\text { of splats }\end{array}$ & $\begin{array}{l}\text { Diameter } \\
(\mu \mathrm{m})\end{array}$ & $\mathbf{a} / \mathbf{b}$ & $\begin{array}{l}\text { Numbers of } \\
\text { splats }\end{array}$ & $\begin{array}{l}\text { Diameter } \\
(\mu \mathrm{m})\end{array}$ & $\mathbf{a} / \mathbf{b}$ \\
\hline $15-20$ & 1 & 1) 19.4 & 1) 0.98 & 4 & $\begin{array}{l}\text { 1) } 15.4 \\
\text { 2) } 16.7 \\
\text { 3) } 18.3 \\
\text { 4) } 19.5 \\
\end{array}$ & $\begin{array}{l}\text { 1) } 0.98 \\
\text { 2) } 1.13 \\
\text { 3) } 1.11 \\
\text { 4) } 0.86 \\
\end{array}$ & 3 & $\begin{array}{l}\text { 1) } 16.6 \\
\text { 2) } 15.2 \\
\text { 3) } 18.4\end{array}$ & $\begin{array}{l}\text { 1) } 1.13 \\
\text { 2) } 1.03 \\
\text { 3) } 0.86\end{array}$ \\
\hline $20-25$ & 4 & $\begin{array}{l}\text { 1) } 20.3 \\
\text { 2) } 21.4 \\
\text { 3) } 24.8 \\
\text { 4) } 24.6\end{array}$ & $\begin{array}{l}\text { 1) } 0.94 \\
\text { 2) } 0.89 \\
\text { 3) } 1.14 \\
\text { 4) } 1.17\end{array}$ & 5 & $\begin{array}{l}\text { 1) } 20.2 \\
\text { 2) } 21.4 \\
\text { 3) } 22.3 \\
\text { 4) } 22.7 \\
\text { 5) } 24.6\end{array}$ & $\begin{array}{l}\text { 1) } 0.91 \\
\text { 2) } 0.87 \\
\text { 3) } 1.12 \\
\text { 4) } 0.91 \\
\text { 5) } 1.03\end{array}$ & 6 & $\begin{array}{l}\text { 1) } 22.3 \\
\text { 2) } 20.1 \\
\text { 3) } 24.5 \\
\text { 4) } 23.7 \\
\text { 5) } 22.8 \\
\text { 6) } 21.3 \\
\end{array}$ & $\begin{array}{l}\text { 1) } 1.12 \\
\text { 2) } 1.18 \\
\text { 3) } 0.81 \\
\text { 4) } 0.78 \\
\text { 5) } 0.84 \\
\text { 6) } 1.04\end{array}$ \\
\hline $25-30$ & 1 & 1) 28.9 & 1) 1.02 & 4 & $\begin{array}{l}\text { 1) } 25.1 \\
\text { 2) } 26.4 \\
\text { 3) } 27.3 \\
\text { 4) } 29.1 \\
\end{array}$ & $\begin{array}{l}\text { 1) } 0.87 \\
\text { 2) } 0.98 \\
\text { 3) } 0.89 \\
\text { 4) } 1.12 \\
\end{array}$ & 2 & $\begin{array}{l}\text { 1) } 29.6 \\
\text { 2) } 28.4\end{array}$ & $\begin{array}{l}\text { 1) } 1.14 \\
\text { 2) } 0.98\end{array}$ \\
\hline 30-35 & 1 & 1) 30.5 & 1) 1.16 & 2 & 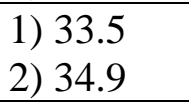 & 1) 1.06 & 1 & 1) 30.8 & 1) 1.18 \\
\hline $35-40$ & 1 & 1) 38.4 & 1) 1.04 & 1 & 1) 39.4 & 1) 1.27 & 2 & 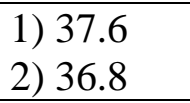 & 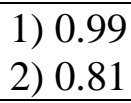 \\
\hline $40-45$ & 8 & $\begin{array}{l}\text { 1) } 44.2 \\
\text { 2) } 40.6 \\
\text { 3) } 43.2 \\
\text { 4) } 44.1 \\
\text { 5) } 44.7 \\
\text { 6) } 40.8\end{array}$ & $\begin{array}{l}\text { 1) } 1.02 \\
\text { 2) } 1.12 \\
\text { 3) } 0.98 \\
\text { 4) } 0.99 \\
\text { 5) } 1.05 \\
\text { 6) } 1.18\end{array}$ & 5 & $\begin{array}{l}\text { 1) } 44.8 \\
\text { 2) } 43.7 \\
\text { 3) } 44.9 \\
\text { 4) } 40.2 \\
\text { 5) } 41.3\end{array}$ & $\begin{array}{l}\text { 1) } 0.95 \\
\text { 2) } 0.79 \\
\text { 3) } 0.84 \\
\text { 4) } 0.79 \\
\text { 5) } 1.12\end{array}$ & 1 & 1) 43.5 & 1) 0.76 \\
\hline
\end{tabular}




\begin{tabular}{|c|c|c|c|c|c|c|c|c|c|}
\hline & & $\begin{array}{l}\text { 7) } 41.8 \\
\text { 8) } 41.1 \\
\end{array}$ & $\begin{array}{l}\text { 7) } 1.22 \\
\text { 8) } 1.34 \\
\end{array}$ & & & & & & \\
\hline $45-50$ & 7 & $\begin{array}{l}\text { 1) } 47.8 \\
\text { 2) } 46.3 \\
\text { 3) } 45.1 \\
\text { 4) } 48.8 \\
\text { 5) } 49.5 \\
\text { 6) } 48.2 \\
\text { 7) } 47.3\end{array}$ & $\begin{array}{l}\text { 1) } 1.19 \\
\text { 2) } 1.2 \\
\text { 3) } 0.85 \\
\text { 4) } 0.98 \\
\text { 5) } 1.14 \\
\text { 6) } 0.99 \\
\text { 7) } 0.91\end{array}$ & 8 & $\begin{array}{l}\text { 1) } 45.6 \\
\text { 2) } 46.7 \\
\text { 3) } 47.4 \\
\text { 4) } 48.9 \\
\text { 5) } 49.1 \\
\text { 6) } 49.8 \\
\text { 7) } 46.3 \\
\text { 8) } 48.3\end{array}$ & $\begin{array}{l}\text { 1) } 0.90 \\
\text { 2) } 1.19 \\
\text { 3) } 1.23 \\
\text { 4) } 0.96 \\
\text { 5) } 0.99 \\
\text { 6) } 1.07 \\
\text { 7) } 1.12 \\
\text { 8) } 1.15\end{array}$ & 1 & 1) 47.8 & 1) 0.98 \\
\hline $50-55$ & 3 & $\begin{array}{l}\text { 1) } 50.3 \\
\text { 2) } 53.4 \\
\text { 3) } 57.8 \\
\end{array}$ & $\begin{array}{l}\text { 1) } 1.02 \\
\text { 2) } 1.11 \\
\text { 3) } 0.99 \\
\end{array}$ & 1 & 1) 53.4 & 1) 0.93 & 1 & 1) 54.8 & 1) 0.89 \\
\hline $55-60$ & 1 & 1) 58.5 & 1) 1.07 & 1 & 1) 59.2 & 1) 0.94 & 2 & $\begin{array}{l}\text { 1) } 59.8 \\
\text { 2) } 56.3 \\
\end{array}$ & $\begin{array}{l}\text { 1) } 0.81 \\
\text { 2) } 1.01 \\
\end{array}$ \\
\hline $60-65$ & 4 & $\begin{array}{l}\text { 1) } 60.2 \\
\text { 2) } 61.4 \\
\text { 3) } 63.8 \\
\text { 4) } 64.2\end{array}$ & $\begin{array}{l}\text { 1) } 1.05 \\
\text { 2) } 1.13 \\
\text { 3) } 1.21 \\
\text { 4) } 0.87\end{array}$ & 0 & - & - & 0 & - & - \\
\hline
\end{tabular}


APPENDIX Table 3. Parameters used for formation of 2D image for Power $28 \mathrm{~kW}$ and substrate temperature $250{ }^{\circ} \mathrm{C}$

\begin{tabular}{|c|c|c|c|c|c|c|c|c|c|}
\hline \multirow{2}{*}{$\begin{array}{l}\text { Size } \\
\text { distribution } \\
(\mu \mathrm{m})\end{array}$} & \multicolumn{3}{|c|}{ Disk-shaped splats } & \multicolumn{3}{|c|}{ Fingered (Splashed) splats } & \multicolumn{3}{|c|}{ Fragmented splats } \\
\hline & $\begin{array}{l}\text { Numbers } \\
\text { of splats }\end{array}$ & $\begin{array}{l}\text { Diameter } \\
(\mu \mathrm{m})\end{array}$ & $\mathbf{a} / \mathbf{b}$ & $\begin{array}{l}\text { Numbers } \\
\text { of splats }\end{array}$ & $\begin{array}{l}\text { Diameter } \\
(\mu \mathrm{m})\end{array}$ & $\mathbf{a} / \mathbf{b}$ & $\begin{array}{l}\text { Numbers of } \\
\text { splats }\end{array}$ & $\begin{array}{l}\text { Diameter } \\
(\mu \mathrm{m})\end{array}$ & $\mathbf{a} / \mathbf{b}$ \\
\hline 15-20 & 1 & 1) 18.4 & 1) 1.13 & 0 & - & - & 0 & - & - \\
\hline $20-25$ & 1 & 1) 21.6 & 1) 0.98 & 1 & 1) 22.3 & 1) 0.89 & 0 & - & - \\
\hline \multirow[t]{5}{*}{ 25-30 } & 3 & 1) 25.6 & 1) 0.84 & 5 & 1) 25.3 & 1) 1.13 & 4 & 1) 25.2 & 1) 0.91 \\
\hline & & 2) 27.8 & 2) 1.03 & & 2) 26.7 & 2) 1.05 & & 2) 26.7 & 2) 0.89 \\
\hline & & 3) 29.2 & 3) 1.23 & & 3) 27.8 & 3) 1.24 & & 3) 27.4 & 3) 0.86 \\
\hline & & & & & 4) 28.4 & 4) 1.15 & & 4) 28.3 & 4) 1.13 \\
\hline & & & & & 5) 29.6 & 5) 0.87 & & 5) 29.4 & 5) 1.08 \\
\hline \multirow[t]{5}{*}{ 30-35 } & 5 & 1) 30.2 & 1) 1.13 & 3 & 1) 34.6 & 1) 0.84 & 3 & 1) 34.2 & 1) 1.01 \\
\hline & & 2) 34.6 & 2) 1.08 & & 2) 33.8 & 2) 1.21 & & 2) 33.8 & 2) 0.93 \\
\hline & & 3) 33.7 & 3) 1.02 & & 3) 31.4 & 3) 1.02 & & 3) 30.7 & 3) 0.86 \\
\hline & & 4) 31.6 & 4) 0.99 & & & & & & \\
\hline & & 5) 34.1 & 5) 0.87 & & & & & & \\
\hline \multirow[t]{4}{*}{$35-40$} & 3 & 1) 35.4 & 1) 0.75 & 4 & 1) 37.2 & 1) 1.02 & 2 & 1) 39.7 & 1) 0.95 \\
\hline & & 2) 36.8 & 2) 1.12 & & 2) 38.4 & 2) 0.97 & & 2) 38.7 & 2) 1.01 \\
\hline & & 3) 38.4 & 3) 0.89 & & 3) 39.5 & 3) 0.94 & & & \\
\hline & & & & & 4) 38.6 & 4) 0.92 & & & \\
\hline \multirow[t]{7}{*}{$40-45$} & 7 & 1) 40.2 & 1) 0.87 & 4 & 1) 44.7 & 1) 1.01 & 1 & 1) 43.2 & 1) 1.03 \\
\hline & & 2) 41.3 & 2) 0.82 & & 2) 43.2 & 2) 0.94 & & & \\
\hline & & 3) 42.8 & 3) 1.07 & & 3) 40.3 & 3) 0.98 & & & \\
\hline & & 4) 44.8 & 4) 1.18 & & 4) 42.8 & 4) 1.12 & & & \\
\hline & & 5) 42.1 & 5) 1.13 & & & & & & \\
\hline & & 6) 40.8 & 6) 0.85 & & & & & & \\
\hline & & 7) 41.3 & 7) 1.04 & & & & & & \\
\hline \multirow[t]{2}{*}{$45-50$} & 7 & 1) 45.3 & 1) 1.01 & 6 & 1) 45.1 & 1) 0.98 & 5 & 1) 45.4 & 1) 1.09 \\
\hline & & 2) 46.7 & 2) 1.12 & & 2) 46.4 & 2) 1.13 & & 2) 47.8 & 2) 0.97 \\
\hline
\end{tabular}




\begin{tabular}{|c|c|c|c|c|c|c|c|c|c|}
\hline & & 3) 47.8 & 3) 1.13 & & 3) 47.8 & 3) 1.20 & & 3) 48.4 & 3) 1.03 \\
\hline & & 4) 44.9 & 4) 1.08 & & 4) 48.6 & 4) 1.18 & & 4) 49.9 & 4) 1.08 \\
\hline & & 5) 43.4 & 5) 0.98 & & 5) 49.4 & 5) 1.17 & & 5) 47.3 & 5) 1.2 \\
\hline & & 6) 45.8 & 6) 0.99 & & 6) 45.3 & 6) 1.01 & & & \\
\hline & & 7) 46.1 & 7) 1.14 & & & & & & \\
\hline $50-55$ & 4 & 1) 52.3 & 1) 1.12 & 0 & - & - & 0 & - & - \\
\hline & & 2) 53.6 & 2) 1.13 & & & & & & \\
\hline & & 3) 54.8 & 3) 1.06 & & & & & & \\
\hline & & 4) 50.5 & 4) 1.08 & & & & & & \\
\hline 55-60 & 3 & 1) 56.7 & 1) 1.14 & 2 & 1) 57.8 & 1) 1.21 & 0 & - & - \\
\hline & & 2) 57.8 & 2) 1.04 & & 2) 58.9 & 2) 1.09 & & & \\
\hline & & 3) 59.6 & 3) 1.09 & & & & & & \\
\hline $60-65$ & 1 & 1) 62.3 & 1) 0.98 & 1 & 1) 63.7 & 1) 1.13 & 1 & 1) 60.3 & 1) 0.76 \\
\hline 65-70 & 3 & 1) 65.4 & 1) 0.94 & 0 & - & - & 0 & - & - \\
\hline & & 2) 67.3 & 2) 0.98 & & & & & & \\
\hline & & 3) 69.2 & 3) 1.07 & & & & & & \\
\hline
\end{tabular}


APPENDIX Table 4. Parameters used for formation of 2D image for Power $32 \mathrm{~kW}$ and substrate temperature $100{ }^{\circ} \mathrm{C}$

\begin{tabular}{|c|c|c|c|c|c|c|c|c|c|}
\hline \multirow{2}{*}{$\begin{array}{l}\text { Size } \\
\text { distribution } \\
(\mu \mathrm{m})\end{array}$} & \multicolumn{3}{|c|}{ Disk-shaped splats } & \multicolumn{3}{|c|}{ Fingered (Splashed) splats } & \multicolumn{3}{|c|}{ Fragmented splats } \\
\hline & $\begin{array}{l}\text { Numbers } \\
\text { of splats }\end{array}$ & $\begin{array}{l}\text { Diameter } \\
(\mu \mathrm{m})\end{array}$ & $\mathbf{a} / \mathbf{b}$ & $\begin{array}{l}\text { Numbers } \\
\text { of splats }\end{array}$ & $\begin{array}{l}\text { Diameter } \\
(\mu \mathrm{m})\end{array}$ & $\mathbf{a} / \mathbf{b}$ & $\begin{array}{l}\text { Numbers of } \\
\text { splats }\end{array}$ & $\begin{array}{l}\text { Diameter } \\
(\mu \mathrm{m})\end{array}$ & $\mathbf{a} / \mathbf{b}$ \\
\hline \multirow[t]{2}{*}{$15-20$} & 1 & 1) 18.6 & 1) 1.02 & 2 & 1) 16.3 & 1) 0.98 & 0 & - & - \\
\hline & & & & & 2) 18.4 & 2) 1.14 & & & \\
\hline \multirow[t]{2}{*}{$20-25$} & 1 & 1) 22.3 & 1) 1.13 & 1 & 1) 24.6 & 1) 1.04 & 2 & 1) 20.8 & 1) 0.98 \\
\hline & & & & & & & & 2) 22.6 & 2) 1.08 \\
\hline \multirow[t]{8}{*}{$25-30$} & 4 & 1) 25.6 & 1) 0.98 & 4 & 1) 28.9 & 1) 1.02 & 8 & 1) 26.2 & 1) 1.17 \\
\hline & & 2) 26.1 & 2) 1.13 & & 2) 27.4 & 2) 1.13 & & 2) 27.4 & 2) 1.19 \\
\hline & & 3) 27.4 & 3) 1.04 & & 3) 25.1 & 3) 1.23 & & 3) 27.9 & 3) 1.01 \\
\hline & & 4) 29.8 & 4) 1.02 & & 4) 26.8 & 4) 1.17 & & 4) 28.4 & 4) 1.12 \\
\hline & & & & & & & & 5) 26.2 & 5) 1.20 \\
\hline & & & & & & & & 6) 29.5 & 6) 1.13 \\
\hline & & & & & & & & 7) 28.8 & 7) 1.08 \\
\hline & & & & & & & & 8) 27.6 & 8) 1.22 \\
\hline \multirow[t]{7}{*}{ 30-35 } & 3 & 1) 33.6 & 1) 1.09 & 7 & 1) 34.9 & 1) 1.02 & 4 & 1) 33.6 & 1) 0.87 \\
\hline & & 2) 34.8 & 2) 1.33 & & 2) 31.8 & 2) 1.31 & & 2) 32.8 & 2) 0.79 \\
\hline & & 3) 30.6 & 3) 0.97 & & 3) 30.8 & 3) 0.98 & & 3) 34.8 & 3) 1.03 \\
\hline & & & & & 4) 30.2 & 4) 0.86 & & 4) 33.5 & 4) 1.13 \\
\hline & & & & & 5) 31.7 & 5) 0.91 & & & \\
\hline & & & & & 6) 32.9 & 6) 0.94 & & & \\
\hline & & & & & 7) 33.2 & 7) 1.13 & & & \\
\hline \multirow[t]{6}{*}{$35-40$} & 4 & 1) 35.6 & 1) 1.13 & 7 & 1) 39.6 & 1) 1.02 & 8 & 1) 35.6 & 1) 1.02 \\
\hline & & 2) 36.8 & 2) 1.17 & & 2) 39.3 & 2) 1.08 & & 2) 37.9 & 2) 1.01 \\
\hline & & 3) 38.1 & 3) 1.07 & & 3) 38.4 & 3) 0.93 & & 3) 38.6 & 3) 0.98 \\
\hline & & 4) 39.5 & 4) 1.09 & & 4) 35.1 & 4) 0.92 & & 4) 35.3 & 4) 0.97 \\
\hline & & & & & 5) 36.8 & 5) 1.12 & & 5) 38.4 & 5) 1.13 \\
\hline & & & & & 6) 38.1 & 6) 1.14 & & 6) 36.1 & 6) 1.24 \\
\hline
\end{tabular}




\begin{tabular}{|c|c|c|c|c|c|c|c|c|c|}
\hline & & & & & 7) 37.5 & 7) 0.89 & & $\begin{array}{l}\text { 7) } 38.8 \\
\text { 8) } 39.4\end{array}$ & 7) 0.88 \\
\hline $40-45$ & 1 & 1) 44.3 & 1) 1.04 & 2 & $\begin{array}{l}\text { 1) } 42.4 \\
\text { 2) } 44.8\end{array}$ & $\begin{array}{l}\text { 1) } 0.92 \\
\text { 2) } 1.02\end{array}$ & 8 & $\begin{array}{l}\text { 1) } 40.6 \\
\text { 2) } 41.4 \\
\text { 3) } 43.4 \\
\text { 4) } 44.8 \\
\text { 5) } 40.4 \\
\text { 6) } 40.1 \\
\text { 7) } 41.9 \\
\text { 8) } 42.3\end{array}$ & $\begin{array}{l}\text { 1) } 0.98 \\
\text { 2) } 0.87 \\
\text { 3) } 0.79 \\
\text { 4) } 1.12 \\
\text { 5) } 1.32 \\
\text { 6) } 1.14 \\
\text { 7) } 1.11 \\
\text { 8) } 1.09\end{array}$ \\
\hline $45-50$ & 2 & $\begin{array}{l}\text { 1) } 46.7 \\
\text { 2) } 47.3 \\
\end{array}$ & $\begin{array}{l}\text { 1) } 0.9 \\
\text { 2) } 0.97\end{array}$ & 1 & 1) 47.8 & 1) 1.15 & 0 & - & - \\
\hline $50-55$ & 1 & 1) 50.3 & 1) 0.93 & 2 & $\begin{array}{l}\text { 1) } 54.3 \\
\text { 2) } 53.7\end{array}$ & $\begin{array}{l}\text { 1) } 1.07 \\
\text { 2) } 0.98\end{array}$ & 3 & $\begin{array}{l}\text { 1) } 52.8 \\
\text { 2) } 54.9 \\
\text { 3) } 51.4\end{array}$ & $\begin{array}{l}\text { 1) } 0.8 \\
\text { 2) } 0.91 \\
\text { 3) } 1.12 \\
\end{array}$ \\
\hline $55-60$ & 1 & 1) 57.6 & 1) 1.21 & 1 & 1) 55.6 & 1) 1.04 & 0 & - & - \\
\hline 60-65 & 0 & - & - & 1 & 1) 63.4 & 1) 1.13 & 0 & - & - \\
\hline $65-70$ & 0 & - & - & 1 & 1) 67.1 & 1) 0.93 & 0 & - & - \\
\hline
\end{tabular}


APPENDIX Table 5. Parameters used for formation of 2D image for Power $32 \mathrm{~kW}$ and substrate temperature $180{ }^{\circ} \mathrm{C}$

\begin{tabular}{|c|c|c|c|c|c|c|c|c|c|}
\hline \multirow{2}{*}{$\begin{array}{l}\text { Size } \\
\text { distribution } \\
(\mu \mathrm{m})\end{array}$} & \multicolumn{3}{|c|}{ Disk-shaped splats } & \multicolumn{3}{|c|}{ Fingered (Splashed) splats } & \multicolumn{3}{|c|}{ Fragmented splats } \\
\hline & $\begin{array}{l}\text { Numbers } \\
\text { of splats }\end{array}$ & $\begin{array}{l}\text { Diameter } \\
(\mu \mathrm{m})\end{array}$ & $\mathbf{a} / \mathbf{b}$ & $\begin{array}{l}\text { Numbers } \\
\text { of splats }\end{array}$ & $\begin{array}{l}\text { Diameter } \\
(\mu \mathrm{m})\end{array}$ & $\mathbf{a} / \mathbf{b}$ & $\begin{array}{l}\text { Numbers of } \\
\text { splats }\end{array}$ & $\begin{array}{l}\text { Diameter } \\
(\mu \mathrm{m})\end{array}$ & $\mathbf{a} / \mathbf{b}$ \\
\hline 15-20 & 1 & 1) 19.2 & 1) 1.03 & 0 & - & - & 0 & - & - \\
\hline \multirow[t]{4}{*}{$20-25$} & 4 & 1) 21.4 & 1) 1.12 & 3 & 1) 20.1 & 1) 1.14 & 2 & 1) 24.6 & 1) 0.88 \\
\hline & & 2) 22.3 & 2) 0.97 & & 2) 21.3 & 2) 1.04 & & 2) 23.9 & 2) 0.94 \\
\hline & & 3) 24.7 & 3) 0.81 & & 3) 22.4 & 3) 0.84 & & & \\
\hline & & 4) 24.1 & 4) 0.79 & & & & & & \\
\hline \multirow[t]{6}{*}{$25-30$} & 5 & 1) 25.2 & 1) 0.89 & 6 & 1) 27.8 & 1) 1.12 & 2 & 1) 25.1 & 1) 0.96 \\
\hline & & 2) 26.7 & 2) 0.79 & & 2) 28.4 & 2) 1.03 & & 2) 29.9 & 2) 0.89 \\
\hline & & 3) 27.1 & 3) 0.99 & & 3) 29.8 & 3) 1.04 & & & \\
\hline & & 4) 28.9 & 4) 1.02 & & 4) 25.2 & 4) 1.16 & & & \\
\hline & & 5) 29.4 & 5) 1.23 & & 5) 26.3 & 5) 1.18 & & & \\
\hline & & & & & 6) 28.3 & 6) 0.93 & & & \\
\hline \multirow[t]{4}{*}{ 30-35 } & 2 & 1) 30.2 & 1) 1.09 & 4 & 1) 34.5 & 1) 0.87 & 2 & 1) 33.4 & 1) 1.14 \\
\hline & & 2) 33.4 & 2) 0.96 & & 2) 33.8 & 2) 1.07 & & 2) 34.2 & 2) 1.09 \\
\hline & & & & & 3) 31.8 & 3) 1.15 & & & \\
\hline & & & & & 4) 30.5 & 4) 0.95 & & & \\
\hline \multirow[t]{4}{*}{$35-40$} & 4 & 1) 38.5 & 1) 1.01 & 3 & 1) 37.8 & 1) 0.99 & 3 & 1) 36.3 & 1) 1.09 \\
\hline & & 2) 39.6 & 2) 0.98 & & 2) 38.9 & 2) 1.02 & & 2) 37.9 & 2) 1.17 \\
\hline & & 3) 35.1 & 3) 0.95 & & 3) 39.2 & 3) 1.26 & & 3) 38.1 & 3) 1.03 \\
\hline & & 4) 36.3 & 4) 1.13 & & & & & & \\
\hline \multirow[t]{6}{*}{$40-45$} & 11 & 1) 40.1 & 1) 0.98 & 3 & 1) 43.2 & 1) 1.15 & 1 & 1) 43.2 & 1) 1.02 \\
\hline & & 2) 41.3 & 2) 1.12 & & 2) 44.8 & 2) 1.06 & & & \\
\hline & & 3) 41.8 & 3) 1.14 & & 3) 40.4 & 3) 1.11 & & & \\
\hline & & 4) 42.3 & 4) 1.19 & & & & & & \\
\hline & & 5) 43.5 & 5) 1.21 & & & & & & \\
\hline & & 6) 44.9 & 6) 1.17 & & & & & & \\
\hline
\end{tabular}




\begin{tabular}{|c|c|c|c|c|c|c|c|c|c|}
\hline & & $\begin{array}{l}\text { 7) } 42.5 \\
\text { 8) } 40.9 \\
\text { 9) } 40.4 \\
\text { 10) } 41.5 \\
\text { 11) } 42.8 \\
\end{array}$ & $\begin{array}{l}\text { 7) } 0.89 \\
\text { 8) } 0.97 \\
\text { 9) } 0.99 \\
\text { 10) } 1.4 \\
\text { 11) } 1.2 \\
\end{array}$ & & & & & & \\
\hline $45-50$ & 3 & $\begin{array}{l}\text { 1) } 45.9 \\
\text { 2) } 46.4 \\
\text { 3) } 49.4 \\
\end{array}$ & $\begin{array}{l}\text { 1) } 1.03 \\
\text { 2) } 0.98\end{array}$ & 2 & $\begin{array}{l}\text { 1) } 48.1 \\
\text { 2) } 49.5\end{array}$ & $\begin{array}{l}\text { 1) } 1.21 \\
\text { 2) } 1.01\end{array}$ & 1 & 1) 48.1 & 1) 0.98 \\
\hline 50-55 & 2 & $\begin{array}{l}\text { 1) } 52.3 \\
\text { 2) } 54.8 \\
\end{array}$ & $\begin{array}{l}\text { 1) } 0.96 \\
\text { 2) } 0.89 \\
\end{array}$ & 0 & - & - & 0 & - & - \\
\hline $55-60$ & 1 & 1) 57.2 & 1) 0.91 & 1 & 1) 58.9 & 1) 0.91 & 1 & 1) 59.1 & 1) 0.94 \\
\hline $60-65$ & 1 & 1) 63.7 & 1) 0.96 & 2 & 1) 64.9 & 1) 1.11 & 1 & 1) 63.1 & 1) 1.03 \\
\hline 65-70 & 1 & 1) 65.9 & 1) 0.84 & 1 & 1) 67.4 & 1) 1.01 & 2 & $\begin{array}{l}\text { 1) } 68.3 \\
\text { 2) } 69.4 \\
\end{array}$ & $\begin{array}{l}\text { 1) } 0.98 \\
\text { 2) } 0.83\end{array}$ \\
\hline $70-75$ & 2 & $\begin{array}{l}\text { 1) } 72.4 \\
\text { 2) } 74.9\end{array}$ & $\begin{array}{l}\text { 1) } 0.94 \\
\text { 2) } 1.13\end{array}$ & 1 & 1) 73.2 & 1) 0.81 & 0 & - & - \\
\hline 75-80 & 1 & 1) 78.1 & 1) 1.03 & 1 & 1) 77.9 & 1) 1.18 & 0 & - & - \\
\hline
\end{tabular}


APPENDIX Table 6. Parameters used for formation of 2D image for Power $32 \mathrm{~kW}$ and substrate temperature $250{ }^{\circ} \mathrm{C}$

\begin{tabular}{|c|c|c|c|c|c|c|c|c|c|}
\hline \multirow{2}{*}{$\begin{array}{l}\text { Size } \\
\text { distribution } \\
(\mu \mathrm{m})\end{array}$} & \multicolumn{3}{|c|}{ Disk-shaped splats } & \multicolumn{3}{|c|}{ Fingered (Splashed) splats } & \multicolumn{3}{|c|}{ Fragmented splats } \\
\hline & $\begin{array}{l}\text { Numbers } \\
\text { of splats }\end{array}$ & $\begin{array}{l}\text { Diameter } \\
(\mu \mathrm{m})\end{array}$ & $\mathbf{a} / \mathbf{b}$ & $\begin{array}{l}\text { Numbers } \\
\text { of splats }\end{array}$ & $\begin{array}{l}\text { Diameter } \\
(\mu \mathrm{m})\end{array}$ & $\mathbf{a} / \mathbf{b}$ & $\begin{array}{l}\text { Numbers } \\
\text { of splats }\end{array}$ & $\begin{array}{l}\text { Diameter } \\
(\mu \mathrm{m})\end{array}$ & $\mathbf{a} / \mathbf{b}$ \\
\hline $20-25$ & 1 & 1) 23.6 & 1) 0.98 & 2 & $\begin{array}{l}\text { 1) } 23.6 \\
\text { 2) } 24.7\end{array}$ & $\begin{array}{l}\text { 1) } 0.86 \\
\text { 2) } 1.04\end{array}$ & 1 & 1) 20.3 & 1) 1.12 \\
\hline $25-30$ & 5 & $\begin{array}{l}\text { 1) } 26.7 \\
\text { 2) } 27.4 \\
\text { 3) } 28.9 \\
\text { 4) } 29.1 \\
\text { 5) } 26.8\end{array}$ & $\begin{array}{l}\text { 1) } 0.88 \\
\text { 2) } 0.87 \\
\text { 3) } 0.93 \\
\text { 4) } 0.96 \\
\text { 5) } 1.12\end{array}$ & 2 & $\begin{array}{l}\text { 1) } 28.1 \\
\text { 2) } 29.4\end{array}$ & $\begin{array}{l}\text { 1) } 1.08 \\
\text { 2) } 0.94\end{array}$ & 2 & 1) 29.9 & 1) 1.01 \\
\hline $30-35$ & 5 & $\begin{array}{l}\text { 1) } 33.4 \\
\text { 2) } 32.8 \\
\text { 3) } 34.1 \\
\text { 4) } 30.8 \\
\text { 5) } 31.2 \\
\end{array}$ & $\begin{array}{l}\text { 1) } 1.17 \\
\text { 2) } 1.03 \\
\text { 3) } 1.15 \\
\text { 4) } 1.01 \\
\text { 5) } 0.96 \\
\end{array}$ & 4 & $\begin{array}{l}\text { 1) } 33.6 \\
\text { 2) } 37.4 \\
\text { 3) } 39.1 \\
\text { 4) } 30.8\end{array}$ & $\begin{array}{l}\text { 1) } 1.03 \\
\text { 2) } 1.19 \\
\text { 3) } 1.02 \\
\text { 4) } 0.98\end{array}$ & 2 & $\begin{array}{l}\text { 1) } 37.9 \\
\text { 2) } 38.2\end{array}$ & $\begin{array}{l}\text { 1) } 1.03 \\
\text { 2) } 0.98\end{array}$ \\
\hline $35-40$ & 4 & $\begin{array}{l}\text { 1) } 36.8 \\
\text { 2) } 37.2 \\
\text { 3) } 38.4 \\
\text { 4) } 39.1 \\
\end{array}$ & $\begin{array}{l}\text { 1) } 0.98 \\
\text { 2) } 1.07 \\
\text { 3) } 1.12 \\
\text { 4) } 1.21\end{array}$ & 1 & 1) 38.9 & 1) 0.87 & 3 & $\begin{array}{l}\text { 1) } 37.2 \\
\text { 2) } 35.6 \\
\text { 3) } 38.9\end{array}$ & $\begin{array}{l}\text { 1) } 0.97 \\
\text { 2) } 1.12 \\
\text { 3) } 1.03\end{array}$ \\
\hline $40-45$ & 5 & $\begin{array}{l}\text { 1) } 44.1 \\
\text { 2) } 40.8 \\
\text { 3) } 42.6 \\
\text { 4) } 44.2 \\
\text { 5) } 43.5\end{array}$ & $\begin{array}{l}\text { 1) } 1.11 \\
\text { 2) } 1.09 \\
\text { 3) } 1.10 \\
\text { 4) } 0.98 \\
\text { 5) } 1.21\end{array}$ & 6 & $\begin{array}{l}\text { 1) } 44.2 \\
\text { 2) } 43.8 \\
\text { 3) } 41.8 \\
\text { 4) } 44.6 \\
\text { 5) } 42.1\end{array}$ & $\begin{array}{l}\text { 1) } 1.01 \\
\text { 2) } 1.26 \\
\text { 3) } 0.98 \\
\text { 4) } 0.89 \\
\text { 5) } 0.96\end{array}$ & 1 & 1) 44.2 & 1) 0.91 \\
\hline $45-50$ & 6 & $\begin{array}{l}\text { 1) } 45.1 \\
\text { 2) } 46.8 \\
\text { 3) } 47.5\end{array}$ & $\begin{array}{l}\text { 1) } 1.01 \\
\text { 2) } 1.03 \\
\text { 3) } 1.11\end{array}$ & 2 & $\begin{array}{l}\text { 1) } 46.2 \\
\text { 2) } 47.8\end{array}$ & $\begin{array}{l}\text { 1) } 0.95 \\
\text { 2) } 1.01\end{array}$ & 1 & 1) 48.9 & 1) 0.88 \\
\hline
\end{tabular}




\begin{tabular}{|c|c|c|c|c|c|c|c|c|c|}
\hline & & $\begin{array}{l}\text { 4) } 49.5 \\
\text { 5) } 47.3 \\
\text { 6) } 46.3\end{array}$ & $\begin{array}{l}\text { 4) } 0.99 \\
\text { 5) } 0.89 \\
\text { 6) } 0.93\end{array}$ & & & & & & \\
\hline $50-55$ & 7 & $\begin{array}{l}\text { 1) } 50.3 \\
\text { 2) } 51.4 \\
\text { 3) } 54.3 \\
\text { 4) } 54.8 \\
\text { 5) } 52.3 \\
\text { 6) } 54.7 \\
\text { 7) } 52.8\end{array}$ & $\begin{array}{l}\text { 1) } 1.04 \\
\text { 2) } 1.03 \\
\text { 3) } 0.93 \\
\text { 4) } 0.96 \\
\text { 5) } 0.86 \\
\text { 6) } 0.89 \\
\text { 7) } 1.19\end{array}$ & 0 & - & - & 0 & - & - \\
\hline $55-60$ & 4 & $\begin{array}{l}\text { 1) } 55.7 \\
\text { 2) } 58.9 \\
\text { 3) } 59.8 \\
\text { 4) } 56.1 \\
\end{array}$ & $\begin{array}{l}\text { 1) } 1.01 \\
\text { 2) } 1.24 \\
\text { 3) } 0.88 \\
\text { 4) } 0.95 \\
\end{array}$ & 1 & 1) 55.8 & 1) 1.11 & 1 & 1) 58.4 & 1) 1.08 \\
\hline $60-65$ & 1 & 1) 62.5 & 1) 0.93 & 2 & $\begin{array}{l}\text { 1) } 64.8 \\
\text { 2) } 62.3\end{array}$ & $\begin{array}{l}\text { 1) } 0.93 \\
\text { 2) } 0.97\end{array}$ & 1 & 1) 64.9 & 1.04 \\
\hline $65-70$ & 1 & 1) 67.9 & 1) 0.99 & 1 & 1) 68.9 & 1) 1.01 & 1 & 1) 69.5 & 1.21 \\
\hline $70-75$ & 2 & $\begin{array}{l}\text { 1) } 73.8 \\
\text { 2) } 74.7\end{array}$ & $\begin{array}{l}\text { 1) } 1.22 \\
\text { 2) } 1.02\end{array}$ & 0 & - & - & 0 & - & - \\
\hline $75-80$ & 1 & 1) 78.9 & 1) 0.97 & 0 & - & - & 0 & - & - \\
\hline $80-85$ & 1 & 1) 84.6 & 1) 0.94 & 1 & 1) 83.2 & 1) 1.06 & 0 & - & - \\
\hline
\end{tabular}


APPENDIX Table 7. Parameters used for formation of 2D image for Power $35 \mathrm{~kW}$ and substrate temperature $100{ }^{\circ} \mathrm{C}$

\begin{tabular}{|c|c|c|c|c|c|c|c|c|c|}
\hline \multirow{2}{*}{$\begin{array}{l}\text { Size } \\
\text { distribution } \\
(\mu \mathrm{m})\end{array}$} & \multicolumn{3}{|c|}{ Disk-shaped splats } & \multicolumn{3}{|c|}{ Fingered (Splashed) splats } & \multicolumn{3}{|c|}{ Fragmented splats } \\
\hline & $\begin{array}{l}\text { Numbers } \\
\text { of splats }\end{array}$ & $\begin{array}{l}\text { Diameter } \\
(\mu \mathrm{m})\end{array}$ & $\mathbf{a} / \mathbf{b}$ & $\begin{array}{l}\text { Numbers } \\
\text { of splats }\end{array}$ & $\begin{array}{l}\text { Diameter } \\
(\mu \mathrm{m})\end{array}$ & $\mathbf{a} / \mathbf{b}$ & $\begin{array}{l}\text { Numbers } \\
\text { of splats }\end{array}$ & $\begin{array}{l}\text { Diameter } \\
(\mu \mathrm{m})\end{array}$ & $\mathbf{a} / \mathbf{b}$ \\
\hline $20-25$ & 1 & 1) 22.7 & 1) 1.08 & 2 & $\begin{array}{l}\text { 1) } 21.3 \\
\text { 2) } 20.8\end{array}$ & $\begin{array}{l}\text { 1) } 1.12 \\
\text { 2) } 0.96\end{array}$ & 3 & $\begin{array}{l}\text { 1) } 24.5 \\
\text { 2) } 23.7 \\
\text { 3) } 23.8\end{array}$ & $\begin{array}{l}\text { 1) } 1.03 \\
\text { 2) } 1.28 \\
\text { 3) } 1.18\end{array}$ \\
\hline $25-30$ & 2 & $\begin{array}{l}\text { 1) } 25.6 \\
\text { 2) } 27.4\end{array}$ & $\begin{array}{l}\text { 1) } 1.09 \\
\text { 2) } 1.12\end{array}$ & 3 & $\begin{array}{l}\text { 1) } 26.7 \\
\text { 2) } 28.4 \\
\text { 3) } 29.3 \\
\end{array}$ & $\begin{array}{l}\text { 1) } 1.05 \\
\text { 2) } 1.15 \\
\text { 3) } 1.20 \\
\end{array}$ & 2 & $\begin{array}{l}\text { 1) } 28.6 \\
\text { 2) } 25.4\end{array}$ & 1) 1.03 \\
\hline 30-35 & 3 & $\begin{array}{l}\text { 1) } 30.5 \\
\text { 2) } 34.2 \\
\text { 3) } 33.7\end{array}$ & $\begin{array}{l}\text { 1) } 0.98 \\
\text { 2) } 1.06 \\
\text { 3) } 0.87\end{array}$ & 5 & $\begin{array}{l}\text { 1) } 33.2 \\
\text { 2) } 32.4 \\
\text { 3) } 30.4 \\
\text { 4) } 34.7 \\
\text { 5) } 31.9 \\
\end{array}$ & $\begin{array}{l}\text { 1) } 1.04 \\
\text { 2) } 1.13 \\
\text { 3) } 1.07 \\
\text { 4) } 0.99 \\
\text { 5) } 0.86 \\
\end{array}$ & 2 & $\begin{array}{l}\text { 1) } 34.2 \\
\text { 2) } 33.7\end{array}$ & 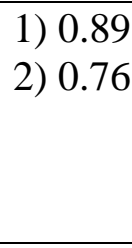 \\
\hline $35-40$ & 4 & $\begin{array}{l}\text { 1) } 38.9 \\
\text { 2) } 35.1 \\
\text { 3) } 36.3 \\
\text { 4) } 37.8 \\
\end{array}$ & $\begin{array}{l}\text { 1) } 0.89 \\
\text { 2) } 0.94 \\
\text { 3) } 1.09 \\
\text { 4) } 1.22 \\
\end{array}$ & 3 & $\begin{array}{l}\text { 1) } 38.9 \\
\text { 2) } 37.4 \\
\text { 3) } 38.9\end{array}$ & $\begin{array}{l}\text { 1) } 0.96 \\
\text { 2) } 0.99 \\
\text { 3) } 1.02\end{array}$ & 3 & $\begin{array}{l}\text { 1) } 38.1 \\
\text { 2) } 37.1 \\
\text { 3) } 39.2\end{array}$ & $\begin{array}{l}\text { 1) } 0.94 \\
\text { 2) } 1.02 \\
\text { 3) } 1.14\end{array}$ \\
\hline $40-45$ & 1 & 1) 43.1 & 1) 1.02 & 6 & $\begin{array}{l}\text { 1) } 41.3 \\
\text { 2) } 42.4 \\
\text { 3) } 44.7 \\
\text { 4) } 44.9 \\
\text { 5) } 40.1 \\
\text { 6) } 41.5\end{array}$ & $\begin{array}{l}\text { 1) } 1.02 \\
\text { 2) } 1.13 \\
\text { 3) } 1.07 \\
\text { 4) } 1.2 \\
\text { 5) } 0.99 \\
\text { 6) } 0.97\end{array}$ & 1 & 1) 43.2 & 1) 1.01 \\
\hline 45-50 & 2 & $\begin{array}{l}\text { 1) } 45.1 \\
\text { 2) } 46.8\end{array}$ & $\begin{array}{l}\text { 1) } 1.02 \\
\text { 2) } 1.13\end{array}$ & 4 & $\begin{array}{l}\text { 1) } 47.3 \\
\text { 2) } 49.8 \\
\text { 3) } 46.1\end{array}$ & $\begin{array}{l}\text { 1) } 1.02 \\
\text { 2) } 1.13 \\
\text { 3) } 0.98\end{array}$ & 6 & $\begin{array}{l}\text { 1) } 48.1 \\
\text { 2) } 46.3 \\
\text { 3) } 45.9\end{array}$ & $\begin{array}{l}\text { 1) } 1.03 \\
\text { 2) } 1.13 \\
\text { 3) } 1.20\end{array}$ \\
\hline
\end{tabular}




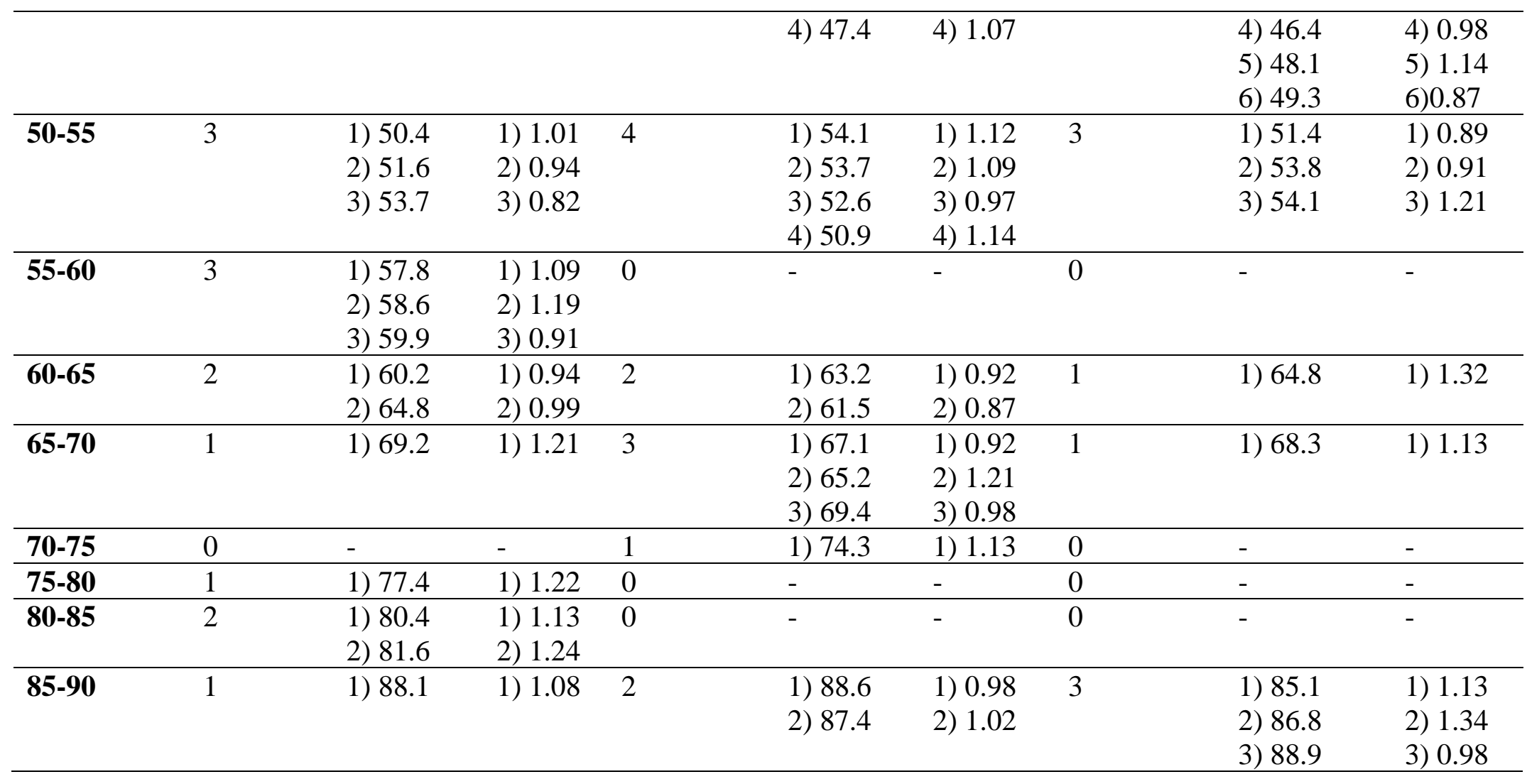


APPENDIX Table 8. Parameters used for formation of 2D image for Power $35 \mathrm{~kW}$ and substrate temperature $180{ }^{\circ} \mathrm{C}$

\begin{tabular}{|c|c|c|c|c|c|c|c|c|c|}
\hline \multirow{2}{*}{$\begin{array}{l}\text { Size } \\
\text { distribution } \\
(\mu \mathrm{m})\end{array}$} & \multicolumn{3}{|c|}{ Disk-shaped splats } & \multicolumn{3}{|c|}{ Fingered (Splashed) splats } & \multicolumn{3}{|c|}{ Fragmented splats } \\
\hline & $\begin{array}{l}\text { Numbers } \\
\text { of splats }\end{array}$ & $\begin{array}{l}\text { Diameter } \\
(\mu \mathrm{m})\end{array}$ & $\mathbf{a} / \mathbf{b}$ & $\begin{array}{l}\text { Numbers } \\
\text { of splats }\end{array}$ & $\begin{array}{l}\text { Diameter } \\
(\mu \mathrm{m})\end{array}$ & $\mathbf{a} / \mathbf{b}$ & $\begin{array}{l}\text { Numbers of } \\
\text { splats }\end{array}$ & $\begin{array}{l}\text { Diameter } \\
(\mu \mathrm{m})\end{array}$ & $\mathbf{a} / \mathbf{b}$ \\
\hline \multirow[t]{2}{*}{$20-25$} & 1 & 1) 18.6 & 1) 1.21 & 2 & 1) 17.3 & 1) 1.04 & 2 & 1) 15.3 & 1) 0.87 \\
\hline & & & & & 2) 16.8 & 2) 0.97 & & 2) 19.8 & 2) 1.13 \\
\hline \multirow[t]{3}{*}{ 25-30 } & 3 & 1) 22.3 & 1) 1.11 & 1 & 1) 24.8 & 1) 0.95 & 1 & 1) 22.6 & 1) 1.03 \\
\hline & & 2) 23.8 & 2) 1.09 & & & & & & \\
\hline & & 3) 24.7 & 3) 0.98 & & & & & & \\
\hline \multirow[t]{6}{*}{$30-35$} & 6 & 1) 28.9 & 1) 1.01 & 2 & 1) 28.9 & 1) 0.98 & 2 & 1) 27.6 & 1) 1.07 \\
\hline & & 2) 26.4 & 2) 1.03 & & 2) 29.5 & 2) 1.06 & & 2) 25.2 & 2) 1.12 \\
\hline & & 3) 25.9 & 3) 0.99 & & & & & & \\
\hline & & 4) 25.1 & 4) 1.00 & & & & & & \\
\hline & & 5) 27.9 & 5) 1.03 & & & & & & \\
\hline & & 6) 29.8 & 6) 1.07 & & & & & & \\
\hline \multirow[t]{6}{*}{$35-40$} & 6 & 1) 30.3 & 1) 1.01 & 1 & 1) 33.5 & 1) 0.98 & 2 & 1) 32.6 & 1) 1.12 \\
\hline & & 2) 33.9 & 2) 1.23 & & & & & 2) 37.9 & 2) 1.02 \\
\hline & & 3) 34.7 & 3) 1.01 & & & & & & \\
\hline & & 4) 35.1 & 4) 1.00 & & & & & & \\
\hline & & 5) 39.4 & 5) 1.06 & & & & & & \\
\hline & & 6) 39.2 & 6) 0.99 & & & & & & \\
\hline \multirow[t]{4}{*}{$40-45$} & 4 & 1) 36.2 & 1) 1.08 & 2 & 1) 39.2 & 1) 1.03 & 2 & 1) 36.4 & 1) 1.14 \\
\hline & & 2) 35.4 & 2) 0.95 & & & & & 2) 37.1 & 2) 1.04 \\
\hline & & 3) 38.9 & 3) 1.11 & & & & & & \\
\hline & & 4) 39.1 & 4) 0.98 & & & & & & \\
\hline \multirow[t]{3}{*}{$45-50$} & 4 & 1) 40.2 & 1) 1.01 & 2 & 1) 43.9 & 1) 1.12 & 2 & 1) 41.6 & 1) 1.04 \\
\hline & & 2) 41.7 & 2) 0.98 & & & & & 2) 42.3 & 2) 1.13 \\
\hline & & 3) 42.9 & 3) 0.97 & & & & & & \\
\hline
\end{tabular}




\begin{tabular}{|c|c|c|c|c|c|c|c|c|c|}
\hline & & 4) 43.6 & 4) 1.04 & & & & & & \\
\hline \multirow[t]{6}{*}{$50-55$} & 6 & 1) 45.8 & 1) 1.01 & 1 & 1) 48.7 & 1) 1.02 & 5 & 1) 45.1 & 1) 1.03 \\
\hline & & 2) 46.7 & 2) 0.98 & & & & & 2) 47.8 & 2) 1.14 \\
\hline & & 3) 47.9 & 3) 1.12 & & & & & 3) 48.9 & 3) 0.99 \\
\hline & & 4) 48.3 & 4) 1.13 & & & & & 4) 49.2 & 4) 0.98 \\
\hline & & 5) 49.2 & 5) 1.06 & & & & & 5) 49.4 & 5) 1.01 \\
\hline & & 6) 49.8 & 6) 1.09 & & & & & & \\
\hline \multirow[t]{4}{*}{$55-60$} & 2 & 1) 50.5 & 1) 1.12 & 1 & 1) 54.8 & 1) 1.14 & 4 & 1) 54.6 & 1) 1.04 \\
\hline & & 2) 53.8 & 2) 1.03 & & & & & 2) 52.5 & 2) 1.24 \\
\hline & & & & & & & & 3) 51.8 & 3) 0.98 \\
\hline & & & & & & & & 4) 50.7 & 4) 0.87 \\
\hline \multirow[t]{2}{*}{$60-65$} & 2 & 1) 55.8 & 1) 1.09 & 1 & 1) 59.8 & 1) 1.13 & 1 & 1) 59.2 & 1) 0.95 \\
\hline & & 2) 59.6 & 2) 1.12 & & & & & & \\
\hline \multirow[t]{2}{*}{$65-70$} & 2 & 1) 63.8 & 1) 1.22 & 0 & - & - & 0 & - & - \\
\hline & & 2) 64.9 & 2) 1.01 & & & & & & \\
\hline \multirow[t]{2}{*}{$70-75$} & 1 & 1) 68.9 & 1) 0.98 & 1 & 1) 69.4 & 1) 0.89 & 2 & 1) 66.8 & 1) 1.22 \\
\hline & & & & & & & & 2) 67.4 & 2) 1.03 \\
\hline \multirow[t]{2}{*}{$75-80$} & 1 & 1) 73.6 & 1) 1.03 & 0 & - & - & 2 & 1) 74.8 & 1) 1.13 \\
\hline & & & & & & & & 2) 73.2 & 2) 1.09 \\
\hline \multirow[t]{2}{*}{$80-85$} & 2 & 1) 79.5 & 1) 1.01 & 0 & - & - & 1 & 1) 79.2 & 1) 1.01 \\
\hline & & 2) 78.1 & 2) 1.03 & & & & & & \\
\hline \multirow[t]{2}{*}{$85-90$} & 1 & 1) 83.2 & 1) 0.99 & 2 & 1) 82.4 & 1) 0.98 & 2 & 1) 83.6 & 1) 0.97 \\
\hline & & & & & 2) 81.6 & 2) 0.93 & & 2) 84.7 & 2) 1.05 \\
\hline
\end{tabular}


APPENDIX Table 9. Parameters used for formation of 2D image for Power $35 \mathrm{~kW}$ and substrate temperature $250{ }^{\circ} \mathrm{C}$

\begin{tabular}{|c|c|c|c|c|c|c|c|c|c|}
\hline \multirow{2}{*}{$\begin{array}{l}\text { Size } \\
\text { distribution } \\
(\mu \mathrm{m})\end{array}$} & \multicolumn{3}{|c|}{ Disk-shaped splats } & \multicolumn{3}{|c|}{ Fingered (Splashed) splats } & \multicolumn{3}{|c|}{ Fragmented splats } \\
\hline & $\begin{array}{l}\text { Numbers } \\
\text { of splats }\end{array}$ & $\begin{array}{l}\text { Diameter } \\
(\mu \mathrm{m})\end{array}$ & $\mathbf{a} / \mathbf{b}$ & $\begin{array}{l}\text { Numbers } \\
\text { of splats }\end{array}$ & $\begin{array}{l}\text { Diameter } \\
(\mu \mathrm{m})\end{array}$ & $\mathbf{a} / \mathbf{b}$ & $\begin{array}{l}\text { Numbers of } \\
\text { splats }\end{array}$ & $\begin{array}{l}\text { Diameter } \\
(\mu \mathrm{m})\end{array}$ & $\mathbf{a} / \mathbf{b}$ \\
\hline $20-25$ & 1 & 1) 23.5 & 1) 0.98 & 2 & $\begin{array}{l}\text { 1) } 24.8 \\
\text { 2) } 23.1\end{array}$ & $\begin{array}{l}\text { 1) } 1.02 \\
\text { 2) } 1.22\end{array}$ & 1 & 1) 23.6 & 1) 1.01 \\
\hline $25-30$ & 2 & $\begin{array}{l}\text { 1) } 25.2 \\
\text { 2) } 26.7\end{array}$ & $\begin{array}{l}\text { 1) } 1.12 \\
\text { 2) } 1.13\end{array}$ & 1 & $\begin{array}{l}\text { 1) } 28.9 \\
\text { 2) } 27.6\end{array}$ & $\begin{array}{l}\text { 1) } 1.02 \\
\text { 2) } 1.13\end{array}$ & 0 & - & - \\
\hline 30-35 & 3 & $\begin{array}{l}\text { 1) } 33.2 \\
\text { 2) } 34.6 \\
\text { 3) } 34.9\end{array}$ & $\begin{array}{l}\text { 1) } 1.02 \\
\text { 2) } 0.99 \\
\text { 3) } 1.03\end{array}$ & 0 & - & - & 0 & - & - \\
\hline $35-40$ & 2 & $\begin{array}{l}\text { 1) } 37.9 \\
\text { 2) } 38.9 \\
\end{array}$ & $\begin{array}{l}\text { 1) } 0.95 \\
\text { 2) } 0.87 \\
\end{array}$ & 1 & 1) 36.9 & 1) 1.13 & 1 & 1) 37.4 & 1) 1.22 \\
\hline $40-45$ & 8 & $\begin{array}{l}\text { 1) } 40.2 \\
\text { 2) } 41.4 \\
\text { 3) } 41.6 \\
\text { 4) } 42.8 \\
\text { 5) } 43.2 \\
\text { 6) } 44.6 \\
\text { 7) } 44.5 \\
\text { 8) } 44.9\end{array}$ & $\begin{array}{l}\text { 1) } 0.88 \\
\text { 2) } 0.89 \\
\text { 3) } 1.12 \\
\text { 4) } 1.01 \\
\text { 5) } 1.09 \\
\text { 6) } 1.15 \\
\text { 7) } 1.09 \\
\text { 8) } 1.04 \\
\end{array}$ & 2 & $\begin{array}{l}\text { 1) } 43.2 \\
\text { 2) } 44.1\end{array}$ & 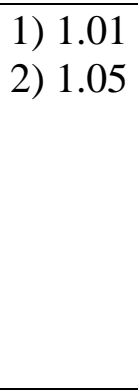 & 2 & $\begin{array}{l}\text { 1) } 42.8 \\
\text { 2) } 44.6\end{array}$ & $\begin{array}{l}\text { 1) } 1.04 \\
\text { 2) } 1.13\end{array}$ \\
\hline $45-50$ & 7 & $\begin{array}{l}\text { 1) } 45.2 \\
\text { 2) } 46.8 \\
\text { 3) } 47.2 \\
\text { 4) } 48.3 \\
\text { 5) } 49.2 \\
\text { 6) } 49.4 \\
\text { 7) } 49.9\end{array}$ & $\begin{array}{l}\text { 1) } 1.22 \\
\text { 2) } 1.23 \\
\text { 3) } 0.99 \\
\text { 4) } 0.98 \\
\text { 5) } 0.87 \\
\text { 6) } 0.88 \\
\text { 7) } 0.78\end{array}$ & 2 & $\begin{array}{l}\text { 1) } 48.3 \\
\text { 2) } 47.4\end{array}$ & $\begin{array}{l}\text { 1) } 1.02 \\
\text { 2) } 1.03\end{array}$ & 1 & 1) 49.2 & 1) 1.23 \\
\hline
\end{tabular}




\begin{tabular}{|c|c|c|c|c|c|c|c|c|c|}
\hline $50-55$ & 10 & $\begin{array}{l}\text { 1) } 50.3 \\
\text { 2) } 50.8 \\
\text { 3) } 51.2 \\
\text { 4) } 52.3 \\
\text { 5) } 53.4 \\
\text { 6) } 53.8 \\
\text { 7) } 54.1 \\
\text { 8) } 54.3 \\
\text { 9) } 54.4 \\
\text { 10) } 54.7\end{array}$ & $\begin{array}{l}\text { 1) } 1.01 \\
\text { 2) } 1.03 \\
\text { 3) } 1.06 \\
\text { 4) } 1.08 \\
\text { 5) } 1.09 \\
\text { 6) } 0.99 \\
\text { 7) } 0.87 \\
\text { 8) } 0.92 \\
\text { 9) } 0.96 \\
\text { 10) } 1.0\end{array}$ & 1 & 1) 54.3 & 1) 1.05 & 0 & - & - \\
\hline 55-60 & 4 & $\begin{array}{l}\text { 1) } 55.6 \\
\text { 2) } 56.9 \\
\text { 3) } 57.2 \\
\text { 4) } 59.2\end{array}$ & $\begin{array}{l}\text { 1) } 1.03 \\
\text { 2) } 1.22 \\
\text { 3) } 1.07 \\
\text { 4) } 0.88\end{array}$ & 8 & $\begin{array}{l}\text { 1) } 55.1 \\
\text { 2) } 55.4 \\
\text { 3) } 55.8 \\
\text { 4) } 56.5 \\
\text { 5) } 57.9 \\
\text { 6) } 58.4 \\
\text { 7) } 59.4 \\
\text { 8) } 59.6\end{array}$ & $\begin{array}{l}\text { 1) } 0.99 \\
\text { 2) } 1.21 \\
\text { 3) } 1.04 \\
\text { 4) } 1.01 \\
\text { 5) } 1.10 \\
\text { 6) } 1.12 \\
\text { 7) } 1.14 \\
\text { 8) } 1.02\end{array}$ & 1 & 1) 57.4 & 1) 0.82 \\
\hline 60-65 & 2 & $\begin{array}{l}\text { 1) } 63.1 \\
\text { 2) } 64.7\end{array}$ & $\begin{array}{l}\text { 1) } 0.98 \\
\text { 2) } 1.03\end{array}$ & 2 & $\begin{array}{l}\text { 1) } 60.4 \\
\text { 2) } 64.9\end{array}$ & 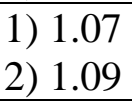 & 1 & 1) 64.6 & 1) 0.97 \\
\hline 65-70 & 2 & $\begin{array}{l}\text { 1) } 65.6 \\
\text { 2) } 66.3 \\
\end{array}$ & $\begin{array}{l}\text { 1) } 1.01 \\
\text { 2) } 0.98 \\
\end{array}$ & 1 & 1) 67.2 & 1) 1.01 & 0 & - & - \\
\hline 70-75 & 3 & $\begin{array}{l}\text { 1) } 70.3 \\
\text { 2) } 72.8 \\
\text { 3) } 74.6\end{array}$ & $\begin{array}{l}\text { 1) } 1.04 \\
\text { 2) } 1.12 \\
\text { 3) } 0.98\end{array}$ & 0 & - & - & 0 & - & - \\
\hline $75-80$ & 3 & $\begin{array}{l}\text { 1) } 75.8 \\
\text { 2) } 76.4 \\
\text { 3) } 78.5\end{array}$ & $\begin{array}{l}\text { 1) } 0.99 \\
\text { 2) } 1.21 \\
\text { 3) } 0.98\end{array}$ & 0 & - & - & 0 & - & - \\
\hline 80-85 & 1 & 1) 82.8 & 1) 1.03 & 1 & 1) 84.7 & 1) 1.23 & 0 & - & - \\
\hline
\end{tabular}


1) 86.4

2) 85.3

1) 1.19

2) 1.07 